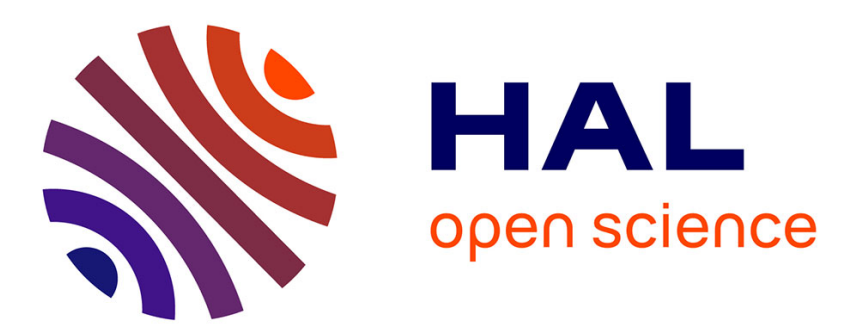

\title{
Gas-phase basicities of polyfunctional molecules. Part 2 : saturated basic sites
}

Guy Bouchoux, Jean-Yves Salpin

\section{To cite this version:}

Guy Bouchoux, Jean-Yves Salpin. Gas-phase basicities of polyfunctional molecules. Part 2: saturated basic sites. Mass Spectrometry Reviews, 2012, 31 (3), pp.353-390. 10.1002/mas.20343 . hal00760015

\section{HAL Id: hal-00760015 https://hal.science/hal-00760015}

Submitted on 5 Oct 2018

HAL is a multi-disciplinary open access archive for the deposit and dissemination of scientific research documents, whether they are published or not. The documents may come from teaching and research institutions in France or abroad, or from public or private research centers.
L'archive ouverte pluridisciplinaire HAL, est destinée au dépôt et à la diffusion de documents scientifiques de niveau recherche, publiés ou non, émanant des établissements d'enseignement et de recherche français ou étrangers, des laboratoires publics ou privés. 


\title{
Gas-phase basicities of polyfunctional molecules. Part 2: saturated basic sites
}

\author{
Guy Bouchoux ${ }^{1,2^{*}}$ and Jean-Yves Salpin ${ }^{3,4}$
}

(1) Ecole Polytechnique - Laboratoire des Mécanismes Réactionnels (DCMR) - Département de Chimie - 91120 Palaiseau. France.

(2) CNRS - UMR 7651

(3) Université d'Evry Val d'Essonne - Laboratoire Analyse et Modélisation pour la Biologie et l'Environnement (LAMBE) - Bâtiment Maupertuis - Bd F. Mitterrand - 91025 Evry. France (4) CNRS - UMR 8587

* Correspondence to: Guy Bouchoux. Laboratoire des Mécanismes Réactionnels.

Département de Chimie. Ecole Polytechnique. 91120 Palaiseau. France.

E-mail address: bouchoux@dcmr.polytechnique.fr

Telephone: (33) 169334842

FAX: $\quad$ (33) 169334803 


\section{Table of contents}

I. Introduction
A. Thermochemical parameters
B. Methods of determination of GB, PA and $\Delta_{\mathrm{p}} \mathrm{S}^{\circ}$
C. Internal hydrogen bonds

II. Amines
A. Aliphatic polyamines
a. Hydrazines
b. Diamines and polyamines
B. Cyclic and aromatic polyamines
a. Cyclic diamines
b. Aryl-alkyl amines
c. Aromatic diamines, proton sponges
C. Aminoalcohols
a. Hydroxylamine and derivatives
b. $\alpha, \omega$ - aliphatic aminoalcohols

III. Alcohols and ethers
A. Unsaturated alcohols and phenols
B. Saturated acyclic and cyclic polyols
a. Hydrogen peroxide and derivatives
b. $\alpha, \omega$-diols
c. Acyclic triols
d. Cyclic polyols
C. Ethers and hydroxy-ethers
a. Peroxides and methoxy oxides
b. Methoxy alcohols
c. Aliphatic polyethers
d. Cyclic mono-ethers
e. Cyclic polyethers

References 


\begin{abstract}
The present article is the second part of a general overview of the gas-phase protonation thermochemistry of polyfunctional molecules. The first part of the review (Mass Spectrom. Rev., 2007, 26:775-835) was devoted to the description of the physico-chemical concepts and of the methods of determination, both experimental and theoretical, of gas-phase basicity. Several clues concerning the structural and energetic aspects of the protonation of isolated species have been emphasized. In the present paper, specific examples are examined. The field of investigation is limited to molecules containing a "saturated" basic site i.e. nitrogen or oxygen atoms engaged in simple $\sigma$ bonds with their neighbouring. Aliphatic, cyclic and aromatic poly- amines, aminoalcohols, alcohols, ethers and hydroxyl-ethers, are successively presented.
\end{abstract}

\title{
Keywords
}

Protonation thermochemistry; Protonation site; Intramolecular hydrogen bond; Polyfunctional interactions.

\section{Running title}

Polyfunctional molecules with saturated basic sites. 


\section{Introduction}

The different methods of ion formation developed in mass spectrometry during the last 45 years, from chemical ionization to electrospray and matrix assisted laser desorption ionization, invariably involve protonation (or deprotonation) of the sample molecules. In addition to its powerful analytical applications mass spectrometry also allows the study of intrinsic molecular properties among which thermochemical parameters such as gas-phase basicities and acidities. In this review we intend to present a survey of the structural and energetic aspects of the gas phase protonation process of "real", i.e. polyfunctional, molecules.

In the first part of the present review (Bouchoux, 2007), experimental and theoretical methods of determination of gas-phase basicities were presented and the structural effect upon these quantities (nature of the basic site, substituent effects, hydrogen bonding...) were recalled. This second part focuses on selected types of polyfunctional molecules. We limit here the field of investigation to molecules containing a "saturated" basic site i.e. nitrogen or oxygen atoms engaged in simple $\sigma$ bonds with their neighbouring. This, somewhat arbitrary choice, includes polyfunctional molecules containing amines, alcohols or ethers functional groups on aliphatic and alicyclic backbone. In this survey, we also consider species where the basic atoms are bonded to unsaturated carbons.

After a brief reminder of the necessary fundamentals of gas-phase basicity, the review is organized in two chapters entitled "Amines" and "Alcohols and Ethers". Each chapter provides evaluated experimental and theoretical protonation thermochemistry data and describes the structure and behavior of the formed protonated species.

\section{A. Thermochemical parameters}

Proton affinity, $\mathrm{PA}(\mathrm{M})$, and gas-phase basicity, $\mathrm{GB}(\mathrm{M})$, of a molecule $\mathrm{M}$ are defined as the standard enthalpy and standard Gibbs free energy of reaction (1) at 298.15 K (Lias et al., 1984; Lias et al., 1988; 2005; Bouchoux, 2007):

$\underset{\text { (gas) }}{\mathrm{MH}^{+}} \rightarrow \underset{\text { (gas) }}{\mathrm{M}}+\underset{\text { (gas) }}{\mathrm{H}^{+}}$

Proton affinity, $\mathrm{PA}(\mathrm{M})=\Delta_{1} \mathrm{H}_{298^{\circ}}$

Gas phase basicity, $\mathbf{G B}(M)=\Delta_{1} \mathbf{G}_{298}{ }^{\circ}$

Introducing the entropy of the reaction (1), $\Delta_{1} \mathrm{~S}_{\mathrm{T}}{ }^{\circ}$, the thermodynamic relationship $\Delta \mathrm{G}_{\mathrm{T}}{ }^{\circ}=\Delta \mathrm{H}_{\mathrm{T}}{ }^{\circ}-$ $\mathrm{T} \Delta \mathrm{S}_{\mathrm{T}}{ }^{\circ}$ leads to eq. (2) at $298 \mathrm{~K}$ :

$$
\mathrm{GB}(\mathrm{M})=\mathrm{PA}(\mathrm{M})-298 \Delta_{1} \mathrm{~S}_{298}{ }^{\circ}
$$

It is a custom to denote "protonation entropy" or "half reaction entropy" the difference in absolute entropies:

$$
\Delta_{\mathrm{p}} \mathrm{S}_{\mathrm{T}}{ }^{\circ}(\mathrm{M})=\mathrm{S}_{\mathrm{T}}{ }^{\circ}\left(\mathrm{MH}^{+}\right)-\mathrm{S}_{\mathrm{T}}{ }^{\circ}(\mathrm{M})
$$

This definition allows expressing the gas phase basicity as: 


$$
\mathrm{GB}(\mathrm{M})=\mathrm{PA}(\mathrm{M})-298\left[\mathrm{~S}_{298}{ }^{\circ}\left(\mathrm{H}^{+}\right)-\Delta_{\mathrm{p}} \mathrm{S}_{298}{ }^{\circ}(\mathrm{M})\right]
$$

, with $\mathrm{S}_{298}{ }^{\circ}\left(\mathrm{H}^{+}\right)$being the translational entropy of one mole of protons (i.e., equal to $108.7 \mathrm{~J} . \mathrm{mol}^{-1} \cdot \mathrm{K}^{-1}$ if considered as an ideal monoatomic gas at $298 \mathrm{~K}$ ).

\section{B. Methods of determination of GB, PA and $\Delta_{\mathrm{p}} \mathrm{S}^{\circ}$.}

As detailed in the first part of the present review (Bouchoux, 2007) all the experimental methods of determination of gas phase basicity or proton affinity are related to a proton transfer reaction (i) between the molecule of interest, $M$, and a reference base, $B_{i}$ :

$$
\mathrm{MH}^{+}+\mathrm{B}_{\mathrm{i}} \quad \rightarrow \quad \mathrm{M} \quad+\quad \mathrm{B}_{\mathrm{i}} \mathrm{H}^{+}
$$

Thus, it is essential to recall the thermochemical relationships associated with reaction (i) at an operational (actual or "effective") temperature T. Assuming that the enthalpy and entropy variations in the temperature range $298 \rightarrow \mathrm{T}$ are negligible (i.e. $\Delta_{\mathrm{i}} \mathrm{H}^{\circ}{ }_{298 \rightarrow \mathrm{T}}$ and $\Delta_{\mathrm{i}} \mathrm{H}^{\circ}{ }_{298 \rightarrow \mathrm{T}} \sim 0$ (Bouchoux, 2007)), the standard Gibbs free energy of reaction (i) at temperature $\mathrm{T}$ may be expressed by:

$$
\begin{array}{ll} 
& \Delta_{\mathrm{i}} \mathrm{G}^{\circ}{ }_{\mathrm{T}} \sim \mathrm{GB}(\mathrm{M})-\mathrm{GB}(\mathrm{B})-(\mathrm{T}-298) \Delta_{\mathrm{i}} \mathrm{S}^{\circ}{ }_{298} \\
\text { or } & \Delta_{\mathrm{i}} \mathrm{G}^{\circ}{ }_{\mathrm{T}} \sim \mathrm{PA}(\mathrm{M})-\mathrm{PA}(\mathrm{B})-\mathrm{T} \Delta_{\mathrm{i}} \mathrm{S}^{\circ}{ }_{298} \\
\text { with } & \Delta_{\mathrm{i}} \mathrm{S}^{\circ}{ }_{298}=\Delta_{\mathrm{p}} \mathrm{S}^{\circ}{ }_{298}(\mathrm{~B})-\Delta_{\mathrm{p}} \mathrm{S}^{\circ}{ }_{298}(\mathrm{M})
\end{array}
$$

The experimental methods allowing the determination of gas phase basicity or proton affinity consist in obtaining $\Delta_{\mathrm{i}} \mathrm{G}^{\circ}{ }_{\mathrm{T}}$ (or an approximation of it) from experimental observables (essentially ion abundances) through "master" relationships based on thermochemical and kinetic theories. These procedures are the so-called "equilibrium", "kinetic" and "thermokinetic" methods (Ervin, 2001; Gal et al., 2001; Bouchoux, 2007). A summary of these methods and of their underlying statements is given in Table 1.

Table 1. Summary of the experimental methods of determination of gas-phase basicities.

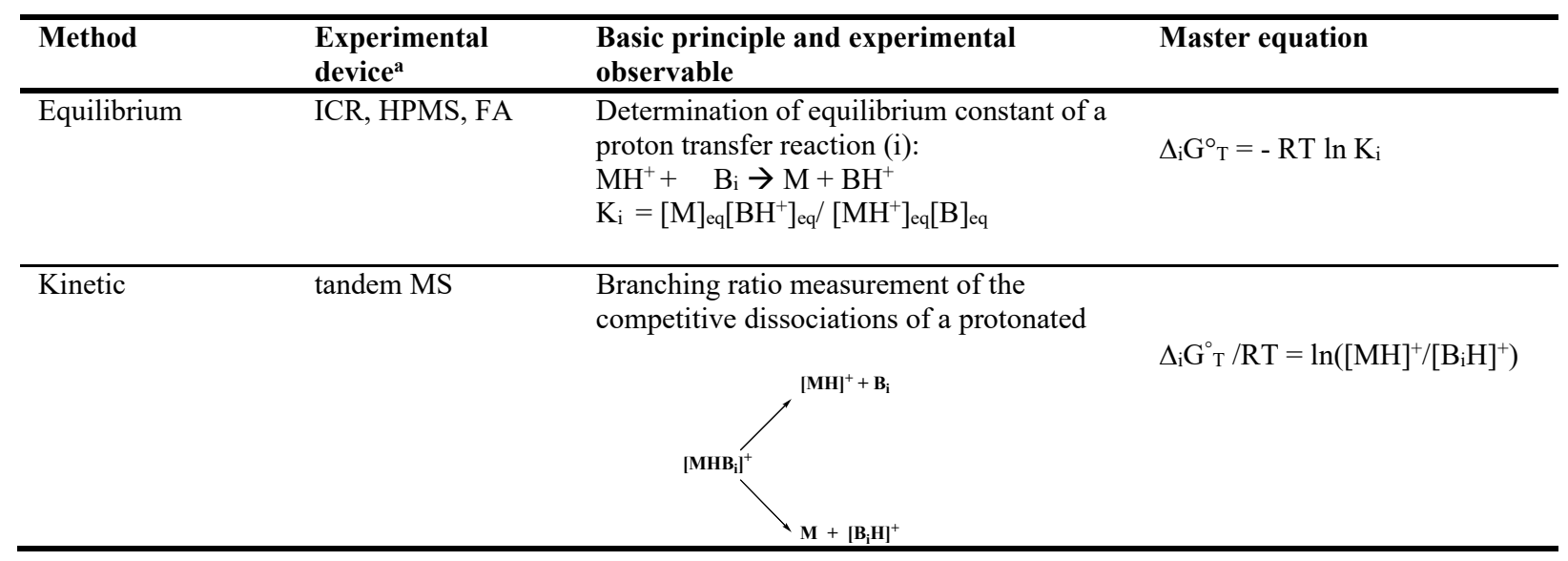




\begin{tabular}{|c|c|c|c|}
\hline & & adduct: & \\
\hline \multirow[t]{2}{*}{ Thermokinetic } & FT-ICR & $\begin{array}{l}\text { Measurement of the bimolecular rate } \\
\text { constant kbim: }\end{array}$ & $\begin{array}{l}\mathrm{k}_{\text {bim }} / \mathrm{k}_{\text {coll }}= \\
{\left[1+\exp \left(\left(\Delta_{\mathrm{i}} \mathrm{G}_{\mathrm{T}}^{\circ}\right) / \mathrm{RT}\right)\right]^{-1}}\end{array}$ \\
\hline & & $\mathrm{MH}^{+}+\quad \begin{array}{l}\mathrm{k}_{\text {bim }} \\
\mathrm{B}_{\mathrm{i}} \rightarrow \mathrm{M}+\mathrm{BH}^{+}\end{array}$ & \\
\hline
\end{tabular}

a) FT- ICR=Fourier Transform-Ion Cyclotron Resonance, HPMS= High Pressure Mass Spectrometry, FA= Flowing Afterglow.

In the "equilibrium method", the equilibrium constant $\mathrm{K}_{\mathrm{i}}$ of reaction (i) is measured at a temperature $\mathrm{T}$ and related to the Gibbs free energy change by the well-known relationship $\Delta_{\mathrm{i}} \mathrm{G}^{\circ} \mathrm{T}=-\mathrm{RT} \ln \mathrm{K}_{\mathrm{i}}$. Then, the $298 \mathrm{~K}$ gas-phase basicity of $\mathrm{M}$ is deduced from eq. (5). Moreover, if experiments are conducted at variable temperature, the enthalpy and entropy components of $\Delta_{\mathrm{i}} \mathrm{G}^{\circ}{ }_{\mathrm{T}}$ may be disclosed by plotting $\ln \mathrm{K}_{\mathrm{i}}$ against $1 / \mathrm{T}$ following the wellknown van't Hoff method. This procedure may consequently lead to $\mathrm{PA}(\mathrm{M})$ and $\Delta_{\mathrm{p}} \mathrm{S}^{\circ}(\mathrm{M})$. $\mathrm{K}_{\mathrm{i}}$ is generally deduced from measurements of $\mathrm{MH}^{+}$and $\mathrm{BH}^{+}$ion abundances and partial pressures of the neutrals. Another procedure consists in determining the forward and reverse rates of reaction (i), $\mathrm{k}_{\mathrm{f}}$ and $\mathrm{k}_{\mathrm{r}}$, and to estimate the equilibrium constant via $\mathrm{K}_{\mathrm{i}}=\mathrm{k}_{\mathrm{f}} / \mathrm{k}_{\mathrm{r}}$. The accuracy of the method is lying on the precise knowledge of the true temperature $\mathrm{T}$ of the experiment and of the partial pressure of M and B (Meot-Ner, 2003; Bouchoux, 2007).

Rather than considering a direct bimolecular proton exchange such as in reactions (i), the "kinetic methods" use the competitive dissociations of an adduct ion $[\mathrm{MHB}]^{+}$into $\mathrm{MH}^{+}+\mathrm{B}$ or $\mathrm{M}+\mathrm{BH}^{+}$, i.e. the reactants and products of reaction (i). By using a tandem mass spectrometer, the adduct $\left[\mathrm{MHB}_{\mathrm{i}}\right]^{+}$may be selected and its dissociations analysed by the second part of the instrument. Considering gas phase basicity determination, the ratio of peak intensities $\left[\mathrm{MH}^{+}\right] /\left[\mathrm{B}_{\mathrm{i}} \mathrm{H}^{+}\right]$is ideally related to $\Delta_{\mathrm{i}} \mathrm{G}_{\mathrm{T}}^{\circ}$ via the relationship $\Delta_{\mathrm{i}} \mathrm{G}^{\circ} \mathrm{T}=\mathrm{RT}$ $\ln \left(\left[\mathrm{MH}^{+}\right] /\left[\mathrm{B}_{\mathrm{i}} \mathrm{H}^{+}\right]\right)$. A series of experiments using several bases $\mathrm{B}_{\mathrm{i}}$ is treated by plotting $\ln \left(\left[\mathrm{MH}^{+}\right] /\left[\mathrm{B}_{\mathrm{i}} \mathrm{H}^{+}\right]\right)$vs $\mathrm{PA}\left(\mathrm{B}_{\mathrm{i}}\right)$ in order to deduce the relevant thermochemical parameter. There are two means to handle the data. In the so called "simple kinetic method", the $\mathrm{x}$-intercept of the $\ln \left(\left[\mathrm{MH}^{+}\right] /\left[\mathrm{B}_{\mathrm{i}} \mathrm{H}^{+}\right]\right)$vs $\mathrm{PA}\left(\mathrm{B}_{\mathrm{i}}\right)$ fitting line is equated to PA(M). However, the $\mathrm{x}$-intercept is equal to an "apparent proton affinity" equal to the difference [PA(M) $\left.\mathrm{T}\left(\Delta_{\mathrm{p}} \mathrm{S}^{\circ}(\mathrm{M})-\Delta_{\mathrm{p}} \mathrm{S}^{\circ}(\mathrm{B})\right)\right]$. The determination of PA(M) by the "simple kinetic method" supposes consequently that the term $\mathrm{T}\left(\Delta_{\mathrm{p}} \mathrm{S}^{\circ}(\mathrm{M})-\Delta_{\mathrm{p}} \mathrm{S}^{\circ}(\mathrm{B})\right)$ can be neglected. In situations where this quantity is not negligible a more elaborate method such as the "extended kinetic method" is needed. This latter allows the determination of both parameters $\mathrm{PA}(\mathrm{M})$ and $\Delta_{\mathrm{p}} \mathrm{S}^{\circ}(\mathrm{M})$ by considering several sets of experiments corresponding to different temperatures $T_{j}$. A crucial caveat of the kinetic method is that $T_{j}$ does not correspond to a true thermodynamic temperature but to an empirical parameter (called the "effective temperature") depending on the ion activation conditions (Ervin, 2002; Ervin \& Armentrout, 2004; Bouchoux, 2007).

Finally, the "thermokinetic method" makes use of the bimolecular rate constant $\mathrm{k}_{\mathrm{bim}}$ of the forward reaction (i). By using the canonical thermodynamic formulation of the transition state theory, $\mathrm{k}_{\text {bim }}$ can be related to the Gibbs free energy of the reaction, $\Delta_{\mathrm{i}} \mathrm{G}^{\circ} \mathrm{T}$, and consequently to $\mathrm{GB}(\mathrm{M})$. This latter parameter may be obtained by plotting $\mathrm{k}_{\mathrm{bim}}$ for a series of experiments involving different bases $\mathrm{B}_{\mathrm{i}}$ and fitting the data by a sigmoid parametric function.

Beside experimental determinations, protonation thermochemistry may be obtained using quantum chemistry calculations. Moreover, these latter methods bring valuable structural information on the neutral and 
ionized species hardly obtainable experimentally. The theoretical proton affinity of a molecule M, i.e. the standard enthalpy of reaction (1) at $298 \mathrm{~K}$, is given, by:

$\mathrm{PA}(\mathrm{M})=\mathrm{E}^{\circ}(\mathrm{M})+\mathrm{ZPVE}(\mathrm{M})+\Delta \mathrm{H}^{\circ}{ }_{0 \rightarrow 298}(\mathrm{M})-\mathrm{E}^{\circ}\left(\mathrm{MH}^{+}\right)-\mathrm{ZPVE}\left(\mathrm{MH}^{+}\right)-\Delta \mathrm{H}^{\circ}{ }_{0 \rightarrow 298}\left(\mathrm{MH}^{+}\right)+6.2 \mathrm{~kJ} / \mathrm{mol}$

where $\mathrm{E}^{\circ}$ is the potential energy of the system relative to infinitely separated electrons and nuclei (the so-called "total energy"), ZPVE the zero point vibrational energy and $\Delta \mathrm{H}^{\circ}{ }_{0 \rightarrow 298}$ the thermal contribution to enthalpy at $298 \mathrm{~K}$. The $6.2 \mathrm{~kJ} / \mathrm{mol}$ term appearing in equation (8) corresponds to the translational enthalpy of the proton $(5 / 2 \mathrm{RT})$ at $298 \mathrm{~K}$.

Reliable computation of proton affinity thus needs a high accuracy on $\mathrm{E}^{\circ}$ and on the vibrational contribution to energy $\triangle \mathrm{ZPVE}$ and $\Delta \mathrm{H}^{\circ}{ }_{0 \rightarrow 298}$. Fortunately, the extraordinary development of quantum chemistry calculations during the last ten years has brought methods able to predict enthalpy variations at the "chemical accuracy level" (i.e. with deviation less than $4 \mathrm{~kJ} \cdot \mathrm{mol}^{-1}$ ). Presently, techniques which may approach this level of accuracy are essentially composite methods such as Gn (Curtiss et al., 1991; Baboul et al., 1999; Curtiss et al., 2000; Curtiss \& Raghavachari, 2002; Curtiss et al., 2005), CBSn (Ochterski et al., 1996) and Wn (Martin \& de Oliveira, 1999) and the last generation of density functional theory (Zhao \& Truhlar, 2008; Schwabe \& Grimme, 2008). Accuracy on the theoretical protonation thermochemistry is obviously dependent on the level of theory used but also to the effectiveness of identifying the most stable neutral and ionized structures and conformations. Moreover, care should be taken to compare theoretical data where the zero point energies and thermal correction for enthalpies at finite temperature ( $298 \mathrm{~K})$ have been conveniently considered.

\section{Internal hydrogen bonds}

PA (M) and GB (M) increase with increasing the basic strength of the molecule $\mathrm{M}$ and are therefore direct measures of its intrinsic basicity. Protonation entropy, $\Delta_{p} S^{\circ}(M)$, the necessary link between PA (M) and GB (M), may be seen as a measure of the disorder appearing or disappearing upon protonation of the molecule M. Structural effects, in particular, substituent interactions in polyfunctional molecules $\mathrm{M}$, or their protonated forms $\mathrm{MH}^{+}$, have a profound influence on $\mathrm{PA}(\mathrm{M}), \mathrm{GB}(\mathrm{M})$ and $\Delta_{\mathrm{p}} \mathrm{S}^{\circ}(\mathrm{M})$ values. Internal hydrogen bonding is one of the factors that may affect these thermochemical parameters because it stabilizes differently the neutral and the protonated forms of the molecule.

Intramolecular hydrogen bonding of the type $\mathrm{X}-\mathrm{H} . . . \mathrm{Y}$ is expected to stabilize the corresponding species if the donor group, $\mathrm{X}-\mathrm{H}$, and the acceptor part, $\mathrm{Y}$, may interact without insurmountable constraint. As mentioned in part 1 of this review during the examination of bimolecular systems (Bouchoux, 2007), hydrogen bond energies are considerably enhanced when the hydrogen donor is a protonated molecule. Stabilization through hydrogen bonding typically amount to $10-20 \mathrm{~kJ} / \mathrm{mol}$ for neutral molecules and to $50-140 \mathrm{~kJ} / \mathrm{mol}$ for ionized species. A stronger stabilization is consequently expected during the formation of intramolecular hydrogen bonds in the protonated molecule $\mathrm{MH}^{+}$than in the neutral $\mathrm{M}$. The first consequence is an increase of the proton affinity of the corresponding molecule. This explains why polyfunctional molecules present generally higher proton affinities than their monofunctional counterparts. Simultaneously, the formation of this strong 
intramolecular hydrogen bond leads to higher rotational barriers in $\mathrm{MH}^{+}$than in $\mathrm{M}$. In other word, internally hydrogen bonded conformations are more constrained in $\mathrm{MH}^{+}$than in $\mathrm{M}$ due to the difference in the hydrogen bond strengths. The consequence is that the entropy of the protonated structure becomes lower than that of the neutral base and protonation thus results in a negative $\Delta_{\mathrm{p}} \mathrm{S}^{\circ}(\mathrm{M})$.

Ideal systems for studying such effect are molecules possessing two basic sites separated by a flexible aliphatic chain. It is thus not surprising that this phenomenon has been first evidenced in studies devoted to the gas phase basicities of aliphatic $\alpha, \omega$-diamines (Aue et al., 1973; Yamdagni \& Kebarle, 1973). It has been amply illustrated latter on for a large variety of polyfunctional molecules. The scope of the present review is however limited to "saturated" basic sites i.e. to molecules containing amine, alcohol or ether functions. Unsaturated polyfunctional molecules will be examined in a separated part of this review.

Thermochemistry of internal hydrogen bonds has been tentatively evaluated under several angles:

(i) The difference between the PA of the considered polyfunctional molecule $\mathrm{M}$ and the PA of a monofunctional reference B may be used to estimate the internal hydrogen bond strength (Meot-Ner, 2005). The value $\Delta \mathrm{H}_{\mathrm{M}-\mathrm{B}}=\mathrm{PA}(\mathrm{M})-\mathrm{PA}(\mathrm{B})$ is obviously dependent on the choice of the monofunctional base $\mathrm{B}$ (the best approach is probably to compare two molecules $\mathrm{M}$ and $\mathrm{B}$ of similar polarizabilities). It is generally observed that $\Delta \mathrm{H}_{\mathrm{M}-\mathrm{B}}$ increases when the distance between the two basic sites $\mathrm{X}$ and $\mathrm{Y}$ increases. Another interesting observation is that the difference $\Delta \mathrm{H}_{\mathrm{M}-\mathrm{B}}$ also increases with the difference in electronegativity between $\mathrm{X}$ and $\mathrm{Y}$.

(ii) A comparison of $\Delta \mathrm{H}_{\mathrm{M}-\mathrm{B}}$ and the ionic hydrogen bond enthalpies of bimolecular $\mathrm{XH}^{+} \ldots \mathrm{Y}$ clusters $\left(\Delta_{\mathrm{C}} \mathrm{H}_{\mathrm{XY}}\right.$, see part I of this review (Bouchoux, 2007)) provides an insight on the strain energies associated with the cyclisation by internal hydrogen bonding. Indeed, the difference $\Delta \mathrm{H}_{\text {strain }}=\Delta_{\mathrm{c}} \mathrm{H}_{\mathrm{XY}}-\Delta \mathrm{H}_{\mathrm{M}-\mathrm{B}}$ decreases with increasing the ring size, as expected (Meot-Ner, 2005).

(iii) Another means to measure the structural and energetic changes induced by the protonation is to use the measured protonation entropy $\Delta_{\mathrm{p}} \mathrm{S}^{\circ}(\mathrm{M})$. As indicated above, a decrease in entropy is expected upon protonation thus leading to a negative $\Delta_{\mathrm{p}} \mathrm{S}^{\circ}(\mathrm{M})$. The general observation is that $\Delta_{\mathrm{p}} \mathrm{S}^{\circ}(\mathrm{M})$ is indeed negative for aliphatic bifunctional molecules but that its absolute value increases as the $\mathrm{X}-\mathrm{Y}$ distance increases. This observation is obviously in line with the decrease in entropy associated with a cyclisation of the system. To a rough comparison it may be recalled that the entropy difference between a cycloalkane and its corresponding linear counterpart is $-40,-50,-60$ and $-100 \mathrm{~J}^{-} \mathrm{mol}^{-1} \cdot \mathrm{K}^{-1}$ for the $\mathrm{C}_{3}-\mathrm{C}_{6}$ series (Benson, 1976). A similar trend is observed for $\Delta_{\mathrm{p}} \mathrm{S}^{\circ}(\mathrm{M})$ of diamines, diols, aminoalcohols and ethers.

(iv) The overall stability provided by protonation has been characterized by Mautner (Meot-Ner, 2005) in term of the temperature required to open the internal hydrogen bond. Assuming thermal equilibrium, half of the population is opened at a temperature $\mathrm{T}_{\mathrm{open}}$ which gives $\Delta \mathrm{G}=0$ i.e. $\Delta \mathrm{H}_{\mathrm{M}-\mathrm{B}} / \Delta_{\mathrm{p}} \mathrm{S}^{\circ}(\mathrm{M})$ (Meot-Ner, 2005). Indeed, an increase of $\mathrm{T}_{\text {open }}$ with the number of carbon atoms is observed for diamines, diols and diketones but the situation is more balanced for diethers and methoxy alcohols (Meot-Ner, 2005).

(v) For most of the polyfunctional molecules studied in the present review, $\Delta \mathrm{H}_{\mathrm{M}-\mathrm{B}}$ i.e. the increase in proton affinity originating from internal hydrogen bonding falls in the $10-100 \mathrm{~kJ} / \mathrm{mol}$ range. On the other hand, protonation entropies $\Delta_{\mathrm{p}} \mathrm{S}^{\circ}(\mathrm{M})$ are generally situated around -20 to $-100 \mathrm{~J} \cdot \mathrm{mol}^{-1} \cdot \mathrm{K}^{-1}$. This corresponds to a $\mathrm{T} \Delta_{1} \mathrm{~S}^{\circ}$ 
contribution to the gas phase basicity of -6 to $-30 \mathrm{~kJ} / \mathrm{mol}$. The overall effect of the occurrence of internal hydrogen bonding is consequently to increase the gas phase basicity of polyfunctional molecules.

(vi) Quantum chemistry calculations may be also used to estimate internal hydrogen bond strength by simply comparing the enthalpies of the cyclized and fully opened conformers (Deakyne, 2003; Bouchoux, 2007). Concerning protonation entropies, theoretical estimates are less evident to obtain since entropy calculation for large molecular systems containing several internal rotations need a detailed knowledge of all the rotational barriers and an accurate method of calculation of the entropy of hindered rotations (Bouchoux, 2007).

\section{Amines}

Before examining the polyfunctional molecules containing an amino group, the major trends observed on the gas-phase basicities of simple alkylamines can be briefly recalled. Firstly, an increase of the proton affinity is observed with increasing the chain length since the stabilizing interaction between the charge and the polarizable alkyl chain increases. Secondly, a significant increase in basicity is observed when passing from primary to secondary and tertiary amines. The consequences of these two major structural effects are illustrated by the PA values of the first members of the alkylamine series in Table 2.

Table 2. Proton affinities of selected alkyl amines $(\mathrm{kJ} / \mathrm{mol})$.

\begin{tabular}{cccc}
\hline $\mathrm{R}$ & $\mathrm{PA}\left(\mathrm{RNH}_{2}\right)$ & $\mathrm{PA}\left(\mathrm{RNHCH}_{3}\right)$ & $\left.\mathrm{PA}\left(\mathrm{RN}_{(\mathrm{CH}}\right)_{2}\right)$ \\
\hline $\mathrm{CH}_{3}$ & 899.0 & 929.5 & 948.9 \\
$\mathrm{C}_{2} \mathrm{H}_{5}$ & 912.0 & 942.2 & 960.1 \\
$\mathrm{n}-\mathrm{C}_{3} \mathrm{H}_{7}$ & 917.8 & {$[964.4]$} & 962.8 \\
$\mathrm{n}-\mathrm{C}_{4} \mathrm{H}_{9}$ & 921.5 & & 969.2 \\
$\mathrm{n}-\mathrm{C}_{5} \mathrm{H}_{11}$ & $923.5[924.5]$ & & {$[969.9]$} \\
$\mathrm{n}-\mathrm{C}_{6} \mathrm{H}_{13}$ & $927.5[926.5]$ & & {$[973.0]$} \\
$\mathrm{n}-\mathrm{C}_{7} \mathrm{H}_{15}$ & $923.2[928.0]$ & & {$[975.0]$} \\
$\mathrm{n}-\mathrm{C}_{8} \mathrm{H}_{17}$ & {$[928.9]$} & &
\end{tabular}

a) From the Hunter \& Lias compilation (Hunter \& Lias, 1998). Into brackets, estimated by comparison with homologous molecules. Note that the protonation entropies $\Delta_{\mathrm{p}} \mathrm{S}_{298}{ }^{\circ}(\mathrm{M})$ of primary, secondary and tertiary amines are assigned $-2,-5$ and $+5.6 \mathrm{~J}^{-\mathrm{K}^{-1}}$. $\mathrm{mol}^{-1}$, respectively in Hunter \& Lias (Hunter \& Lias, 1998). The corresponding gas phase basicities are thus easily deduced using equation (4).

Another illustration of the alkyl chain (or polarizability) effect is the increase in proton affinity observed in the series aziridine, azetidine, pyrrolidine and piperidine $(905.5,943.4,948.3,954.0 \mathrm{~kJ} / \mathrm{mol}$ (Hunter \& Lias, 1998). With the exception of aziridine, these PA values are comparable to those of the corresponding alkyl secondary amine. The very low PA value of aziridine may be explained by the occurrence of significant strain energy in the protonated form due to the repulsion between the two methylene groups and the increase of electronegativity of the nitrogen atom due to the increased s character of its atomic orbitals containing the lone pairs.

Moreover, linear relationships are generally observed in homogeneous series between the proton affinities (or the gas-phase basicities) and parameters related to the number of atoms of the molecule or of the aliphatic chain (Bouchoux, 2007). For example, Figure 1 illustrates the correlations PA vs. $1 / n$ (where $n$ is the total atom number of the molecule) for the primary and tertiary amines.

Figure 1. 
The basicity properties of the amino group is dramatically modified if bonded to an unsaturated $\mathrm{C}=\mathrm{C}$ group. Accordingly, it is expected that the conjugation of the nitrogen lone pair with $\pi$-electrons would result in a lower basicity of the amino group. Moreover, protonation on the $\mathrm{C}=\mathrm{C}$ may produce a cation stabilized by the donating effect of the nitrogen lone pair. It is exactly what has been established by G2 computation on both ethynylamine and vinylamine (Mó et al., 1999). In fact, these simple molecules appear to be carbon and not nitrogen bases (Scheme 1). Protonation at the $C_{\beta}$ atom is preferred by 61.5 (vinylamine) and $98.8 \mathrm{~kJ} / \mathrm{mol}$ (ethynylamine) over the nitrogen atom. (Note that the PA values given in Hunter\&Lias for vinylamine, 899 $\mathrm{J} / \mathrm{mol}$, is of questionable accuracy).

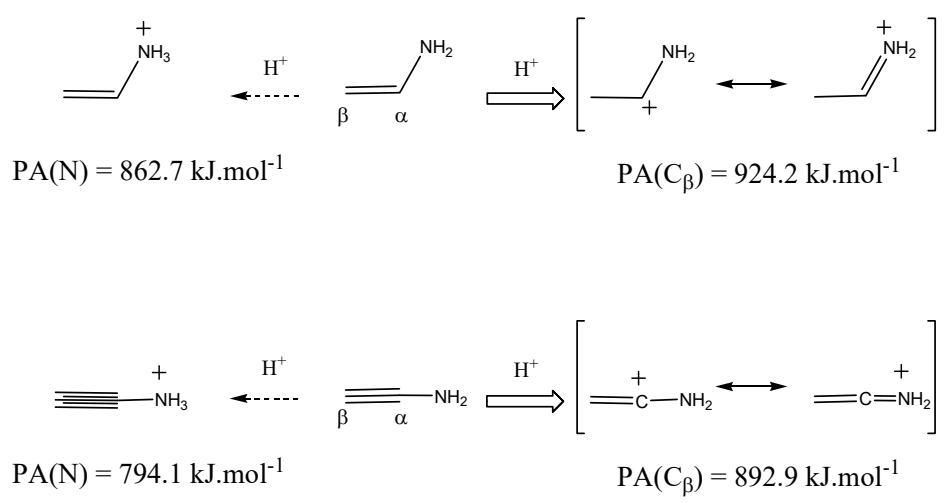

Scheme 1

In this context, the case of aniline is also of interest. This molecule has been the subject of numerous experimental and theoretical studies since several decades (Lau \& Kebarle, 1976; Pollack et al., 1977; Summerhays et al., 1977; Maquestiau et al., 1980; Lau et al., 1981; Wood et al., 1983; Dookeran \& Harrison, 1995; Smith et al., 1995; Hillebrand et al., 1996; Nold \& Wesdemiotis, 1996; Harrison \& Tu, 2000; Russo et al., 2000; Flammang et al., 2004; Nam et al., 2006; Pasker et al., 2006). In their tabulation, Hunter\&Lias (Hunter \& Lias, 1998) proposed for aniline an evaluated proton affinity value of $882.5 \mathrm{~kJ} / \mathrm{mol}$ (assuming $\Delta_{\mathrm{p}} \mathrm{S}_{298}{ }^{\circ}=2 \mathrm{~J}^{\circ} \mathrm{mol}^{-}$ ${ }^{1} \cdot \mathrm{K}^{-1}$ and an average GB value of $850.6 \mathrm{~kJ} / \mathrm{mol}$ ). The question as to whether this value corresponds to protonation on the amino group or on the ring is however of interest. Various experiments using collision induced dissociations, neutralization-reionization or proton exchanges on deuteriated species are interpretable if both the ring protonated and $\mathrm{N}$-protonated species were formed. In fact it appears that a mixture of tautomers is generally produced, the composition of which depends on the protonating reagent used, the lifetime of the ions sampled and the method of sampling (Harrison \& Tu, 2000). These results strongly suggest that the proton affinities at the nitrogen atom and at some of the carbon atoms of aniline are very close together.

Computational chemistry does provide a conclusive result if a sufficiently high level of theory is used. Concerning the C-protonated forms, there is a general consensus to conclude on the better stability of the $\mathrm{C}_{\text {para- }}$ protonated tautomer followed by $\mathrm{C}_{\text {ortho }}, \mathrm{C}_{\text {meta }}$ and $\mathrm{C}_{\text {ipso }}$ (Hillebrand et al., 1996; Russo et al., 2000; Flammang et al., 2004; Nam et al., 2006). By contrast, computation of proton affinities on $\mathrm{N}$ and $\mathrm{C}_{\text {para }}$ positions results in contradictory results. For example, favoured protonation of $\mathrm{N}$ is predicted at the G2MP2 level $\left(\mathrm{PA}(\text { aniline })_{\mathrm{N}}=874.9\right.$ and $\mathrm{PA}(\text { aniline })_{\text {para }}=871.9 \mathrm{~kJ} / \mathrm{mol}$, but the $5 / 2 \mathrm{RT}$ term is probably missing in this computation (Russo et al., 2000)). More recently, B3LYP/6-311++G(d,p) calculation provide contrasting results 
since the PA estimates become $\mathrm{PA}(\text { aniline })_{\mathrm{N}}=877.8$ and $\mathrm{PA}(\text { aniline })_{\text {para }}=886.5 \mathrm{~kJ} / \mathrm{mol}$ (Nam et al., 2006). Our G3 calculations give $\mathrm{PA}(\text { aniline })_{\mathrm{N}}=880.8 \mathrm{~kJ} / \mathrm{mol}, \mathrm{PA}(\text { aniline })_{\text {para }}=877.7 \mathrm{~kJ} / \mathrm{mol}$ and $\mathrm{PA}(\text { aniline })_{\text {ortho }}=856.8$ $\mathrm{kJ} / \mathrm{mol}$, confirming a slightly better basicity of the nitrogen atom with respect to the para carbon atom. The corresponding gas-phase basicities calculated at the $\mathrm{G} 3$ level are $\mathrm{GB}(\text { aniline })_{\mathrm{N}}=854.3 \mathrm{~kJ} / \mathrm{mol}$ and $\mathrm{GB}$ (aniline) $)_{\text {para }}=846.6 \mathrm{~kJ} / \mathrm{mol}$, thus a larger difference in GB is observed by comparison with PA. This difference obviously comes from a difference in $\Delta_{\mathrm{p}} \mathrm{S}_{298^{\circ}}$, the G3 protonation entropies are indeed equal to 19.7 and 4.4 J.mol ${ }^{-1} \cdot \mathrm{K}^{-1}$ for the $\mathrm{N}$ and $\mathrm{C}_{\text {para }}$ protonations. This result is not unexpected because the $\mathrm{NH}_{3}$ group of the $\mathrm{N}$-protonated aniline may be considered as a quasi free rotation. By analogy, the entropy contribution of a $\mathrm{CH}_{3}$

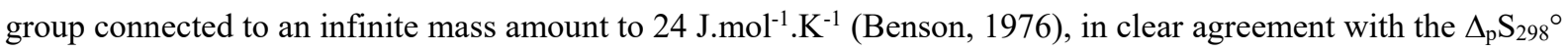
calculated for the N-protonation.

\section{A. Aliphatic polyamines}

\section{a. Hydrazines}

Thermochemistry of gaseous hydrazine has attracted interest during the years (Armstrong et al., 1997; Boulanger et al., 2006; Boulanger et al., 2008), probably because of the large exothermicity of its combustion reaction explaining its major use as a rocket fuel. The protonation thermochemistry of gaseous hydrazine itself and of a series of alkyl hydrazines has been examined by the equilibrium method using high pressure mass spectrometry (Meot-Ner et al., 1984; Nelsen et al., 1988). The authors reported $\Delta \mathrm{G}^{\circ}$ derived from equilibrium constant measurements at 550-600K from which $298 \mathrm{~K}$ gas-phase basicities and proton affinities may be deduced assuming that the protonation entropies results only from the symmetry correction i.e. are limited to $\Delta_{\mathrm{p}} \mathrm{S}^{\circ}=-\mathrm{R} \ln \left(\sigma_{\mathrm{MH}} / \sigma_{\mathrm{M}}\right)$. The data are summarized in Table 3. Scheme 2 contains the structures of the cyclic hydrazines studied by Nelsen et al (Nelsen et al., 1988), the numbering is that used by the authors.

Table 3. Protonation thermochemistry of hydrazines (equilibrium method)

\begin{tabular}{|c|c|c|c|c|}
\hline $\mathrm{M}$ & $\mathrm{GB}(\mathrm{M})^{\mathrm{a}}$ & $\mathrm{PA}(\mathrm{M})^{\mathrm{a}}$ & $\Delta_{\mathrm{p}} \mathrm{S}^{\circ}(\mathrm{M})^{\mathrm{a}}$ & $\mathrm{IE}_{\mathrm{v}}^{\mathrm{b}}$ \\
\hline $\mathrm{NH}_{2} \mathrm{NH}_{2}$ & $823.2 \pm 0.9^{\mathrm{c}}$ & $854.6^{\mathrm{c}}$ & $3.4^{\mathrm{c}}$ & $9.95^{\mathrm{j}}$ \\
\hline $\mathrm{NH}_{2} \mathrm{NHCH}_{3}$ & $866.4 \pm 1.1^{\mathrm{d}}$ & 898.8 & 0 & $9.35^{\mathrm{j}}, 9.36^{\mathrm{k}}$ \\
\hline $\mathrm{NH}_{2} \mathrm{~N}\left(\mathrm{CH}_{3}\right)_{2}$ & $893.3^{\mathrm{c}}$ & 925.7 & 0 & $8.85^{\mathrm{j}}, 8.86^{\mathrm{k}}$ \\
\hline$\left(\mathrm{CH}_{3}\right)_{2} \mathrm{NN}\left(\mathrm{CH}_{3}\right)_{2}$ & $918.2 \pm 0.4^{\mathrm{c}, \mathrm{e}}$ & 948.9 & $5.8^{\mathrm{g}}$ & $8.27^{\mathrm{h}}, 8.38^{\mathrm{k}}$ \\
\hline$\left(\mathrm{CH}_{3}\right)_{2} \mathrm{NN}\left(\mathrm{CH}_{3}\right)\left(\mathrm{nC}_{3} \mathrm{H}_{7}\right)$ & $934.1^{\mathrm{c}}$ & 966.5 & 0 & $8.14^{\mathrm{h}}$ \\
\hline$\left(\mathrm{CH}_{3}\right)\left(\mathrm{C}_{2} \mathrm{H}_{5}\right) \mathrm{NN}\left(\mathrm{CH}_{3}\right)\left(\mathrm{C}_{2} \mathrm{H}_{5}\right)$ & $932.9 \pm 0.6^{\mathrm{e}}$ & 965.3 & 0 & $8.08^{\mathrm{h}}$ \\
\hline$\left(\mathrm{CH}_{3}\right)_{2} \mathrm{NN}\left(\mathrm{CH}_{3}\right)\left(\mathrm{nC}_{4} \mathrm{H}_{9}\right)$ & $937.9^{c}$ & 970.3 & 0 & $8.12^{\mathrm{h}}$ \\
\hline$\left(\mathrm{CH}_{3}\right)_{2} \mathrm{NN}\left(\mathrm{CH}_{3}\right)\left(\mathrm{tC}_{4} \mathrm{H}_{9}\right)$ & $936.4^{\mathrm{d}}$ & 968.8 & 0 & $7.89^{\mathrm{h}}$ \\
\hline$\left(\mathrm{C}_{2} \mathrm{H}_{5}\right)_{2} \mathrm{NN}\left(\mathrm{C}_{2} \mathrm{H}_{5}\right)_{2}$ & $935.3^{\mathrm{d}}$ & 966.0 & 5.8 & $7.94^{\mathrm{h}}$ \\
\hline$\left(\mathrm{CH}_{3}\right)\left(\mathrm{nC}_{3} \mathrm{H}_{7}\right) \mathrm{NN}\left(\mathrm{CH}_{3}\right)\left(\mathrm{nC}_{3} \mathrm{H}_{7}\right)$ & $941.2 \pm 0.2^{\mathrm{e}}$ & 971.9 & 5.8 & $8.03^{\mathrm{e}}$ \\
\hline$\left(\mathrm{CH}_{3}\right)\left(\mathrm{nC}_{4} \mathrm{H}_{9}\right) \mathrm{NN}\left(\mathrm{CH}_{3}\right)\left(\mathrm{nC}_{4} \mathrm{H}_{9}\right)$ & $945.2 \pm 1.2 \mathrm{e}^{\mathrm{c}}$ & 975.3 & 5.8 & $8.02^{\mathrm{e}}$ \\
\hline$\left(\mathrm{CH}_{3}\right)\left(\mathrm{nC}_{5} \mathrm{H}_{11}\right) \mathrm{NN}\left(\mathrm{CH}_{3}\right)\left(\mathrm{nC}_{5} \mathrm{H}_{11}\right)$ & $946.4 \pm 0.8^{\mathrm{e}}$ & 976.5 & 5.8 & $8.01^{\mathrm{e}}$ \\
\hline$\left(\mathrm{CH}_{3}\right)\left(\mathrm{iC}_{4} \mathrm{H}_{9}\right) \mathrm{NN}\left(\mathrm{CH}_{3}\right)\left(\mathrm{iC}_{4} \mathrm{H}_{9}\right)$ & $949.0 \pm 1.2^{\mathrm{e}}$ & 979.1 & 5.8 & $8.03^{\mathrm{i}}$ \\
\hline$\left(\mathrm{CH}_{3}\right)\left(\right.$ neoC $\left._{5} \mathrm{H}_{11}\right) \mathrm{NN}\left(\mathrm{CH}_{3}\right)\left(\right.$ neoC $\left._{5} \mathrm{H}_{11}\right)$ & $947.1 \pm 1.8^{\mathrm{e}}$ & 977.2 & 5.8 & $7.91^{\mathrm{i}}$ \\
\hline $\mathrm{h} 8^{\mathrm{f}}$ & $949.0 \pm 2.0^{\mathrm{e}}$ & 979.7 & 5.8 & $7.91^{\mathrm{h}}$ \\
\hline
\end{tabular}




\begin{tabular}{|c|c|c|c|c|}
\hline $\mathrm{h} 9^{\mathrm{f}}$ & $950.5 \pm 1.8^{\mathrm{e}}$ & 981.2 & 5.8 & $7.89^{\mathrm{h}}$ \\
\hline $\mathrm{h} 10^{\mathrm{f}}$ & $928.5 \pm 0.8^{\mathrm{e}}$ & 959.2 & 5.8 & $7.78^{\mathrm{h}}$ \\
\hline $\mathrm{h} 11^{\mathrm{f}}$ & $938.0 \pm 0.8^{\mathrm{e}}$ & 968.7 & 5.8 & $7.81^{\mathrm{h}}$ \\
\hline $\mathrm{h} 12^{\mathrm{f}}$ & $936.0 \pm 0.5^{\mathrm{e}}$ & 966.7 & 5.8 & $7.88^{\mathrm{h}}$ \\
\hline $\mathrm{h} 13^{\mathrm{f}}$ & $947.3 \pm 0.98^{\mathrm{e}}$ & 978.0 & 5.8 & $7.87^{\mathrm{h}}$ \\
\hline $\mathrm{h} 14^{\mathrm{f}}$ & $947.9 \pm 1.4^{\mathrm{e}}$ & 978.6 & 5.8 & $7.61^{\mathrm{h}}$ \\
\hline $\mathrm{h} 15^{\mathrm{f}}$ & $944.2 \pm 1.4^{\mathrm{e}}$ & 974.9 & 5.8 & $7.66^{\mathrm{h}}$ \\
\hline $\mathrm{h} 16^{\mathrm{f}}$ & $950.0 \pm 1.1^{\mathrm{e}}$ & 980.7 & 5.8 & $7.46^{\mathrm{h}}$ \\
\hline $\mathrm{h} 17^{\mathrm{f}}$ & $936.8^{\mathrm{e}}$ & 967.5 & 5.8 & $7.99^{\mathrm{e}}$ \\
\hline
\end{tabular}

a) PA and GB in $\mathrm{kJ} \mathrm{mol}^{-1} ; \Delta_{\mathrm{p}} \mathrm{S}^{\circ}$ in J.K $\mathrm{K}^{-1} \cdot \mathrm{mol}^{-1}$;b) Vertical ionization energies in $\mathrm{eV}$; c) Mautner et al 1984; d) Hunter\&Lias 1998; e) Nelsen et al 1988; f) see Scheme 2 for structural assignment; g) $\Delta_{\mathrm{p}} \mathrm{S}^{\circ}=\mathrm{R} \ln 2$; h) Nelsen et al 1976; i) Nelsen et al 1978; j) Nelsen\&Buschek 1974; k) Boulanger et al 2006.<smiles>C1CCN(N2CCCC2)C1</smiles>

h8<smiles>C1CN2CCCN2C1</smiles>

h13

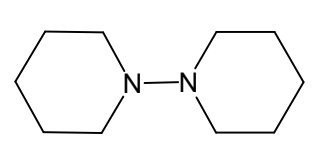

h9<smiles>C1CCN2CCCCN2C1</smiles>

h14

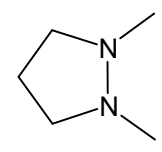

h10<smiles>CN1C2CCC(C2)N1C</smiles>

h15<smiles>CN1CCCCN1C</smiles>

h11<smiles>CN1C2CCC(CC2)N1C</smiles>

h16<smiles>CN1CCCCCN1C</smiles>

h12<smiles>CN1CC=CCN1C</smiles>

h17

Scheme 2. Cyclic tetraalkyl hydrazine (numbered following Nelsen et al 1988)

The experimental proton affinity of hydrazine is equal to $854.6 \mathrm{~kJ} / \mathrm{mol}$, a value practically identical to the proton affinity of ammonia, $853.6 \mathrm{~kJ} / \mathrm{mol}$. This may be explained by the opposite effects of the electronegativity and polarizability of the second $\mathrm{NH}_{2}$ group. It may be recalled for example that the proton affinity of methylamine, $899 \mathrm{~kJ} / \mathrm{mol}$, is significantly higher than that of ammonia due to the polarizability of the methyl group which stabilize protonated methylamine. The $\mathrm{NH}_{2}$ group may play a similar part in hydrazine, however this effect is counterbalanced by the electronegativity of the nitrogen atom. This is corroborated by molecular orbital calculations. As depicted in Scheme 3, the NN bond length is only slightly elongated when passing from the neutral to the protonated forms of hydrazine (1.438 $\AA$ and $1.446 \AA$, respectively, MP2/6-31G(d) calculations). This is indeed expected when protonation involves one atom linked to atoms of identical electronegativity (Bouchoux, 2007). By contrast, in protonated methylamine, the nitrogen atom can recover its electroneutrality by depopulating the $\mathrm{C}-\mathrm{N}$ bond because of the lower electronegativity of the carbon. As a result, the $\mathrm{C}-\mathrm{N}$ bond passes from $1.464 \AA$ in neutral methylamine to $1.508 \AA$ in its protonated form. 


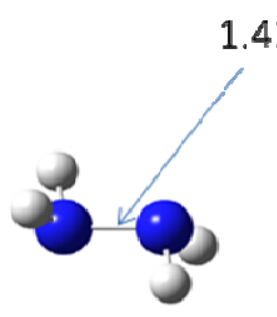

1 Neutral hydrazine

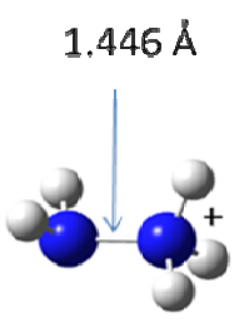

Protonated hydrazine

Scheme 3

Computation of the $298 \mathrm{~K}$ proton affinity of hydrazine at the G2MP2 level has been done by several authors (Armstrong et al., 1997; Oiestad \& Uggerud, 1997). The value, $864 \mathrm{~kJ} / \mathrm{mol}$, is confirmed by our G3 computation (this work) which gives $\mathrm{PA}($ hydrazine) $=866.3 \mathrm{~kJ} / \mathrm{mol}$ using the staggered conformation 2 for neutral hydrazine (Scheme 3) (note that the $D 2 h$ conformer 1 is less stable by $11 \mathrm{~kJ} / \mathrm{mol}$ at the G3 level). Correcting the G3 value by considering isodesmic proton transfer reactions with ammonia and methylamine we obtain PA(hydrazine $)=863.5 \mathrm{~kJ} / \mathrm{mol}$. Thus theory predicts a proton affinity value larger than experiment by ca. $10 \mathrm{~kJ} / \mathrm{mol}$. We note that, similarly, G3 computation gives a protonation entropy of $10 \mathrm{~J} \mathrm{~mol}^{-1} \mathrm{~K}^{-1}$, not $3.4 \mathrm{~J} \mathrm{~mol}^{-1}$ $\mathrm{K}^{-1}$ as determined experimentally (Table 3 ).

Thanks to the large set of data obtained by Mautner and co-workers (Meot-Ner et al., 1984; Nelsen et al., 1988), the role of the alkyl substitution on the basicity of hydrazine may be examined. As seen from examination of Table 3, the proton affinities of alkylhydrazines span a range of values situated between 855 and $980 \mathrm{~kJ} / \mathrm{mol}$. Protonation of unsymmetrical hydrazines is expected to be preferred on the most substituted nitrogen atom. As an illustrative case, let us examine the $\mathrm{N}, \mathrm{N}$-dimethylhydrazine, $\mathrm{NH}_{2} \mathrm{~N}_{(}\left(\mathrm{CH}_{3}\right)_{2}$. Indeed, protonation at the $\mathrm{N}\left(\mathrm{CH}_{3}\right)_{2}$ is favoured over protonation at $\mathrm{NH}_{2}$ by $34 \mathrm{~kJ} / \mathrm{mol}$. The G3 computed $\mathrm{PA}\left(\mathrm{NH}_{2} \mathrm{~N}\left(\mathrm{CH}_{3}\right)_{2}\right)$ is equal to $928.9 \mathrm{~kJ} / \mathrm{mol}$ in correct agreement with the experimental value of $925.7 \mathrm{~kJ} / \mathrm{mol}$ (Table 3).

In their original work, Nelsen et al 1988 compared proton affinities and vertical ionization energies, IE $\mathrm{IE}_{\mathrm{v}}$ of a set of acyclic and cyclic tetralkyl hydrazines. As underlined in partl of the present review (Bouchoux, 2007), electron loss and proton addition may be considered as analogous processes since they generate cations from the neutral of interest. It is consequently expected that the phenomenons which stabilize a positive charge would provide comparable effects on both processes. In line with this simple idea, linear correlations have been found between proton affinities and ionization energies for series of homologous compounds (Bouchoux, 2007), (section IIIB3d). It may be illustrated here for the hydrazines whose thermochemical data are reported in Table 3. Proton affinities are plotted as a function of the increase of vertical ionization energies with respect to hydrazine itself in Figure 2(a). A clear linear correlation (correlation coefficient $=0.988$ ) is obtained using the data relevant to alkyl hydrazines. As already observed (Nelsen et al., 1988) there is clearly a large decrease in vertical ionization energies which is not reflected by a corresponding increase in proton affinity for cyclic 
hydrazines. This phenomenon has been related to the large lone pair-lone pair interactions present in cycloalkyl compounds which influence considerably the ionization energies but relatively less the proton affinity.

Figure 2.

In fact, the proton affinity of alkyl substituted bases is essentially sensitive to the polarizability of the alkyl substituents. This may be illustrated by correlating PA with a parameter related to the alkyl polarizability such as, for example, the number of atoms. As shown in Figure 2(b) a linear correlation is obtained between PA and $1 / \mathrm{n}$ where $\mathrm{n}$ is the total number of atoms of the molecules (Aubry \& Holmes, 2000). Proton affinities of alkyl hydrazines exhibit an excellent linear correlation $(\mathrm{Pr}=0.998)$ with $1 / \mathrm{n}$. Cyclic hydrazines fall on a different, but parallel, line, with a poor correlation coefficient however $(\operatorname{Pr}=0.69)$. As a general trend, at a given number of atoms (a given polarizability) the proton affinity is slightly better for the cyclic hydrazines.

Hydroxylated hydrazine $\mathrm{NH}_{2} \mathrm{NHOH}$ has been claimed to be identified after reaction of hydrazine with ozone in a cryogenic argon matrix (Lascola et al., 1988). This conclusion based on vibrational frequencies assignment has been questioned more recently by Maziarz \& Ball (Maziarz \& Ball, 2002). These latter authors used G2, G3, CBS-QB3 and CBS-APNO computational methods to examine $\mathrm{NH}_{2} \mathrm{NHOH}$, the isomeric oxodiamine $\mathrm{NH}_{2} \mathrm{ONH}_{2}$ and their protonated forms. The proton affinities of the various sites of these two molecules, calculated at the G3 level, are summarized in Scheme 4 (values in $\mathrm{kJ} / \mathrm{mol}$; in bold, G3 calculation performed by us).
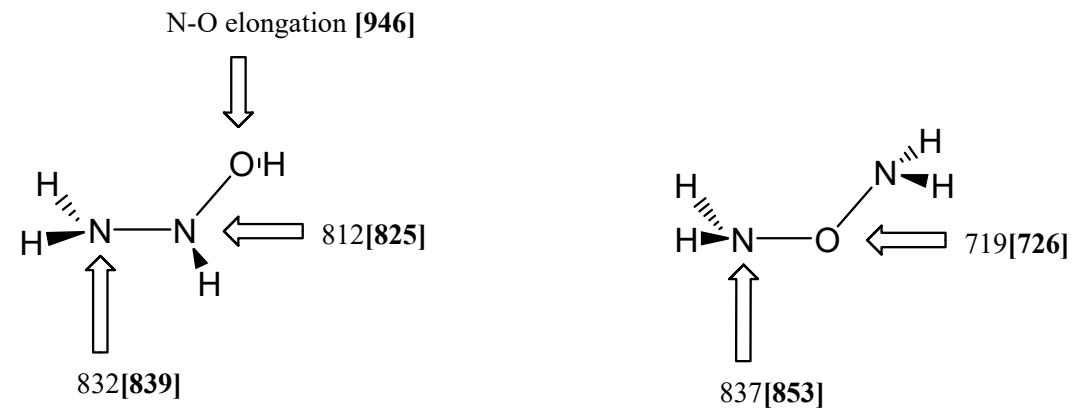

Scheme 4

It immediately appears that protonation at the terminal nitrogen atom of $\mathrm{NH}_{2} \mathrm{NHOH}$ is significantly lower (by ca $25 \mathrm{~kJ} / \mathrm{mol}$ ) than that of hydrazine thus demonstrating a clear destabilizing effect of the hydroxyl group. Proton affinity on the middle nitrogen is slightly lower than in the terminal position and close to that of hydroxylamine ( $\mathrm{PA}=810 \mathrm{~kJ} / \mathrm{mol}$, see below). Finally, Maziarz \& Ball observed that protonation at the oxygen atom lead to $\mathrm{N}-\mathrm{O}$ bond elongation and formation of a proton-bonded complex $\mathrm{H}_{2} \mathrm{O} \ldots \mathrm{H}_{3} \mathrm{~N}_{2}{ }^{+}$, the structure of which being however not detailed (Maziarz \& Ball, 2002). We investigated this protonated form at the G3 level and found that indeed the system evolves toward an ion-neutral complex $\mathrm{H}_{2} \mathrm{O} \ldots{ }^{+} \mathrm{HNH}=\mathrm{NH}$ which is situated 108 $\mathrm{kJ} / \mathrm{mol}$ below the most stable $\mathrm{NH}_{3} \mathrm{NHOH}^{+}$conformer. Protonation at the oxygen atom is associated with a proton affinity of $946 \mathrm{~kJ} / \mathrm{mol}$ and consequently dramatically favoured. 
As expected, the protonation of $\mathrm{NH}_{2} \mathrm{ONH}_{2}$ occurs preferentially on the nitrogen atoms. The proton affinity value is predicted to be $\sim 40 \mathrm{~kJ} / \mathrm{mol}$ above that of hydroxylamine (Maziarz \& Ball, 2002).

\section{b. Diamines and polyamines}

Although known as its hydrochloride in solution, diaminomethane, $\mathrm{NH}_{2} \mathrm{CH}_{2} \mathrm{NH}_{2}$, is not a stable species and thus has not been experimentally investigated. Several N-substituted diaminomethanes have been however described in the literature (Debons \& Loudon, 1980; Khrustalev et al., 2008). G3 computation of the proton affinity of diaminomethane [this work] gives $\mathrm{PA}\left(\mathrm{NH}_{2} \mathrm{CH}_{2} \mathrm{NH}_{2}\right)=922.3 \mathrm{~kJ} / \mathrm{mol}$. It is interesting to note that $\mathrm{PA}\left(\mathrm{NH}_{2} \mathrm{CH}_{2} \mathrm{NH}_{2}\right)$ is larger than the proton affinity of ethylamine by $\sim 10 \mathrm{~kJ} / \mathrm{mol}$ indicating a larger stabilizing effect of the $\mathrm{CH}_{2} \mathrm{NH}_{2}$ group than the ethyl group. However, the polarizabilities of the two groups are very close and even larger for the alkyl group. A possible explanation is the occurrence of a favourable interaction between two of the three $\mathrm{H}$ atoms in the $\mathrm{NH}_{3}{ }^{+}$part of protonated diaminomethane with the second nitrogen atom which indeed brings a net negative charge of -0.38 .

$\alpha, \omega$-diaminoalkanes are probably the most studied polyfunctional molecules from the point of view of their gas-phase basicities (Aue et al., 1973; Yamdagni \& Kebarle, 1973; Meot-Ner et al., 1980; Ikuta \& Nomura, 1987; Ikuta \& Nomura, 1989; Karpas, 1989; Yamabe et al., 1992; Cheng et al., 1993; Green \& Lebrilla, 1998; Reyzer \& Brodbelt, 1998; Wang et al., 1999; Cao et al., 2000; Bouchoux et al., 2001a; Bouchoux et al., 2001b; Bouchoux et al., 2003b; Bouchoux et al., 2003a; Poutsma et al., 2003; Hache et al., 2004; Kumar et al., 2005; Wind et al., 2005; Bouchoux, 2006; Bouchoux \& Buisson, 2006; Salehzadeh \& Bayat, 2006; Salehzadeh et al., 2007; Singh \& Ganguly, 2008; Tian et al., 2009). Gas-phase protonation energetics of the first members of the series of $\alpha, \omega$-alkyldiamines has been studied experimentally more than twenty years ago by ion cyclotron resonance (Aue et al., 1973; Aue \& Bowers, 1979) and pulsed electron beam-high pressure mass spectrometry (Yamdagni \& Kebarle, 1973; Lau et al., 1978; Meot-Ner et al., 1980). The latter experiments were performed at variable temperature allowing the determination of PA and $\Delta_{\mathrm{p}} \mathrm{S}^{\circ}$ after a van't Hoff plot treatment. More recently, these molecules have been studied using the extended kinetic method with the aim to obtain similar information (Cheng et al., 1993; Wang et al., 1999; Cao et al., 2000; Bouchoux et al., 2003b; Bouchoux et al., 2003a; Hahn \& Wesdemiotis, 2003; Wind et al., 2005). Analysis of these data has been conducted using an orthogonal distance regression statistical treatment allowing, in particular, estimating the systematic and random errors on the extended kinetic method results (Bouchoux, 2006). Finally, a gas-phase basicity determination using the thermokinetic method has been also reported for 1,3-diaminopropane (Bouchoux \& Buisson, 2006). The relevant experimental results, adjusted to the commonly used basicity scale (Hunter \& Lias, 1998), are presented in Table 4.

Table 4. Protonation thermochemistry of polyamines.

\begin{tabular}{|c|c|c|c|c|}
\hline $\mathbf{M}$ & Method & $\mathbf{G B}(M)^{\mathrm{a}}$ & $\mathbf{P A}(\mathbf{M})^{\mathbf{a}}$ & $\Delta_{\mathrm{p}} \mathrm{S}^{\circ}(\mathbf{M})^{\mathrm{b}}$ \\
\hline 1,1-diaminomethane & theoretical & 890.0 & $922.4^{\mathrm{r}^{\prime}}$ & 0 (assumed) \\
\hline \multirow[t]{2}{*}{ 1,2-diaminoethane } & equilibrium & $912.4 \pm 2.1^{\mathrm{c}}$ & $951.6 \pm 2.1^{\mathrm{c}}$ & $-22 \pm 3^{c}$ \\
\hline & & $910.9^{d}$ & $960.3^{\mathrm{d}}$ & $-56^{\mathrm{d}}$ \\
\hline
\end{tabular}




\begin{tabular}{|c|c|c|c|c|}
\hline & \multirow{3}{*}{ extended kinetic } & $915.6^{\mathrm{e}}$ & - & - \\
\hline & & $910.6^{\mathrm{h}}$ & $946.3^{\mathrm{h}}$ & $-11^{\mathrm{h}}$ \\
\hline & & $911.7^{\mathrm{i}}$ & $948.3^{\mathrm{i}}$ & $-14^{\mathrm{i}}$ \\
\hline & & $912.9^{n}$ & $949.2^{\mathrm{n}}$ & $-13^{\mathrm{n}}$ \\
\hline & & $910.8^{\circ}$ & $949.5^{\circ}$ & $-21^{\circ}$ \\
\hline & & $909.8^{\mathrm{q}}$ & $947.6^{9}$ & $-18^{\mathrm{q}}$ \\
\hline & average & $911.8 \pm 1.8$ & $950.4 \pm 4.7$ & $-21 \pm 17$ \\
\hline & \multirow[t]{3}{*}{ theoretical } & \multirow[t]{3}{*}{$910.3^{1}$} & $947.7^{1}$ & \multirow[t]{3}{*}{$-17^{1}$} \\
\hline & & & $950.7^{\mathrm{m}}$ & \\
\hline & & & $947.2^{r}$ & \\
\hline \multirow[t]{14}{*}{ 1,3-diaminopropane } & \multirow[t]{4}{*}{ equilibrium } & $939.7 \pm 1.3^{\mathrm{c}}$ & $986.5 \pm 1.3^{\mathrm{c}}$ & $-49 \pm 2^{c}$ \\
\hline & & $938.7^{\mathrm{d}}$ & $995.6^{\mathrm{d}}$ & $-81^{\mathrm{d}}$ \\
\hline & & $942.4^{\mathrm{e}} / 939.6^{\mathrm{f}}$ & - & - \\
\hline & & $937.9 \pm 2.5^{\mathrm{k}}$ & - & - \\
\hline & \multirow[t]{5}{*}{ extended kinetic } & $940.7^{\mathrm{h}}$ & $981.4^{\mathrm{h}}$ & $-28^{\mathrm{h}}$ \\
\hline & & $937.3^{\mathrm{i}}$ & $976.6^{\mathrm{i}}$ & $-23^{\mathrm{i}}$ \\
\hline & & $941.8^{\mathrm{n}}$ & $979.9^{\mathrm{n}}$ & $-19^{n}$ \\
\hline & & $940.0^{\circ}$ & $974.5^{\circ}$ & $-7^{\circ}$ \\
\hline & & $942.4^{\circ}$ & $980.5^{\circ}$ & $-19^{\circ}$ \\
\hline & \multirow{2}{*}{$\begin{array}{c}\text { thermokinetic } \\
\text { average }\end{array}$} & $936.3 \pm 0.3^{\mathrm{k}}$ & - & - \\
\hline & & $939.7 \pm 2.0$ & $982.1 \pm 7.0$ & $-32 \pm 25$ \\
\hline & \multirow[t]{3}{*}{ theoretical } & \multirow[t]{3}{*}{$936.9^{1}$} & $977.7^{1}$ & \multirow[t]{3}{*}{$-29^{1}$} \\
\hline & & & $981.6^{\mathrm{m}}$ & \\
\hline & & & $976.7^{r}$ & \\
\hline \multirow[t]{12}{*}{ 1,4-diaminobutane } & \multirow[t]{3}{*}{ equilibrium } & $953.3^{\mathrm{c}}$ & $1004.5^{\mathrm{c}}$ & $-63 \pm 2^{c}$ \\
\hline & & $955.1^{\mathrm{e}} / 954.3^{\mathrm{f}}$ & - & - \\
\hline & & $951.1 \pm 1.6^{\mathrm{k}}$ & - & - \\
\hline & \multirow[t]{5}{*}{ extended kinetic } & $954.7^{\mathrm{h}}$ & $991.6^{\mathrm{h}}$ & $-15^{\mathrm{h}}$ \\
\hline & & $958.7^{\mathrm{i}}$ & $998.9^{\mathrm{i}}$ & $-26^{\mathrm{i}}$ \\
\hline & & 954.2 & $1004.5^{j}$ & $-60^{\mathrm{j}}$ \\
\hline & & - & $1009.6^{\mathrm{n}}$ & - \\
\hline & & $957.5^{\circ}$ & $993^{\circ}$ & $-11^{\circ}$ \\
\hline & average & $954.9 \pm 2.4$ & $1000.4 \pm 7.1$ & $-35 \pm 25$ \\
\hline & \multirow[t]{3}{*}{ theoretical } & \multirow[t]{3}{*}{$953.6^{1}$} & $999.8^{1}$ & \multirow[t]{3}{*}{$-46^{1}$} \\
\hline & & & $998.3^{p}$ & \\
\hline & & & $1002.0^{r}$ & \\
\hline \multirow[t]{6}{*}{ 1,5-diaminopentane } & \multirow[t]{3}{*}{ equilibrium } & $945.0^{\mathrm{d}}$ & $1001.0^{\mathrm{d}}$ & \multirow[t]{3}{*}{$-78^{\mathrm{d}}$} \\
\hline & & $947.9^{\mathrm{e}} / 944.4^{\mathrm{f}}$ & & \\
\hline & & $947.7^{\mathrm{g}}$ & & \\
\hline & extended kinetic & - & $1000.0^{\mathrm{n}}$ & - \\
\hline & average & $946.3 \pm 1.8$ & $1000.5 \pm 0.7$ & \\
\hline & theoretical & & $997.0^{r}$ & \\
\hline \multirow[t]{3}{*}{ 1,6-diaminohexane } & equilibrium & $947.9^{\mathrm{e}}-944.5^{\mathrm{f}}$ & & \\
\hline & extended kinetic & - & $1007.5^{\mathrm{n}}$ & - \\
\hline & average & $946.2 \pm 2.4$ & & \\
\hline
\end{tabular}




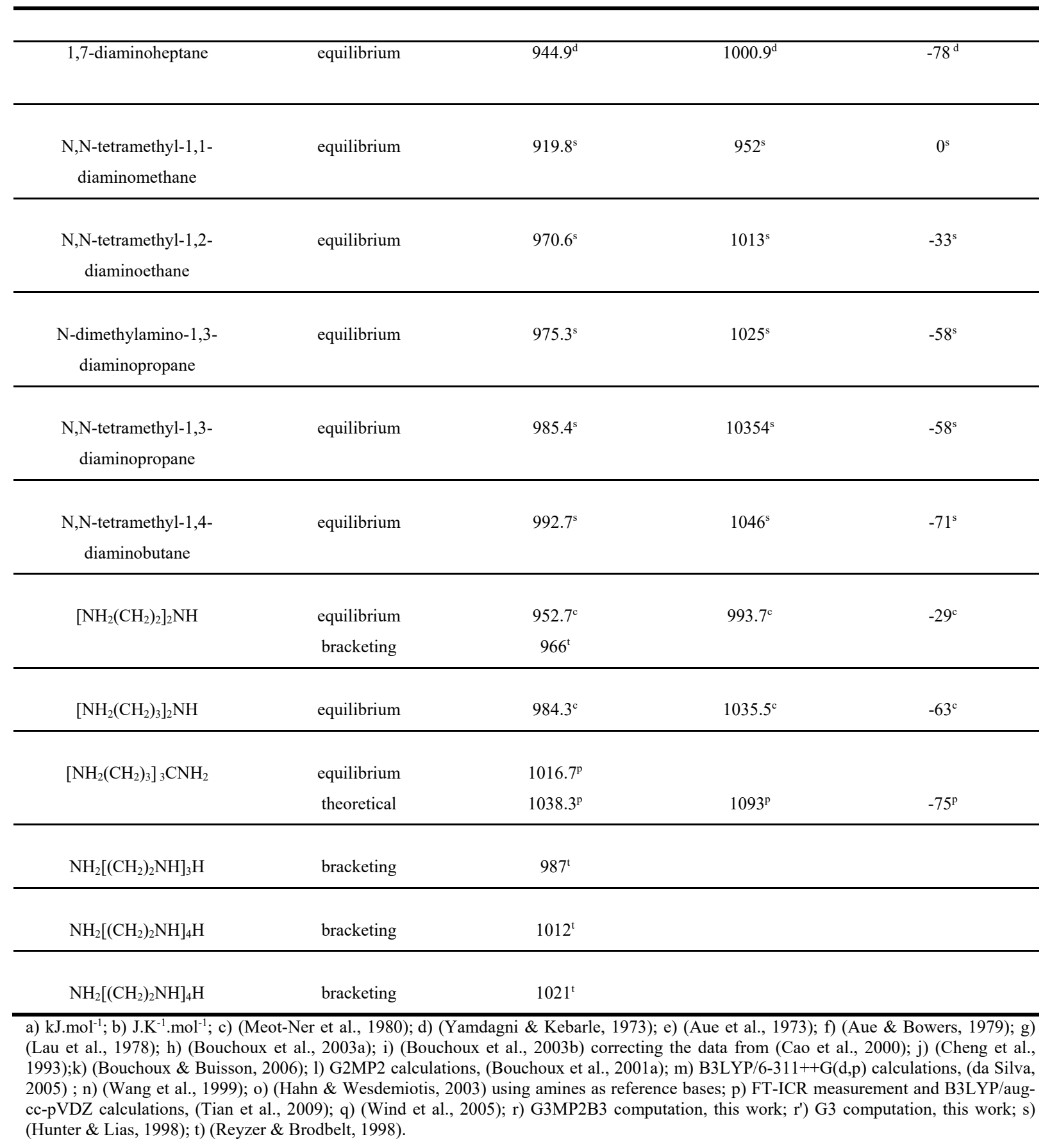

When looking at Table 4, excellent agreement between the gas-phase basicities determinations clearly appears whatever the experimental method used. This is reflected by the small standard deviation (of $\sim 2 \mathrm{~kJ} / \mathrm{mol}$ ) on the averaged GB(M) for 1,2-, 1,3-, 1,4-, 1,5- and 1,6-diaminoalkanes. By contrast, larger errors are associated with proton affinities and protonation entropies. This observation is in line with previous conclusions concerning systematic errors associated to data obtained from extended kinetic method (Armentrout, 2000; Drahos et al., 2004; Ervin \& Armentrout, 2004; Bouchoux, 2006) or equilibrium method at variable temperature (Meot-Ner, 2003). Errors on $\mathrm{PA}(\mathrm{M})$ and $\Delta_{\mathrm{p}} \mathrm{S}^{\circ}(\mathrm{M})$ are particularly significant when $\Delta_{\mathrm{p}} \mathrm{S}^{\circ}(\mathrm{M})$ is important but a compensation effect results in a cancellation of these errors in $\mathrm{GB}(\mathrm{M})$. 
A clear enhancement of the gas-phase basicities is observed when passing from 1,1- to 1,3- and 1,4diaminoalkanes (Table 4). This effect however appears to be blurred, or even reversed, when increasing further the distance between the two basic centres. A comparison with monofunctional amines of similar polarizability indicates that the differences $\Delta \mathrm{GB}$ and $\Delta \mathrm{PA}$ increases from $\sim 10$ to ca. 60 and $75 \mathrm{~kJ} / \mathrm{mol}$, respectively, while $\Delta \mathrm{H}_{\text {strain }}$ (see paragraph IC) decreases from 85 to $20 \mathrm{~kJ} / \mathrm{mol}$ from 1,1- to 1,4-diaminoalkanes (Figure 3). These quantities remain practically constant for 1,5- to 1,7-diaminoalkanes. This evolution clearly parallels that of the $\Delta_{\mathrm{p}} \mathrm{S}^{\circ}(\mathrm{M})$ term which demonstrates an entropy loss upon protonation which increases with the size of the molecule. Note that, by studying the kinetic energy release distribution of protonated dimers involving diamines, Laskin and co-workers (Hache et al., 2004) were able to extract estimates of $\Delta_{\mathrm{p}} \mathrm{S}^{\circ}(\mathrm{M})$ equal to $-37 \pm 13,-52 \pm 15$ and -71 \pm 17 for 1,2-, 1,3- and 1,4-diaminoalkanes.

Figure 3.

These results are indeed fully explainable by the formation of internal hydrogen bonds stronger in the protonated forms than in the neutral forms of these molecules. Quantum chemistry computation confirm these interpretations (Ikuta \& Nomura, 1987; Ikuta \& Nomura, 1989; Yamabe et al., 1992; Wang et al., 1999; Bouchoux et al., 2001a; da Silva, 2005; Kumar et al., 2005; Salehzadeh \& Bayat, 2006; Salehzadeh et al., 2007; Singh \& Ganguly, 2008; Tian et al., 2009). Evidence for cyclisation on the protonated forms of $\alpha, \omega$-diamines was also deduced from ion mobility determinations (Karpas, 1989).

The importance of internal hydrogen bonding during the protonation of $\alpha, \omega$-diaminoalkanes may be illustrated by the key geometrical parameters quoted in Table 5 . The most stable conformers of these neutral and protonated molecules all exhibit a cyclic arrangement that allows formation of an internal $\mathrm{NH} \cdots \mathrm{N}$ hydrogen bond. As a crude comparison, the cases of the $\mathrm{NH}_{3} \cdots \mathrm{NH}_{3}$ and $\mathrm{NH}_{3} / \mathrm{NH}_{3}$ dimers are also considered in order to illustrate the limiting case where no strain effect is expected. Concerning these latter "free" systems, hydrogen bond shortening upon protonation and preference for a linear $\mathrm{NH} \cdots \mathrm{N}$ arrangement are evident from the data in Table 5 . When considering now diaminoalkanes, it appears that the $\mathrm{NH} \cdots \mathrm{N}$ distance is shortened and the $\mathrm{NH} \cdots \mathrm{N}$ angle is enlarged when (i) the size of the molecule increases and (ii) protonation has occurred. This result indicates that the protonated form is stabilized by a stronger internal hydrogen bond than its neutral counterpart and that this phenomenon is strengthened as the size of the ring increases. All these structural and energetic features account for the relatively high basicities of these compounds and of its evolution in the series.

Table 5. Structural data relevant to protonation of $\alpha, \omega$-diaminoalkanes ${ }^{\mathrm{a}}$.

\begin{tabular}{ccccc}
\hline $\mathrm{M}$ & $\begin{array}{c}\mathrm{d}_{\mathrm{NH} \ldots \mathrm{N}} \\
\text { neutral }\end{array}$ & $\begin{array}{c}(\mathrm{NH} \cdots \mathrm{N}) \text { angle } \\
\text { neutral }\end{array}$ & $\begin{array}{c}\mathrm{d}_{\mathrm{NH} \ldots \mathrm{N}} \\
\text { protonated }\end{array}$ & $\begin{array}{c}(\mathrm{NH} \cdots \mathrm{N}) \text { angle } \\
\text { protonated }\end{array}$ \\
\hline 1,2 & 2.448 & 106.2 & 1.841 & 1.652 \\
1,3 & 2.243 & 126.9 & 1.552 & 16.8 \\
1,4 & 2.073 & 150.2 & $1.580^{\mathrm{b}}$ & 171.8 \\
1,5 & $2.293^{\mathrm{b}}$ & 161.5 & 1.152 & 179.7 \\
\hline
\end{tabular}

a) B3LYP/6-31G(d) optimized geometries, lengths in $\AA$, angles in degrees; b) Limited approach probably due to a C(2)C(3) hindrance of rotation; c) $\mathrm{NH}_{3} / \mathrm{NH}_{3}$ and $\mathrm{NH}_{3} / \mathrm{NH}_{4}{ }^{+}$systems. 
Computation of third law entropies for $\mathrm{M}$ and $\mathrm{MH}^{+}$has been reported for 1,2-, 1,3- and 1,4diaminoalkanes (Bouchoux et al., 2001a). The method used consisted to compute vibrational contributions to entropy within the harmonic oscillator approximation except for internal rotations which were treated as hindered rotors. Entropy contribution were calculated by using a procedure developed by Pitzer (Pitzer \& Gwinn, 1942) where the potential energy of the rotors may be approximated by a function of the form $\mathrm{V}_{0} / 2(1-\cos$ $\mathrm{n} \Phi)$ where $\mathrm{V}_{0}$ is the rotational barrier and $\Phi$ the dihedral angle. The resulting $\Delta_{\mathrm{p}} \mathrm{S}^{\circ}(\mathrm{M}),-17,-29$ and $-46 \mathrm{~J}^{-} \mathrm{mol}^{-}$ ${ }^{1} \cdot \mathrm{K}^{-1}$, show correct agreement with the averaged experimental protonation entropies (Table 4).

Table 4 presents also thermochemical data concerning several dimethylamino derivatives of $\alpha, \omega$ diaminoalkanes. Gas-phase basicities are obtained from ICR experiments using the equilibrium method. The proton affinities are deduced by using assumed protonation entropies and are consequently only approximations. The expected increase in basicity due to the tertiary character of the nitrogen atom is indeed evident in Table 4 . As recalled in the introduction of II in the case of monoamines, gas-phase basicity differences between $\mathrm{RNH}_{2}$ and $\mathrm{RN}\left(\mathrm{CH}_{3}\right)_{2}$ amount for $\sim 50 \mathrm{~kJ} / \mathrm{mol}$ (Table 2). It is interesting to note that this difference is roughly recovered for the 1,2-diamines $(\Delta \mathrm{GB}=58 \mathrm{~kJ} / \mathrm{mol})$ but that a clear decrease is observed when passing to $1,3-(\Delta \mathrm{GB}=46$ $\mathrm{kJ} / \mathrm{mol})$ and $1,4-(\Delta \mathrm{GB}=38 \mathrm{~kJ} / \mathrm{mol})$ derivatives.

The gas-phase basicity of a limited number of polyamine has been studied experimentally (Meot-Ner et al., 1980; Reyzer \& Brodbelt, 1998; Tian et al., 2009). These molecules are multidentate ligands which present several possible sites of protonation and multiple possibilities of intramolecular hydrogen bonding and are thus expected to present highly stabilized protonated forms. Diethylene- and dipropylene-triamines, $\left[\mathrm{NH}_{2}\left(\mathrm{CH}_{2}\right)_{2}\right]_{2} \mathrm{NH}$ and $\left[\mathrm{NH}_{2}\left(\mathrm{CH}_{2}\right)_{3}\right]_{2} \mathrm{NH}$, have been studied by high pressure mass spectrometry and their gas-phase basicities have been determined using the equilibrium method (Meot-Ner et al., 1980). Since the measurements have been performed at several temperatures, the authors were able to determine the proton affinities and the protonation entropies. The GB values of these two molecules (952.7 and $984.3 \mathrm{~kJ} / \mathrm{mol}$, respectively, Table 4) are ca 40 $\mathrm{kJ} / \mathrm{mol}$ above that of the monomeric homologues 1,2-ethylenediamine and 1,3-propanediamine, thus demonstrating a significant increase in basicity. More recently, the gas-phase basicity of the tetramine $\left[\mathrm{NH}_{2}\left(\mathrm{CH}_{2}\right)_{3}\right]_{3} \mathrm{CNH}_{2}$ has been determined from measurement of forward and reverse reaction rate of proton transfer in a Fourier transform ion cyclotron resonance mass spectrometer (Tian et al., 2009). The value (1016.7 $\mathrm{kJ} / \mathrm{mol}$ ) is $60 \mathrm{~kJ} / \mathrm{mol}$ higher than $\mathrm{GB}(1,4$-butanediamine) demonstrating a dramatic effect of internal hydrogen bonding. Indeed, this study was completed by B3LYP/aug-cc-pVDZ computations which demonstrate the establishment of three strong hydrogen bonds inside the protonated form and predict a proton affinity of 1093 $\mathrm{kJ} / \mathrm{mol}$. The authors suggest a direct estimate of the protonation entropy (without scaling or correction for hindered rotation) of $-75 \mathrm{~J} \cdot \mathrm{mol}^{-1} \cdot \mathrm{K}^{-1}$. Note that this latter value, combined with the computed PA gives a theoretical GB of 1038.3 clearly higher than experiment by $\sim 20 \mathrm{~kJ} / \mathrm{mol}$.

Reyzer \& Brodbelt (Reyzer \& Brodbelt, 1998) investigated a series of polyamines by the bracketing method in an ion-trap device, approximate gas-phase basicities were deduced from these experiments. Some of the results are indicated in Table 4. A comparison of the bracketing and the equilibrium method is possible for one of the studied molecules: diethylenetriamine, $\left[\mathrm{NH}_{2}\left(\mathrm{CH}_{2}\right)_{3}\right]_{2} \mathrm{NH}$. As observed in Table 4, the two GB values 
agree satisfactorily within $13 \mathrm{~kJ} / \mathrm{mol}$. From the entire set of data, an increase in basicity is evidenced when the number of and the spacing between the nitrogen atoms increases in the molecule. The former effect may be viewed by comparing the GB values obtained for diethylenetriamine, triethylenetetramine, tetraethylenepentamine and pentaethylenehexamine (Table 4).

\section{B. Cyclic and aromatic amines}

\section{a. Cyclic diamines}

Proton affinities of cyclic monoamines 4H-1-azabicyclo[2,2,2]octane, 1, and 5H-1azabicyclo[3,3,3] undecane, $\mathbf{2}$, seem to be close to those of comparable tertiary amines and to the related diamines 1,4-diazabicyclo[2,2,2]octane, 3, and 1,5-diazabicyclo[3,3,3]undecane, 4, (Alder et al., 1981). By contrast, $6 \mathrm{H}-1$-azabicyclo[4,4,4]tetradecane, $\mathbf{5}$ was expected to present an enhanced basicity due to its easier propensity to enjoy an inside protonation. Accordingly, the most stable structure of neutral $\mathbf{5}$ is characterized by inward pyramidalisation of the nitrogen atoms (Howard et al., 1995; Perakyla, 1996; Galasso, 1997). In this fully inverted in,in conformation the $\mathrm{N} . . \mathrm{N}$ distance the nitrogen atom is about $2.8 \AA$. Protonation is supposed to occur inside and thus to produce a $\mathrm{MH}^{+}$ion assuming a strong internal hydrogen bond (Howard et al., 1995; Perakyla, 1996). The expected proton affinity is close to $1080-1100 \mathrm{~kJ} / \mathrm{mol}$ according to HF, B3LYP and MP2/631G(d,p) calculations (Howard et al., 1995; Howard, 2000; Perakyla, 1996). This large proton affinity is mostly (i.e. neglecting the strain energy effects) the result of the nitrogen lone pairs repulsion which destabilizes the neutral and the formation of a strong hydrogen bond which stabilize the protonated form.

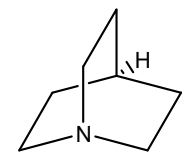

1

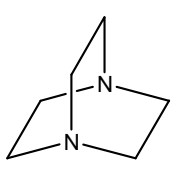

3

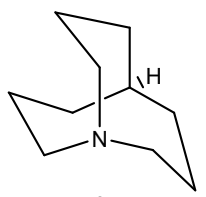

2

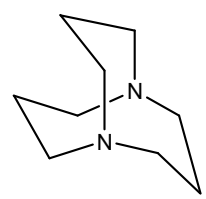

4

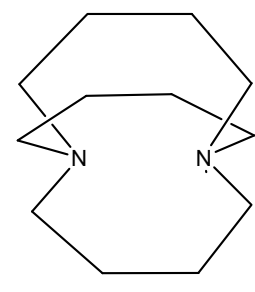

5

Scheme 5

N,N'-polymethylene-syn-1,6:8,13-diimino[14]annulenes $\quad \mathbf{6}$ offers also interesting structural characteristics which influence their gas-phase basicities (Houriet et al., 1989). Starting from $6(n=1)$ (Scheme 6 ) and increasing the number $n$ of methylene groups, gas-phase basicities (determined by the equilibrium method in an ICR cell) present a remarkable discontinuity. While for the first members of the series the GB values are close to $915 \pm 5 \mathrm{~kJ} / \mathrm{mol}$, a significantly larger value of $945 \mathrm{~kJ} / \mathrm{mol}$ is determined for molecules containing five (molecule 7, Scheme 6) and six methylene groups. To interpret these results, it was suggested that an internal hydrogen bond occurs during the protonation when $\mathrm{n}$ is equal or larger to 5 thus leading to a stabilized "inside" 
protonated form. On structural grounds, the formation of an intramolecular bond is less likely, if not impossible, for the lower homologues. These latter diamines will thus give rise to "outside" protonated forms.

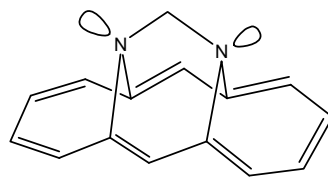

6

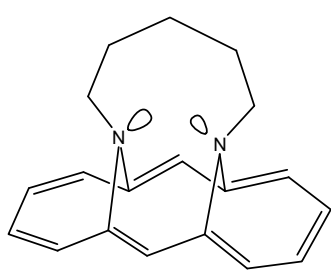

7

Scheme 6

A comprehensive study of the basicity of several $\alpha, \omega$ - and cyclic- diamines in solution (acetonitrile and tetrahydrofuran) and comparison with the gas phase results has been reported recently (Rõõm et al., 2007).

\section{b. Aryl alkyl amines}

Theoretical investigation of the benzene-ammonia neutral system points to the formation of a hydrogen bonded complex with a weak binding energy of about 7-9 kJ/mol (Tsuzuki et al., 2000). By contrast, the interaction energy between benzene and the ammonium cation is equal to ca. $70 \mathrm{~kJ} / \mathrm{mol}$, one order of magnitude higher (Deakyne \& Meot-ner, 1985). This difference in $\mathrm{NH}_{3}$ or $\mathrm{NH}_{4}^{+} \ldots \pi$-electrons interactions leads to the expectation that molecules bearing both nitrogen and $\pi$-electrons system would present enhanced basicities. Indeed, phenyl alkylamines seem to present such structural effects on their basicity. The kinetic method has been used to bracket the basicity of a series of variously substituted phenyl alkylamine (Cardoso et al., 1998). The results, interpreted here in term of gas-phase basicity are presented in Table 6. The increase in chain length from one to four carbon atoms in phenylalkylamines shows an increase in $\mathrm{GB}$ of ca $46 \mathrm{~kJ} / \mathrm{mol}$. By comparison, from ethylamine to butylamine GB increases by only $12 \mathrm{~kJ} / \mathrm{mol}$. The difference $\Delta \mathrm{GB}=\mathrm{GB}$ (phenylalkylamine) $\mathrm{GB}$ (alkylamine), anchored to ethylamine is clearly increasing with the chain length (Table 6). This suggests an interaction between the $\pi$-electron cloud of the aromatic ring and the terminal amino group through the formation of a hydrogen bond which is stronger in the ammonium ion. As observed with $\alpha, \omega$-diamines, it may be noted that $\Delta \mathrm{GB}$ increases rapidly until attaining a plateau for a number of four spacing carbon atoms. The maximum $\Delta \mathrm{GB}$ is however less important than for diamines.

Table 6. Gas-phase basicities of unsubstituted phenylalkylamines.

$\begin{array}{ccc}\mathrm{M} & \mathrm{GB}(\mathrm{M}) & \Delta \mathrm{GB}^{\mathrm{c}} \\ \mathrm{kJ} \cdot \mathrm{mol}^{-1} & 1.3 \\ \mathrm{C}_{6} \mathrm{H}_{5} \mathrm{CH}_{2} \mathrm{NH}_{2} & 879.4^{\mathrm{a}} & 18.4 / 15.9 \\ \mathrm{C}_{6} \mathrm{H}_{5} \mathrm{CH}_{2} \mathrm{CH}_{2} \mathrm{NH}_{2} & 902.3^{\mathrm{a} / 899.8^{\mathrm{b}}} & 31.6 \\ \mathrm{C}_{6} \mathrm{H}_{5} \mathrm{CH}_{2} \mathrm{CH}_{2} \mathrm{CH}_{2} \mathrm{NH}_{2} & 919.2^{\mathrm{b}} & 34.6 \\ \mathrm{C}_{6} \mathrm{H}_{5} \mathrm{CH}_{2} \mathrm{CH}_{2} \mathrm{CH}_{2} \mathrm{CH}_{2} \mathrm{NH}_{2} & 925.2^{\mathrm{b}} & 34\end{array}$

a) Hunter \& Lias 1998 ; b) Cardoso et al 1998; c) $\Delta \mathrm{GB}=\mathrm{GB}(\mathrm{M})-\mathrm{GB}\left(\mathrm{RNH}_{2}\right)$ with $\mathrm{R}=\mathrm{C}_{2} \mathrm{H}_{5}$ to $\mathrm{C}_{5} \mathrm{H}_{11}$. 
Similar increase in the basicity of a $\mathrm{NH}_{2}$ group induced by an aromatic moiety has been demonstrated for the aminoacids phenylalanine and tyrosine (Bouchoux et al., 2009) (Scheme 7). One may also note in passing the cases of aminoethyl pyridine and histamine (Scheme 7) although the $\pi$-electrons $\cdots H N$ interaction is replaced by a more efficient $\mathrm{N}_{\text {imino }} \cdots \mathrm{HN}$ interaction (Raczynska et al., 2005). Accordingly, the gas-phase basicities of these two molecules, 955 and $960 \mathrm{~kJ} / \mathrm{mol}$, respectively, are by far larger than that of 2-phenylethylamine $(902 / 900 \mathrm{~kJ} / \mathrm{mol}$, Table 6).<smiles>NC(Cc1ccccc1)C(=O)O</smiles>

Phenylalanine<smiles>NCCc1ccccn1</smiles>

2-(2-aminoethyl)-pyridine<smiles>NC(Cc1ccc(O)cc1)C(=O)O</smiles>

Tyrosine<smiles>NCCc1c[nH]cn1</smiles>

Histamine

Scheme 7

\section{c. Aromatic diamines, proton sponges}

The remarkable high basicity of 1,8-bis(dimethylamino)-naphtalene 1 (Table 7) in aqueous solution has been reported more than forty years ago (Alder et al., 1968). The determination of its gas-phase basicity has been done ten years later by the equilibrium method using high pressure mass spectrometry (Lau et al., 1978). In the same study, the authors also reported the gas-phase basicity of the unsubstituted 1,8-bis-amino-naphtalene 2. Using their data, GB values of 907 and 983 are obtained for 2 and 1, respectively (Table 7). If compared to aniline $(\mathrm{GB}=850.6 \mathrm{~kJ} / \mathrm{mol}$ ), a clear basicity explosion is associated to these diamino-naphtalene derivatives.

Table 7. Basicity data of several diamino-naphtalenes.

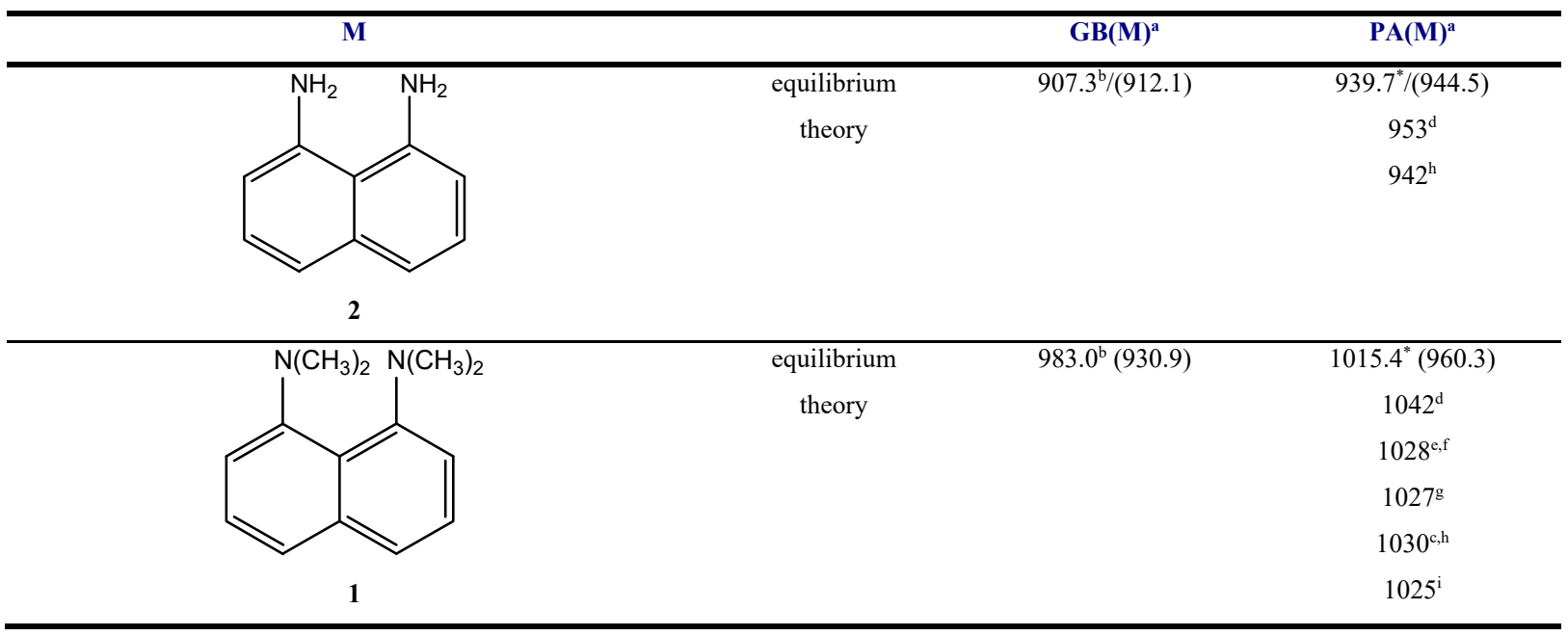




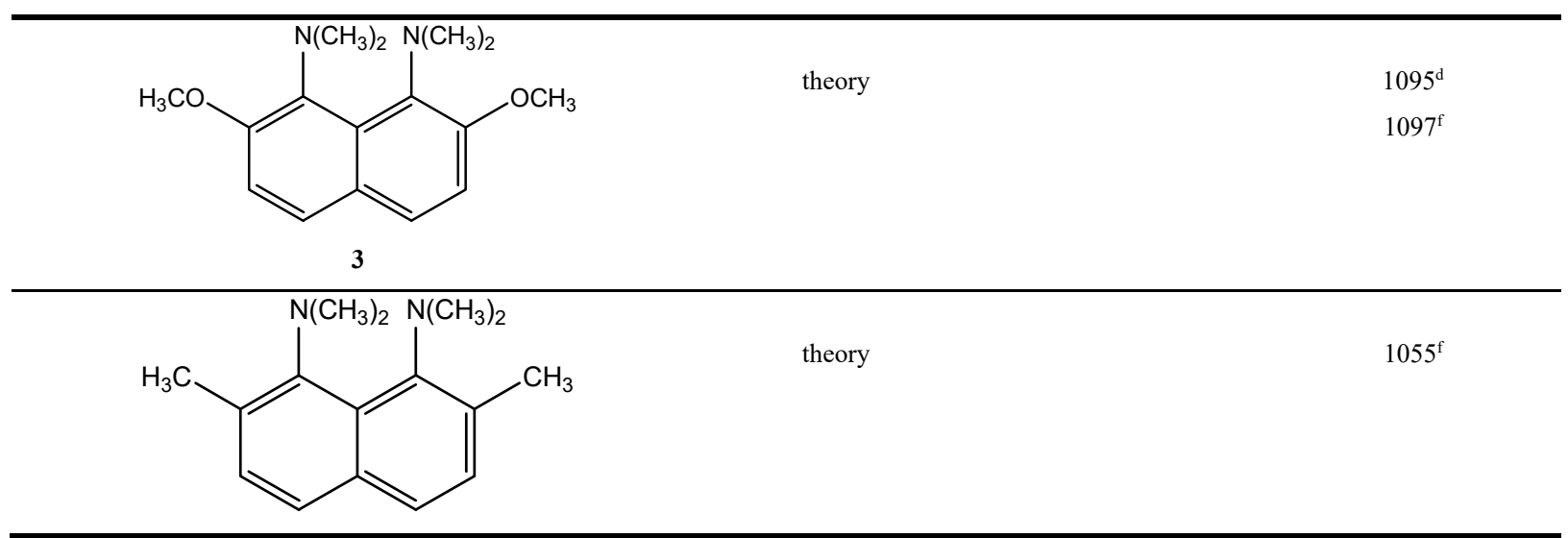

a) $\mathrm{kJ}_{\mathrm{mol}}{ }^{-1}$; b) From (Lau et al., 1978), addition of the experimental free energy change associated to the proton transfer reaction $\mathrm{NH}_{4}{ }^{+}+$ $\mathrm{M} \rightarrow \mathrm{NH}_{3}+\mathrm{MH}^{+}$to the presently accepted value $\mathrm{GB}\left(\mathrm{NH}_{3}\right)=819.0 \mathrm{~kJ} \cdot \mathrm{mol}^{-1}$. No protonation entropy has been assumed when estimating PA from GB. Into parentheses (Hunter \& Lias, 1998); c) HF/6-31G calculation, (Platts et al., 1994), d) MP2/6-31G(d) //HF/6-31G(d) calculations, (Perakyla, 1996); e) B3LYP/6-31+G(d,p) calculation, (Howard, 2000); f) BP/DZVP calculation, (Guo \& Salahub, 2001); g) MP2/6-311+G(d,p)//HF/6-31G(d) calculations, (Kovacevic \& Maksic, 2002); h) B3LYP/6-31+G(d,p)//B3LYP/6-31G(d) calculation, (Ganguly et al., 2007); i) B3LYP/6-31+G(d,p)//B3LYP/6-31G(d) calculation, (Singh \& Ganguly, 2007).

Explanations of this strong basicity enhancement provided by theoretical computations combine hydrogen bond energies, lone pair-lone pair repulsion energies, relief of strain energies and resonance stabilization energies (Platts et al., 1994; Perakyla, 1996; Howard, 2000; Guo \& Salahub, 2001; Kovacevic \& Maksic, 2002; Singh \& Ganguly, 2007; Ganguly et al., 2007). Optimized geometry of neutral 1,8bis(dimethylamino)-naphtalene possesses a $C_{2}$ symmetry with non planar arrangement of the dimethylamino moieties. Protonation results in an asymmetric NH...N bridged arrangement with the two methyl groups nearly perpendicular to the aromatic ring. A general consensus arises for a theoretical proton affinity around 1030 $\mathrm{kJ} / \mathrm{mol}$, the agreement with experimental determination is satisfactory in view of the modest level of theory generally used (Table 7). It is also noteworthy that theory reproduces nicely the $90 \mathrm{~kJ} / \mathrm{mol}$ of difference in proton affinity between $\mathbf{1}$ and 2. A large increase of basicity $(\sim 60 \mathrm{~kJ} / \mathrm{mol})$ is observed between $\mathbf{1}$ and $\mathbf{3}$ thus revealing a considerable impact of the 2,7-methoxy substitution (Guo \& Salahub, 2001). It is concluded from theoretical results that this increase comes from the relief of steric repulsions of the methoxy groups with their neighbouring amino group as a result of protonation.

Proton sponges continue to attract considerable attention and many other molecule with exceptionally high basicity have been described recently (see for example (Raab et al., 2005)). Some of them, containing amidine or guanidine functionalities, i.e. unsaturated basic center, will be described latter on (in a dedicated part of this review).

\section{Aminoalcohols}

\section{a. Hydroxylamine and derivatives}

It has been observed from quantum chemistry calculations that protonation on the most electronegative center of a X-Y bond results in a X-Y bond elongation (Alcami et al., 1990). This is so because, after the X-H bond formation, the $\mathrm{X}$ atom is able to recover its electroneutrality by lowering the electron density along bonds with less electronegative atoms. Conversely, when protonation is occurring on the less electronegative atom a shortening of the X-Y bond is observed. In that case, there is no tendency for $\mathrm{Y}$ to recover its neutrality but the 
positive charge on the $\mathrm{YH}^{+}$moiety induces a polarization of the $\mathrm{X}-\mathrm{YH}^{+}$bond and thus reinforces it. Hydroxylamine, $\mathrm{HONH}_{2}$, offers a clear illustration of these general tendencies. Accordingly, the N-O bond is elongated when protonation occurs on $\mathrm{O}$ and shortened when protonation occurs on $\mathrm{N}$ (by $\sim 0.04 \AA$ in both cases (Alcami et al., 1990; Boulet et al., 1999)).

Hydroxylamine is not stable enough to allow determination of its gas-phase basicity by the equilibrium method (Angelelli et al., 1995). Protonated hydroxylamine ions may be, in contrast, handled easily in a mass spectrometer thus allowing application of the bracketing technique. This has been done in a FT-ICR mass spectrometer cell after formation of the desired ions in an external chemical ionization source and in a B-E tandem mass spectrometer (Angelelli et al., 1995). A qualitative use of their data allow Cacace and co-workers (Angelelli et al., 1995) to propose PA(hydroxylamine) $=810 \pm 8 \mathrm{~kJ} / \mathrm{mol}$.

Figure 4

As recalled in the introduction, the bracketing technique may be seriously improved by using the thermokinetic method (Bouchoux, 2007). Fortunately, Angelelli et al (Angelelli et al., 1995) presented measurements of proton transfer rate constants from protonated hydroxylamine to four reference bases. Using their data we obtain the thermokinetic plot presented in Figure 4 from which the following thermochemical parameters may be deduced: $\mathrm{PA}=818 \pm 4$ and $\mathrm{GB}=788 \pm 4 \mathrm{~kJ} / \mathrm{mol}$.

Proton affinities corresponding to $\mathrm{N}$ and $\mathrm{O}$ protonations have been theoretically computed (Angelelli et al., 1995; Boulet et al., 1999) demonstrating, as expected, a favoured protonation on the nitrogen atom. At the G1 level Angelelli et al (Angelelli et al., 1995) obtain $\mathrm{PA}_{\mathrm{N}}=811$ and $\mathrm{PA}_{\mathrm{O}}=700 \mathrm{~kJ} / \mathrm{mol}$ whereas Boulet et al (Boulet et al., 1999) obtained $\mathrm{PA}_{\mathrm{N}}=814$ and $\mathrm{PA}_{0}=711 \mathrm{~kJ} / \mathrm{mol}$ at the $\operatorname{CCSD}(\mathrm{T}) / 6-311++\mathrm{G}(\mathrm{d}, \mathrm{p}) / / \mathrm{B} 3 \mathrm{LYP} / 6-$ $311++\mathrm{G}(\mathrm{d}, \mathrm{p})$ level. Clearly, these theoretical results are in excellent agreement with experiment as summarized in Scheme 8.

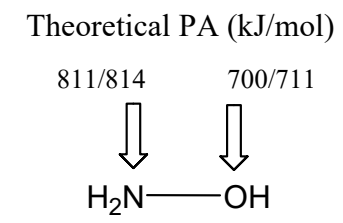

Experimental PA: $810 \pm 8 / 818 \pm 4 \mathrm{~kJ} / \mathrm{mol}$

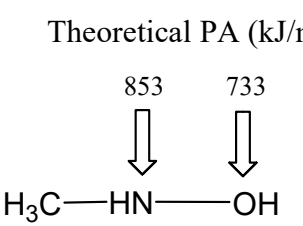

Experimental PA: $858 \mathrm{~kJ} / \mathrm{mol}$
Theoretical PA (kJ/mol)

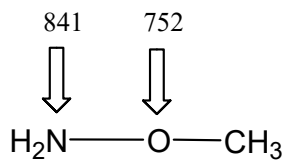

Experimental PA: $848 \mathrm{~kJ} / \mathrm{mol}$

Scheme 8 
The two methyl-hydroxylamines $\mathrm{CH}_{3} \mathrm{NOH}$ and $\mathrm{NH}_{2} \mathrm{OCH}_{3}$ were also examined both experimentally and theoretically from the point of view of their gas-phase basicities (Angelelli et al., 1995). Protonation is still favoured on the nitrogen atom and proton affinities appear to increase significantly when compared to hydroxylamine itself. Scheme 8 summarizes the Angelelli et al. results. A proton affinity of $844.8 \mathrm{~kJ} / \mathrm{mol}$, is given in Hunter and Lias compilation (Hunter \& Lias, 1998) with reference to a personal communication by Taft, this figure is very close to the value of $848.1 \mathrm{~kJ} / \mathrm{mol}$ reported by Angelelli et al. (Angelelli et al., 1995).

Formation of $\left[\mathrm{CH}_{3} \mathrm{NHOH}\right]^{+}$by methylation of hydroxylamine under chemical ionization conditions is attested by collisional activation experiments. This result is fully in line with the fact that this ion is more stable than $\left[\mathrm{NH}_{2} \mathrm{OHCH}_{3}\right]^{+}$by $120 \mathrm{~kJ} / \mathrm{mol}$ (G1 calculation (Angelelli et al., 1995)).

It is noteworthy that the increases in proton affinity observed between hydroxylamine and its methylated homologues are larger than expected if compared with alkyl monoamines. For example, an increase in PA of $30 \mathrm{~kJ} / \mathrm{mol}$ is observed between methylamine and dimethylamine (Table 2) while the difference $\mathrm{PA}\left(\mathrm{CH}_{3} \mathrm{NHOH}\right)-\mathrm{PA}\left(\mathrm{NH}_{2} \mathrm{OH}\right)$ amount for $48 \mathrm{~kJ} / \mathrm{mol}$. This observation is confirmed by the proton affinity of $\mathrm{Et}_{2} \mathrm{NOH}$ which may be deduced from ICR measurements (Bartmess et al., 1983). Using standard techniques for measuring equilibrium gas-phase basicities the authors find that $\mathrm{Et}_{2} \mathrm{NOH}$ is $1.7 \mathrm{~kJ} / \mathrm{mol}$ less basic than propylamine or $50.2 \mathrm{~kJ} / \mathrm{mol}$ less basic than its carbon analogue $\mathrm{Et}_{2} \mathrm{NCH}_{3}$. Neglecting any entropic effect, these data lead to an $\mathrm{Et}_{2} \mathrm{NOH}$ proton affinity of $\sim 918 \mathrm{~kJ} / \mathrm{mol}$. It represents an increase of $118 \mathrm{~kJ} / \mathrm{mol}$ with respect to hydroxylamine. By comparison, the difference $\mathrm{PA}\left(\left(\mathrm{C}_{2} \mathrm{H}_{5}\right)_{2} \mathrm{NCH}_{3}\right)-\mathrm{PA}\left(\mathrm{CH}_{3} \mathrm{NH}_{2}\right)$ represents only $72 \mathrm{~kJ} / \mathrm{mol}$.

It may be finally recalled that results concerning amino substituted hydroxylamine analogues $\mathrm{NH}_{2} \mathrm{NHOH}$ and $\mathrm{NH}_{2} \mathrm{ONH}_{2}$ (Maziarz \& Ball, 2002) have been presented above (see "diamines").

\section{b. $\alpha, \omega$-aliphatic aminoalcohols}

Aminohydroxymethane, $\mathrm{HOCH}_{2} \mathrm{NH}_{2}$, has not been isolated, this molecule is however interesting from several points of view. It is for example expected to be formed by addition of ammonia to formaldehyde and thus the first intermediate in the synthesis of glycine or hexamethylenetetramine, the potential precursors of interstellar aminoacids (Feldmann et al., 2005). $\mathrm{HOCH}_{2} \mathrm{NH}_{2}$, has been theoretically predicted to be a stable isolated species since it is protected against dissociation by energy barriers higher than $230 \mathrm{~kJ} / \mathrm{mol}$ (Feldmann et al., 2005). A G3B3 computation gives a proton affinity, $\mathrm{PA}\left(\mathrm{HOCH}_{2} \mathrm{NH}_{2}\right)$, of $880.4 \mathrm{~kJ} / \mathrm{mol}$ for the N-protonation and of $869.7 \mathrm{~kJ} / \mathrm{mol}$ for the O-protonation (Table 8 ).

Higher $\alpha, \omega$-aliphatic aminoalcohols were investigated experimentally (Meot-Ner et al., 1980; Houriet et al., 1983; Sunner et al., 1986; Bouchoux et al., 2003a; Bouchoux \& Buisson, 2006) and theoretically (Bouchoux et al., 2002a; da Silva, 2005). A summary of the protonation thermochemistry presented in these various studies is given in Table 8. Comparison between experiments can be done only for 1,3- and 1,4aminoalcohols. As observed for diamines, the agreement is excellent when gas-phase basicities are compared. However, considerable differences are evident when considering PA and $\Delta_{\mathrm{p}} \mathrm{S}^{\circ}$. 
Table 8 Protonation thermochemistry of $\alpha, \omega$-aminoalcohols

\begin{tabular}{|c|c|c|c|c|}
\hline $\mathbf{M}$ & Method & GB(M) ${ }^{\mathrm{a}}$ & $\mathbf{P A}(\mathbf{M})^{\mathrm{a}}$ & $\Delta_{\mathrm{p}} \mathrm{S}^{\circ}(\mathrm{M})^{\mathrm{b}}$ \\
\hline $1,1-$ & & & & \\
\hline aminohydroxymethane & theoretical & & $880.4^{\mathrm{i}}$ & \\
\hline \multirow[t]{3}{*}{ 1,2-aminohydroxyethane } & equilibrium & 896.8 & $930.3^{\mathrm{c}}$ & $-3.3^{\mathrm{c}}$ \\
\hline & theoretical & $887.0^{\mathrm{g}}$ & $921.8^{\mathrm{g}}$ & $-8^{\mathrm{g}}$ \\
\hline & & & $929.4^{\mathrm{i}}$ & \\
\hline $1,3-$ & equilibrium & $917.3^{\mathrm{c}}$ & $962.5^{\mathrm{c}}$ & $-43^{\mathrm{c}}$ \\
\hline \multirow[t]{7}{*}{ aminohydroxypropane } & & $914.5^{\mathrm{d}}$ & & \\
\hline & & $913.9 \pm 0.4^{\mathrm{f}}$ & & \\
\hline & extended kinetic & $914.6^{\mathrm{e}}$ & $953.5^{\mathrm{e}}$ & $-22^{\mathrm{e}}$ \\
\hline & thermokinetic & $916.6 \pm 1.3^{\mathrm{f}}$ & & \\
\hline & average & $915.4 \pm 1.5$ & $958.0 \pm 6.4$ & $-33 \pm 15$ \\
\hline & theoretical & $914.8^{\mathrm{g}}$ & $950.6^{\mathrm{g}}$ & $-19^{g}$ \\
\hline & & & $952.3^{\mathrm{i}}$ & \\
\hline \multirow[t]{4}{*}{ 1,4-aminohydroxybutane } & equilibrium & $932.1^{\mathrm{c}}$ & $984.5^{\mathrm{c}}$ & $-67^{c}$ \\
\hline & extended kinetic & $931.7^{\mathrm{e}}$ & $971.9^{\mathrm{e}}$ & $-26^{\mathrm{e}}$ \\
\hline & average & $931.9 \pm 0.3$ & $978.2 \pm 8.9$ & $-47 \pm 29$ \\
\hline & theoretical & $925.1^{\mathrm{g}}$ & $962.5^{\mathrm{g}}$ & $-23^{\mathrm{g}}$ \\
\hline diethanolamine & equilibrium & $820.0^{\mathrm{h}}$ & $874.8^{\mathrm{h}}$ & $0^{\mathrm{h}}$ \\
\hline triethanolamine & equilibrium & $841.0^{\mathrm{h}}$ & $903.7^{\mathrm{h}}$ & $0^{\mathrm{h}}$ \\
\hline
\end{tabular}

a) kJ.mol ${ }^{-1}$; b) J.K ${ }^{-1} \cdot$ mol $^{-1}$; c) (Meot-Ner et al., 1980); d) (Aue \& Bowers, 1979); e) (Bouchoux et al., 2003a); f) (Bouchoux \& Buisson, 2006); g) G2MP2 calculations,(Bouchoux et al., 2002a); h)(Sunner et al., 1986); i) B3LYP/6-311++G(d,p) calculations, (da Silva, 2005); j) G3B3 calculation, this work.

Examination of Table 8 reveals nevertheless an increase in PA of $\sim 100 \mathrm{~kJ} / \mathrm{mol}$ from 1,1- to 1,4aminoalcohols. A parallel decrease in $\Delta_{\mathrm{p}} \mathrm{S}$ is also corroborated for 1,2- to 1,4-aminoalcohols. These evolutions are reproduced by theoretical calculation although with moderate agreement. The structural properties of neutral and protonated 1,2-aminoethanol, 1,3-aminopropanol and 1,4-aminobutanol has been detailed in the first part of this review (Bouchoux, 2007). The most stable conformers of neutral and protonated 1,2-aminoethanol, 1,3aminopropanol and 1,4-aminobutanol are characterized by an internal hydrogen bond. The global stabilization of the protonated forms being larger, an increase in proton affinity results. This effect is amplified in the series when increasing the size of the cycle because of the more efficient $\mathrm{NH} \cdots \mathrm{O}$ alignment.

Stereochemical effects on the intrinsic basicity and on the reactivity of the protonated forms have been demonstrated for 1,2-aminoalcohols (Longevialle et al., 1973; Houriet et al., 1983; Bouchoux et al., 2002a). In the 1970's it has been first observed that the loss of water from protonated steroidal aminoalcohols was intense only if the distance between the oxygen and the nitrogen atoms is too large to allow the formation of an internal 
hydrogen bond (Longevialle et al., 1973). Later, the availability of a series of 1,2-aminoalcohols with constrained geometry has been the starting point of several studies aiming to quantify these observations (Houriet et al., 1983; Bouchoux et al., 2002a). It was observed that the amount of water elimination from the $\mathrm{MH}^{+}$ions increases when the $\mathrm{OCCN}$ dihedral angle increases. This was explained by the formation of a strong hydrogen bond at small dihedral angles in the $\mathrm{N}$-protonated forms, preventing its isomerization to the Oprotonated form which was obviously expected to be at the origin of the water loss. This view has been corroborated by mass spectrometry experiments and quantum chemistry computations (Houriet et al., 1983; Bouchoux et al., 2002a). Moreover, in the same studies, the role of the NCCO angle on the PA of 1,2aminoalcohols has been examined. Figure 5 summarizes these findings.

Figure 5

1,2-aminoethanol has been taken has a model to examine theoretically the effect of the NCCO dihedral angle upon the N-protonation. The potential energies difference between the neutral and the protonated forms is practically constant for $\mathrm{NCCO}$ angles situated between $-50^{\circ}$ and $+50^{\circ}$ and exhibits a clear decrease when the angle exceeds $50^{\circ}$. Figure 5 compares the theoretical prediction with the change in proton affinity experimentally observed when considering molecules with constrained NCCO dihedral angle. In the first region, the small dihedral angle values allow the formation of the internal hydrogen bond in both forms and, as expected, the proton affinity is the highest. Increasing the dihedral angle above $50^{\circ}$, the internal hydrogen bonds are progressively broken, consequently decreasing the proton affinity.

Quantum chemical calculation demonstrates that the O-protonated structure is not stable if the NCCO dihedral angle is lower than $60^{\circ}$ because the proton suddenly shifts to the nitrogen atom. Another finding is that the water loss may be the result of either a 1,2-hydride shift giving rise to an immonium ion or an internal nucleophilic substitution leading to a protonated cyclic amine. This latter is the process of lowest energy for 1,2aminoalcohols and is thus favoured when the NCCO atoms adopt an antiperiplanar arrangement. The $180^{\circ}$ dihedral angle is thus optimum for the elimination of the water molecule. When reducing this angle, it becomes difficult for the nitrogen atom to approach the vicinal carbon back to the $\mathrm{OH}_{2}$ group and thus to promote the water loss.

\section{Alcohols and ethers}

Before exploring in detail the intrinsic basicity of polyols and polyethers, let's first recall the basicity of simple aliphatic alcohols and ethers. The proton affinities of a series of alkyl alcohols and methoxy ethers bearing a linear alkyl chain are summarized in Table 9. Since gaseous protonated alcohols promptly dissociate by water loss, experimental values for compounds having long alkyl chains (more than four carbon atoms) have not been experimentally determined. Values given in Table 9 for higher homologues are deduced from a correlation between proton affinities and ionization energies.

Table 9. Proton affinities of selected alcohols and ethers $(\mathrm{kJ} / \mathrm{mol})$.

\begin{tabular}{ccccc}
\hline $\mathrm{R}$ & $\mathrm{PA}(\mathrm{ROH})$ & $\mathrm{IE}(\mathrm{ROH}) \mathrm{eV}$ & $\left.\mathrm{PA}_{(\mathrm{ROCH}}\right)$ & $\mathrm{IE}\left(\mathrm{ROCH}_{3}\right)$ \\
\hline
\end{tabular}




\begin{tabular}{ccccc}
\hline $\mathrm{CH}_{3}$ & 754.3 & 10.85 & 792.0 & 10.00 \\
$\mathrm{C}_{2} \mathrm{H}_{5}$ & 776.4 & 10.47 & 808.6 & 9.81 \\
$\mathrm{n}-\mathrm{C}_{3} \mathrm{H}_{7}$ & 786.5 & 10.22 & 814.9 & 9.73 \\
$\mathrm{n}-\mathrm{C}_{4} \mathrm{H}_{9}$ & 789.2 & 10.06 & 820.3 & 9.54 \\
$\mathrm{n}-\mathrm{C}_{5} \mathrm{H}_{11}$ & {$[795.0]$} & 10.00 & {$[825.3]$} & 9.67 \\
$\mathrm{C}_{6} \mathrm{H}_{13}$ & {$[800.1]$} & 9.89 & & $\leq 9.48$ \\
$\mathrm{C}_{7} \mathrm{H}_{15}$ & {$[802.3]$} & 9.84 & &
\end{tabular}

a) From the Hunter \& Lias compilation (Hunter \& Lias, 1998). Into brackets, estimated by using a linear correlation PA vs IE. Note that the protonation entropies $\Delta_{\mathrm{p}} \mathrm{S}_{298}{ }^{\circ}(\mathrm{M})$ of alcohols and unsymmetrical ethers are assigned to 7 and $11 \mathrm{~J}^{\mathrm{K}} \mathrm{K}^{-1} \cdot \mathrm{mol}^{-1}$, respectively in Hunter \& Lias (Hunter \& Lias, 1998). The exceptions are methanol $\left(\Delta_{\mathrm{p}} \mathrm{S}_{298}=9 \mathrm{~J} \cdot \mathrm{K}^{-1} \cdot \mathrm{mol}^{-1}\right)$ and dimethyl ethers $\left(\Delta_{\mathrm{p}} \mathrm{S}_{298}=17 \mathrm{~J}_{\mathrm{K}} \mathrm{K}^{-1} \cdot \mathrm{mol}^{-1}\right)$.

Comparison of Table 2 and Table 9 indicates that the proton affinities of primary alcohols are significantly smaller than those of the corresponding primary amines. The proton affinity difference spans from 126 to $145 \mathrm{~kJ} / \mathrm{mol}$, and globally slightly decreases with the increase of the alkyl chain. This important difference is attributed to the difference of electronegativity of the basic centers. It has indeed been observed (Wolf et al., 1977; Bouchoux, 2007) that along a given period of the periodic table, the proton affinity decreases as the electronegativity of the heteroelement increases. The protonation process is characterized by an electron transfer from the lone pair of the heteroelement to the incoming proton, and results in the formation of a covalent $\mathrm{X}-\mathrm{H}$ bond. This electron transfer becomes less favourable with the increase in electronegativity.

For a given series, one can also observe that, like amines and nitriles, the PA increases in the sequence $\mathrm{H}<\mathrm{Me}<\mathrm{Et}<\mathrm{n}-\mathrm{Pr}<\mathrm{n}-\mathrm{Bu}<$ pentyl $<$ hexyl with successively diminishing effects. As already summarized by Bowers (Aue \& Bowers, 1979), polarisable alkyl groups stabilize the positive charge through a charge-induced dipole interaction. This effect is more pronounced as the polarizability of the alkyl chain increases. Aubry and Holmes (Aubry \& Holmes, 2000) also pointed out that the magnitude of the proton affinity of open-chain compounds appears to be related to the size (number of atoms) of the molecule. Their results suggest that the proton affinity should increase along a homologous series, approximately linearly related to $1 / n$, where $n$ is the number of atoms. This is indeed the case for the set of compounds mentioned in Table 9, as illustrated by Figure 6. It is also worth mentioning that the polarizability is linearly related to the number of atoms or electrons of the considered species (Miller, 1990)

Figure 6

Finally, alcohols and ethers share the same protonation site, but the proton affinity of the latter is higher by c.a. $30 \mathrm{~kJ} / \mathrm{mol}$ thanks to the additional stabilization of the protonated form provided by the second alkyl group (presently $\mathrm{CH}_{3}$ ).

\section{A. Unsaturated alcohols, phenols}

The basic properties of alcohols change drastically when the hydroxyl group is borne by a double bond. The simplest enol, namely vinyl alcohol $\mathrm{CH}_{2}=\mathrm{CH}-\mathrm{OH}$ has been studied theoretically. The three different protonation sites of vinyl alcohol (the hydroxyl group, and the two carbon atoms $\alpha$ and $\beta$ ) have been considered by Radom and co-workers (Nobes et al., 1981) during their study of the $\mathrm{C}_{2} \mathrm{H}_{5} \mathrm{O}^{+}$potential energy surface. Results are summarized in Figure 7. 
Figure 7.

Like for the vinylamine, protonation of the simplest enol occurs preferentially on the $\beta$ carbon and leads to the formation of the 1-hydroxyethyl cation. The $\mathrm{C}-\mathrm{O}$ bond is rather short, reflecting a double bond character in accordance with contribution of the valence structure. At the highest level of calculation considered (see Figure 7) the 2-hydroxyethyl cation, which arises from the protonation at the $\alpha$ carbon is predicted to collapse without activation energy to 1-hydroxyethyl cation. The vinyloxonium cation corresponds to the protonation of vinylalcohol on the hydroxyl group. Calculations indicate that this ion is a rather high-energy species since it lies $\sim 100 \mathrm{~kJ} / \mathrm{mol}$ above 1-hydroxyethyl cation. The rearrangement of vinyloxonium to 1-hydroxyethyl cation is a 1,3-sigmatropic shift which has calculated activation energy of $108 \mathrm{~kJ} / \mathrm{mol}$.

In a subsequent study (Nobes \& Radom, 1983), the relative energy between the 1-hydroxymethyl and vinyloxonium cations cation has been refined. A new form of the latter was found, in which the $\mathrm{OH}_{2}$ plane is perpendicular to the CCO plane, and an energy difference of $92 \mathrm{~kJ} / \mathrm{mol}$ was obtained at the highest level of calculation. This value is in excellent agreement with our G3 calculations, which predict the proton affinity of vinylalcohol to be $818.5 \mathrm{~kJ} / \mathrm{mol}$ in the $\beta$ position and $723.4 \mathrm{~kJ} / \mathrm{mol}$ on the oxygen atom (Scheme 9). The difference in proton affinity of the two sites is noticeably larger here $(95 \mathrm{~kJ} / \mathrm{mol})$ than for vinylamine $(61$ $\mathrm{kJ} / \mathrm{mol})$.

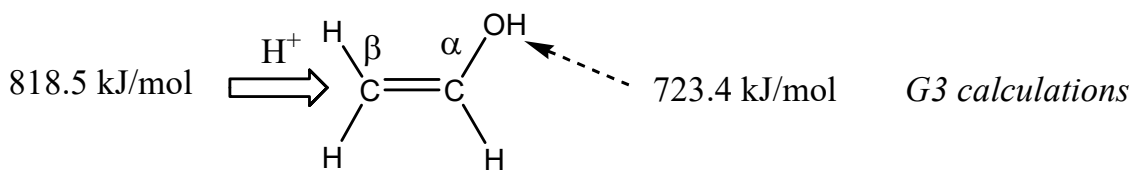

Scheme 9

Much more recently, the proton affinity of an another vinylic alcohol, namely malonaldehyde, has been estimated at the MP2/aug-cc-pVTZ//MP2/6-31+G(d,p) level of calculation (Chan et al., 2005). The two most favourable protonation sites of malonaldehyde correspond to the $\mathrm{C} 3$ and $\mathrm{O} 5$ centers. Protonation of $\mathrm{O} 5$ is preferred by $40 \mathrm{~kJ} \mathrm{~mol}^{-1}$ (Scheme 10).

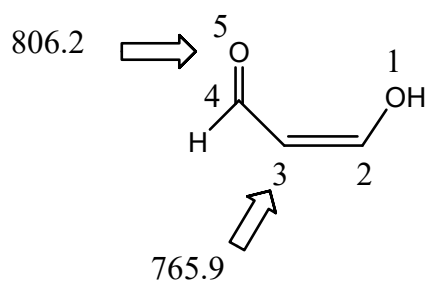

Scheme 10

The positive charge the $\mathrm{C} 3$-protonated product is only delocalized over one $\mathrm{C}$ atom and one $\mathrm{O}$ atom, whereas the positive charge on the $\mathrm{O} 5$-protonated species can be delocalized over two $\mathrm{C}$ atoms and two $\mathrm{O}$ atoms, thus establishing the oxygen atom $\mathrm{O} 5$ as the most basic site. 
The more efficient protonation of the unsaturated carbons is also observed for the phenol molecule. G3 computations reveals indeed that the most probable protonation site of phenol is the para carbon atom (Figure 8), the corresponding proton affinity being equal to $812.9 \mathrm{~kJ} / \mathrm{mol}$, a value which compares favourably with the experimental value of $817.3 \mathrm{~kJ} / \mathrm{mol}$ (Hunter \& Lias, 1998). At the same level of theory the proton affinities of $\mathrm{C}_{\text {ortho }}$ and $\mathrm{O}$ are equal to 793.7 and $744.2 \mathrm{~kJ} / \mathrm{mol}$, respectively. The computed proton affinity does not vary significantly with the level of calculation (see Table 10).

Table 10: protonation thermochemistry of phenol, anisole and derivatives

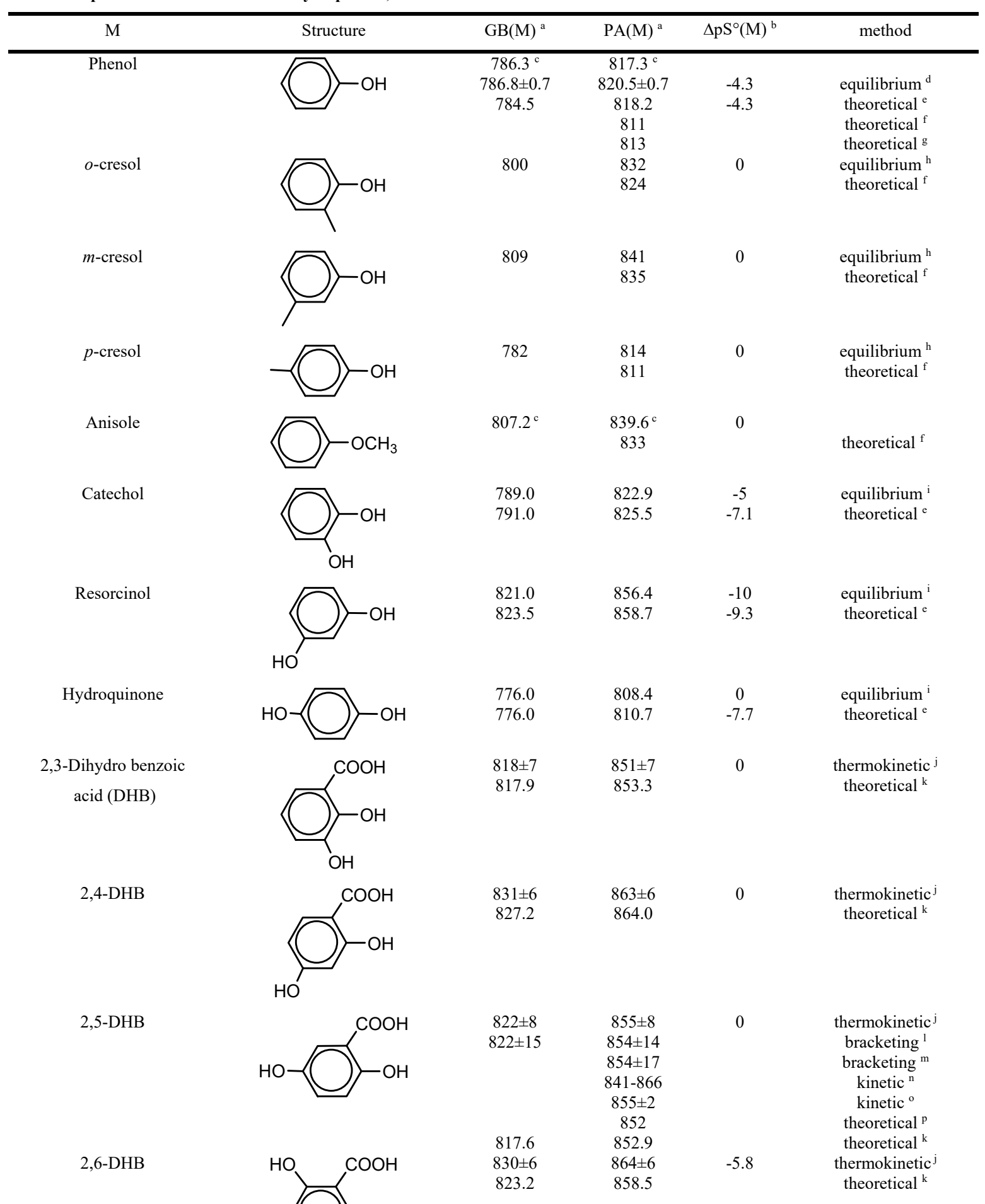


3,4-DHB<smiles>O=C(O)c1ccc(O)c(O)c1</smiles>

3,5-DHB<smiles>O=C(O)c1cc(O)cc(O)c1</smiles>

Caffeic acid<smiles>O=C(O)C=Cc1ccc(O)c(O)c1</smiles>

Ferrulic acid<smiles>COc1cc(/C=C/C(=O)O)ccc1O</smiles>

4-hydroxy- $\alpha$ -

(cyanocinnamic acid)

(4-HCCA)

Sinapinic acid

2-(4-hydroxyphenylazo) benzoic acid (HABA)<smiles>N#CC(=Cc1ccc(O)c(O)c1)C(=O)O</smiles><smiles>COc1cc(/C=C/C(=O)O)cc(OC)c1O</smiles>

$814 \pm 6$ 793.0

$848 \pm 6$

831.7

$-5.8$

thermokinetic $^{j}$ theoretical $^{\mathrm{k}}$

866

kinetic $^{\mathrm{m}}$

$766 \pm 8$

879

bracketing ${ }^{1}$

kinetic $^{\mathrm{m}}$

kinetic $^{\mathrm{m}}$

kinetic $^{\mathrm{n}}$

bracketing ${ }^{k}$ bracketing ${ }^{1}$

kinetic $^{\mathrm{m}}$ kinetic $^{\mathrm{n}}$ bracketing ${ }^{k}$

a) $\mathrm{kJ} \mathrm{mol}^{-1}$; b) J.K ${ }^{-1} \cdot \mathrm{mol}^{-1}$; c) From the Hunter \& Lias compilation (Hunter \& Lias, 1998); d) by using the original equilibrium measurements reported in the Hunter \& Lias compilation (Hunter \& Lias, 1998) and the $\Delta \mathrm{pS}^{\circ}$ (phenol) computed by Bouchoux et al. (Bouchoux et al., 2002b); e) G2(MP2,SVP) calculations (Bouchoux et al., 2002b); f) G3(MP2) calculations (van Beelen et al., 2004); G3 calculations, this work; h) (van Beelen et al., 2004); i) (Bouchoux et al., 2002b); j) (Mormann et al., 2000); k) B3LYP/6-31++G(d,p)//B3LYP6-31G(d) calculations (Rebber et al., 2006); 1) (Steenvoorden et al., 1997); m) (Burton et al., 1997); n) (Jorgensen et al., 1998); o) (Mirza et al., 2004); p) B3LYP/6-311++G(2d,2p)//B3LYP/6-31+G(d,p) calculations (Bourcier \& Hoppilliard, 2002).

The considerable increase of basicity when passing from benzene $(\mathrm{PA}=750.4 \mathrm{~kJ} / \mathrm{mol}$ (Hunter \& Lias, 1998) ) to phenol (817.3 kJ/mol (Hunter \& Lias, 1998)) must be underlined. It demonstrates the important role of the $\mathrm{OH}$ group in para position of the benzenium ion in the stabilization of the positive charge. The effect of an additional substituent on the proton affinity of phenol has been studied by several groups. Van Beelen et al. determined by equilibrium measurements performed by means of a FT-ICR mass spectrometry the gas-phase basicity and proton affinity of the three isomeric methyl phenols, namely $o-, m$ - and $p$-cresol. The experimental values were compared to those estimated at the G3(MP2) level of theory (van Beelen et al., 2004). These results are summarized in Table 10 .

Figure 8 
The various protonation sites were also examined (Figure 8) and it was concluded that the para position with respect to the hydroxyl group is the most basic site for $o$ - and $m$-cresol. As for $p$-cresol, ortho and para positions are of comparable basicity. The preference for protonation at the para position can be accounted to the expected strong stabilization of the positive charge by the oxygen atom and a weaker influence of the methyl group. A good agreement was observed between the G3(MP2) proton affinity associated to the most basic sites and the experimental values.

Addition of a methyl group at the meta position results in an increase in proton affinity of $24 \mathrm{kJmol}^{-1}$ with respect to phenol. The increase is less pronounced for the ortho isomer $\left(15 \mathrm{~kJ} \mathrm{~mol}^{-1}\right)$, and very small $(3 \mathrm{~kJ}$ $\mathrm{mol}^{-1}$ ) for $p$-cresol. A similar trend was obtained for the methylanisoles. (van Beelen et al., 2004). Finally, methylation of the hydroxyl group of phenol (anisole) leads to a substantial increase in the proton affinity $(+32$ $\mathrm{kJ} / \mathrm{mol}$ ), which is of the same magnitude than the difference in basicity observed between aliphatic monoalcohols and monoethers although the protonation site is not the oxygen atom (Table 9). Indeed, as observed for the phenol molecules the para position turned out to be the most basic site of anisole.

The gas-phase basicity of the three dihydroxybenzenes, namely catechol, resorcinol and hydroquinone was determined by measuring their proton transfer equilibrium constants in a high-pressure mass spectrometer (HPMS). Their various protonated forms were explored by quantum chemical calculations at the MP2/6-31G(d) and B3LYP/6-31G(d) levels (Figure 8), and their proton affinities (PA) were calculated at the G2(MP2,SVP) level. To this end, several approaches were considered and the values reported in Table 10 are obtained thanks to isodesmic reactions using benzene as a reference (Bouchoux et al., 2002a). Examination of Table 10 shows an overall good agreement between the experimental and computed proton affinities. Both experimentally and theoretically, the following order of proton affinity was obtained: $\mathrm{PA}\left(3-\mathrm{HOC}_{6} \mathrm{H}_{4} \mathrm{OH}\right)>\mathrm{PA}\left(2-\mathrm{HOC}_{6} \mathrm{H}_{4} \mathrm{OH}\right)>$ $\mathrm{PA}\left(4-\mathrm{HOC}_{6} \mathrm{H}_{4} \mathrm{OH}\right)$, which is similar to the order obtained established for methyl phenols and methyl anisoles (van Beelen et al., 2004).

Examination of Figure 8 indicates that, like for phenol and methyl phenols, the most stable protonated form for catechol and resorcinol corresponds to protonation at the position para with respect to the hydroxyl group $\mathrm{O} 1 \mathrm{H} 1$. Protonation in para is associated with a shortening of the $\mathrm{C}-\mathrm{O} 1$ bond, which indicates conjugation of an electron pair of $\mathrm{O} 1$ with the phenyl ring, and in the particular case of resorcinol, also induces the reinforcement of the intramolecular hydrogen bond established between the two hydroxyls groups. The C-O1 bond shortening also results in an increase of the rotational barrier of the hydroxyl group. Concerning hydroquinone, the para-position is no longer the best protonation site. According to calculations, protonation indeed occurs preferentially onto the ortho position. Note also that protonation at the ipso position is significantly easier for hydroquinone than for its two ortho and meta counterparts. This is attributed to the stabilizing effect of the second hydroxyl group on the positive charge. Unlike methylphenols, for which an increase in the proton affinity is observed regardless of the location of the methyl group, a significant increase of the basicity is observed only when the second hydroxyl group is located onto the meta position. Resorcinol is indeed the most basic isomer because of the participation of both oxygen atoms in stabilizing the protonated form by donating electrons to the $\pi$-electron system. Protonation also induces a freezing of the two internal rotations and thus leads to a significant decrease in entropy. 
The knowledge of thermochemical data such as gas-phase basicities of the matrix molecules used in MALDI (matrix assisted laser desorption ionization) might be helpful in understanding the proton transfer processes occurring in the ionization process, and why some matrices lead to more post-source as well as insource decay. Consequently, several reports during the last decade were devoted to the study of acido/basic properties of MALDI matrices. Among the compounds studied, many of them may be viewed as phenol derivatives, the proton affinity of which being gathered in Table 10. The 2,5-dihydroxybenzoic (2,5-DHB), is the most studied matrix for now. Interestingly, the four methods commonly employed to measure relative gas-phase basicities have been used, and lead to a consistent set of data. Furthermore, the experimental values are in good agreement with two theoretical estimates. According to a recent theoretical study (Bourcier \& Hoppilliard, 2002), the carbonyl group was found to be the most basic site and the protonating hydrogen is stabilized by the oxygen of the ortho hydroxyl group. Mormann et al. employed the thermokinetic method in order to determine the thermochemical acid/base properties of the various isomers of DHB (Mormann et al., 2000). The gas-phase basicities vary from $814 \mathrm{~kJ} \mathrm{~mol}^{-1}$ for the least basic isomer, 3,5-DHB, to $831 \mathrm{~kJ} \mathrm{~mol}^{-1}$ for the most basic isomer, 2,4-DHB. The presence of ortho hydroxy substituent(s) clearly increases the basicity, through electronic stabilization and formation of a hydrogen bond with the protonated carbonyl. The effect of the hydrogen bond seems more pronounced since 2,3- and 2,5-DHB are still more basic than 3,4- and 3,5-DHB. One can also observe that, for all isomers but 3,5-DHB, the agreement with the theoretical estimates is satisfactory. The 3,5DHB is the only isomer for which an intramolecular hydrogen bond cannot be established, resulting to the destabilization of the protonated structures and a subsequent lowering of the proton affinity. Examination of Table 10 indicates that for two matrices, namely 4-HCCA and ferrulic acid, there is a strong discrepancy between the various experimental values. Some of the data must be taken with caution. Bojesen and co-workers (Jorgensen et al., 1998) used the kinetic method at a single collision energy and did not consider any entropy change. Furthermore, they mentioned that the absolute proton affinities deduced from their measurement should be used with caution, because of a lack (for some matrices) of references bases, and an important scattering of the experimental points. It is also worth mentioning that the bracketing technique can be complicated by high internal and kinetic energies in the reactive ion, leading to an underestimate of the GB. Consequently, the proton affinity of both 4-HCCA and ferrulic acid, need to be severely revised.

\section{B. Saturated cyclic and acyclic polyols}

The following section aims at summarizing the gas-phase basicity data of saturated acyclic and cyclic polyols. The molecules considered span from hydrogen peroxide up to $D$-glucose.

\section{a. Hydrogen peroxide and derivatives.}

Hydrogen peroxide may be considered as the simplest diol. The only measurement tabulated in the Hunter \& Lias compilation (Hunter \& Lias, 1998) $(\mathrm{GB}=643.8 \mathrm{~kJ} / \mathrm{mol})$ was obtained in a combined flowing afterglow/drift tube device by the bracketing method (Lindinger et al., 1975). Authors studied ion/molecule reactions occurring between hydrogen peroxide, and a series of small molecules. It was observed that the radical cation $\mathrm{H}_{2} \mathrm{O}_{2}^{++}$, generated by charge transfer between ionized oxygen and $\mathrm{H}_{2} \mathrm{O}_{2}$, reacts by self-protonation to form 
the protonated form of hydrogen peroxide $\mathrm{H}_{3} \mathrm{O}_{2}{ }^{+}$and the $\mathrm{HOO}$ radical. This reaction is fast, establishing that the GB of $\mathrm{H}_{2} \mathrm{O}_{2}$ exceeds that of $\mathrm{HOO}(\mathrm{GB}=628 \mathrm{~kJ} / \mathrm{mol})$. In turn, $\mathrm{H}_{3} \mathrm{O}_{2}{ }^{+}$was found to react by proton transfer reaction with water. The reaction efficiency is high and therefore indicates that the gas-phase basicity of hydrogen peroxide is less than that of water $(660 \mathrm{~kJ} / \mathrm{mol})$. This leads to a bracketed gas-phase basicity of $644 \pm 16$ $\mathrm{kJ} / \mathrm{mol}$.

More recently, the positive ion chemistry of peroxynitric acid $\mathrm{HOONO}_{2}$, an important component of the earth's atmosphere has been studied by combining mass spectrometry experiments and theoretical calculations (Aschi et al., 2000). The MS/MS spectrum of the $\left[\mathrm{H}_{2}, \mathrm{O}_{4}, \mathrm{~N}\right]^{+}$ion $(\mathrm{m} / \mathrm{z} 80)$ formed by proton transfer reaction with $\mathrm{H}_{3} \mathrm{O}^{+}$shows the formation of fragment ions at $m / z 46\left(\mathrm{NO}_{2}{ }^{+}\right)$and $\mathrm{m} / z 34\left(\mathrm{H}_{2} \mathrm{O}_{2}{ }^{+}\right)$, and is strictly similar to the MS/MS spectrum of the $m / z 80$ ion generated by nitration of hydrogen peroxide. This strongly suggests that protonation of peroxynitric acid gives rise to the ion/neutral complex B (Figure 9). This finding is supported by the theoretical study, which indicates that the ion neutral complex, which corresponds to the protonation on the site $\mathbf{b}$, is the most stable form (Figure 9).

Figure 9.

Several problems were encountered during the experimental measurement of the proton affinity of peroxynitric acid. Due to the instability of this compound, the equilibrium method could not be applied. Use of the bracketing method was also hampered by the presence of a side reaction $\left(\mathrm{NO}_{2}{ }^{+}\right.$transfer) to many of the reference bases of appropriate PA. In order to get the PA of this compound, authors employed the kinetic method to evaluate the enthalpy of the following reaction, and subsequently the heat of formation of the ion/neutral complex B $(749 \pm 13 \mathrm{~kJ} / \mathrm{mol})$.

$\mathrm{HOOH}-\mathrm{NO}_{2}^{+} \rightarrow \mathrm{H}_{2} \mathrm{O}_{2}+\mathrm{NO}_{2}^{+}$

Combining the latter value with the known heats of formation of $\mathrm{H}^{+}$and $\mathrm{H}_{2} \mathrm{O}_{2}$ lead to a proton affinity of $736 \pm 16 \mathrm{~kJ} / \mathrm{mol}$. This value is in excellent agreement with the theoretical estimate obtained at the $\mathrm{G} 2$ level of theory $(732 \mathrm{~kJ} / \mathrm{mol})$.

\section{b. Acyclic $\alpha$, $\omega$-diols}

The studies carried out on diamines (vide supra) have shown that a molecule containing two identical functional groups may have a greater proton affinity than that of monofunctional compounds because of internal hydrogen bond formation which can accompany protonation if the molecular geometry is favourable. In this context, the gas-phase chemistry of $\alpha, \omega$-diols has also been studied.

Figure 10.

According to both theoretical (Bouchoux et al., 1993; Bouchoux et al., 1997; Bouchoux \& BerruyerPenaud, 2003; da Silva, 2005) and microwave spectroscopy (Vázquez et al., 1992) studies, the most stable conformation of 1,2-ethanediol, $\mathbf{1}$, presents a dihedral angle OCCO close to 60.0 , allowing the formation of an 
intramolecular hydrogen bond. In fact, the presence of a true hydrogen bond is still a matter of debate. Although the two hydroxyl groups in 1,2-diols are interacting, as evidenced by NMR and IR spectroscopic shifts (Crittenden et al., 2005), a topological analysis of the electron density has shown that neither a bond critical point nor an atomic bond path were detected (Klein, 2002; Klein, 2003), indicating that no intramolecular hydrogen bond is formed. Instead, the interaction seen in 1,2-diols might be a mixture of weak polarization and electrostatic effects. By contrast, intramolecular hydrogen bonds have been characterized for the other diols $(n=3-6)$ (Klein, 2002). Protonation is accompanied by a decrease of the OCCO dihedral angle (Figure 10), which results in a strong intramolecular hydrogen bond, as confirmed by the significant decrease of the $\mathrm{O}_{1}{ }^{\cdots} \mathrm{H}_{2}$ distance. Its strength is however limited by steric and electrostatic constraints, as attested by a non linear $\mathrm{O}-\mathrm{H} \cdots \mathrm{O}$ arrangement. According to a FAB study, protonation of ethylene glycol gives rise to an ion of the type $\mathrm{HO}\left(\mathrm{CH}_{2}\right)_{2} \mathrm{OH}_{2}{ }^{+}$(Van Driel et al., 1985).

The most stable conformation of 1,3-propanediol, 2, is a pseudo-chair structure (Figure 10) in which an intramolecular hydrogen bond is clearly established, as confirmed by the presence of a bond critical point (Klein, 2002). The protonated form $\mathbf{2 H}^{+}$is characterized by the existence of a significant intramolecular hydrogen bond. Determination of the rotational barrier associated with the C-C-O2-H rotation can provide a qualitative estimate of the hydrogen bond strength (Bouchoux \& Berruyer-Penaud, 2003). This rotational barrier was found to increase on going from ethylene glycol up to butanediol. This finding suggests that the intramolecular hydrogen bond is strengthened as the alkyl chain is lengthened. This result is consistent with the fact that protonated 1,4butanediol exhibits a cyclic structure with an almost linear $\mathrm{O} 1 \cdots \mathrm{H} \cdots \mathrm{O} 2$ bond.

During the last years, the acid/base properties of 1,2-ethanediol (1), 1,3-propanediol (2), and 1,4butanediol (3), were studied experimentally, and these results are summarized in Table 11. The values reported in the Hunter and Lias compilation are those obtained by Chen and Stone (Chen \& Stone, 1995), who used highpressure mass spectrometry in order to measure equilibrium constants at various temperatures. This approach allowed not only the GB but also the corresponding proton affinity, and the protonation entropy, $\Delta_{\mathrm{p}} \mathrm{S}^{\circ}$ of $\alpha, \omega$ diols to be determined. From Table 11, we can see, that like diamines, a clear enhancement of the gas-phase basicities of these molecules, with respect to primary alcohols of comparable polarizability, is observed. This finding is indicative of the formation of a strong internal hydrogen bond in the protonated forms of the diols. This effect stabilizes the protonated form and increases their proton affinity. Establishment of internal hydrogen bonding is further confirmed by the observation of an entropy loss upon protonation. Note also that the entropy change accompanying proton transfer to $\alpha, \omega$-alkanediols increase with increasing ring size.

As introduced by Mautner (Meot-Ner et al., 1980; Meot-Ner, 2005), the strength of the hydrogen bond in each diol $\mathrm{HO}\left(\mathrm{CH}_{2}\right)_{\mathrm{n}} \mathrm{OH}$ can be qualitatively estimated by the difference between the PA of the diol and the PA of a monofunctional alcohol of comparable polarizability, such as $\mathrm{CH}_{3}\left(\mathrm{CH}_{2}\right)_{\mathrm{n}} \mathrm{OH}\left(\Delta \mathrm{H}_{\mathrm{M}-\mathrm{B}}=\mathrm{PA}(\mathrm{M})-\mathrm{PA}(\mathrm{B})\right.$, paragraph I.C). By combining the data reported in Tables 9 and 11, one can deduce enthalpy differences $\Delta \mathrm{H}_{\mathrm{M}-\mathrm{B}}$ equal to $31.5,88.2$ and $122 \mathrm{~kJ} / \mathrm{mol}$ for 1,2-ethanediol, 1,3-propanediol and 1,4-butanediol, respectively. Thus, the strength of the hydrogen bond increases when the distance between the two basic sites increases. On the other hand, the formation of the hydrogen bond induces strain in the $\sigma$-bond frame. A comparison of $\Delta \mathrm{H}_{\mathrm{M}-\mathrm{B}}$ and the ionic hydrogen bond energy $\mathrm{D}\left(\mathrm{ROH}_{2}{ }^{+} \ldots \mathrm{O}(\mathrm{H}) \mathrm{R}\right)$ of the symmetric proton bond dimer of alcohols, $(\mathrm{ROH})_{2} \mathrm{H}^{+}$ (129.7 $\pm 8.4 \mathrm{~kJ} / \mathrm{mol}$, (Larson \& McMahon, 1982)) provides an estimate on the strain energies associated with the cyclisation by internal hydrogen bonding. The difference $\Delta \mathrm{H}_{\text {strain }}=129.7-\Delta \mathrm{H}_{\mathrm{M}-\mathrm{B}}$ decreases with increasing the 
ring size, as expected. The value obtained for 1,4-butanediol is close to 0 and therefore suggests that the strain energy should be very weak. Calculations support this assumption since the hydrogen bond appears almost linear (Figure 10). On the other hand, the strain energy for ethylene glycol is very large (near $100 \mathrm{~kJ} / \mathrm{mol}$ ), suggesting a very constrained ring and a rather sharp $\mathrm{OHO}$ angle. This is nicely confirmed by the various theoretical studies, the hydrogen atom being closer from $\mathrm{O} 1$ than from $\mathrm{O} 2$. The situation of the 1,3-diol appears intermediate both experimentally and theoretically. In summary, the internal hydrogen bond strengths and their contribution to the PAs and GBs increase with ring size as the strain decreases and the hydrogen bond approaches optimized geometry.

The gas-phase basicities of these three diols have also been studied by experimental methods. In order to determine the gas-phase basicity of 1,2-ethanediol, Bouchoux et al. used FTMS and the bracketing technique (Bouchoux et al., 1993). For this purpose, $[\mathrm{BH}]^{+}$ions of a series of reference bases $\mathrm{B}$ generated in an external ion source were allowed to react with ethylene glycol. A GB of $777 \mathrm{~kJ} / \mathrm{mol}$ could be deduced from the occurrence or non-occurrence of the proton transfer reaction, a value in good agreement with the equilibrium determination. Authors also estimated the variation of the proton affinity of ethylene glycol as a function of the OCCO dihedral, by defining a parameter $\triangle \mathrm{PA}(\theta)$ corresponding to the difference between the PA calculated at a given angle $\theta$, and the proton affinity of ethylene glycol in its relaxed geometry. An important decrease $(55 \mathrm{~kJ} / \mathrm{mol})$ was observed when 0 increases from 0 to $180^{\circ}$.

An assessment of the kinetic method and its applicability to the determination of the basicity of bidentate molecules has been done by Bouchoux and co-workers in a series of papers. (Bouchoux et al., 2003b; Bouchoux et al., 2003a; Bouchoux, 2006). The results obtained for the three $\alpha, \omega$-alkanediols are reported in the Table 11. From these studies, It could be concluded that the simple treatment using the intercept of the $\ln \left([\mathrm{MH}]^{+} /\left[\mathrm{B}_{\mathrm{i}} \mathrm{H}\right]^{+}\right)$versus $\mathrm{PA}\left(\mathrm{B}_{\mathrm{i}}\right)$ (or $\mathrm{GB}\left(\mathrm{B}_{\mathrm{i}}\right)$ ) plot with the $\mathrm{x}$-axis leads to erroneous results. In the case of polyfunctional molecules, only the use of the "extended kinetic method" or "isothermal point" analysis, which requires performing several experiments at different collision energies, can lead to correct results. From Table 11 , one can see that there is an overall good agreement between the gas-phase basicities determined by the extended kinetic method and those deduced from equilibrium measurements. On the other hand, data indicate that proton affinities and protonation entropies differ markedly. It is generally observed that the measured "apparent" protonation entropies of all the bifunctional molecules examined are significantly less than that obtained by equilibrium methods.

Table 11 Protonation thermochemistry of $\alpha, \omega$-diols and triols

\begin{tabular}{|c|c|c|c|c|}
\hline $\mathrm{M}$ & Method & $\mathrm{GB}(\mathrm{M})^{\mathrm{a}}$ & $\mathrm{PA}(\mathrm{M})^{\mathrm{a}}$ & $\Delta_{\mathrm{p}} \mathrm{S}^{\circ}(\mathrm{M})^{\mathrm{b}}$ \\
\hline \multirow[t]{6}{*}{ 1,2-ethanediol } & equilibrium & $774.3 \pm 3.1^{\mathrm{c}}$ & $817.0 \pm 3.1^{\mathrm{c}}$ & $-35 \pm 1^{c}$ \\
\hline & bracketing & $777^{d}$ & & \\
\hline & extended kinetic & $769.0^{\mathrm{e}}$ & $800.2^{\mathrm{e}}$ & $4^{e}$ \\
\hline & & $769.8^{f}$ & $800.7^{\mathrm{f}}$ & $5^{\mathrm{f}}$ \\
\hline & theoretical & $760.2^{\mathrm{g}}$ & $795.2^{g}$ & $-8^{g}$ \\
\hline & & $773.6^{\mathrm{h}}$ & $815.9^{\mathrm{h}}$ & \\
\hline \multirow[t]{4}{*}{ 1,3-propanediol } & equilibrium & $826.6 \pm 1.7^{c}$ & $877.4 \pm 2.9^{c}$ & $-62 \pm 4^{c}$ \\
\hline & & $819.0 \pm 3.5^{\mathrm{i}}$ & & \\
\hline & extended kinetic & $823.4^{\mathrm{j}}$ & $857.6^{\mathrm{j}}$ & $-6^{\mathrm{j}}$ \\
\hline & & $820.2^{\mathrm{e}}$ & $853.2^{\mathrm{e}}$ & $-2^{\mathrm{e}}$ \\
\hline
\end{tabular}




\begin{tabular}{|c|c|c|c|c|}
\hline & thermokinetic & $826.6 \pm 2.5^{\mathrm{i}}$ & $877.5 \pm 3.6^{\mathrm{i}}$ & $-22^{i}$ \\
\hline & theoretical & $811.8^{\mathrm{g}}$ & $850.3^{\mathrm{g}}$ & $-20^{\mathrm{g}}$ \\
\hline \multirow[t]{4}{*}{ 1,4-butanediol } & equilibrium & $855.7 \pm 4.5^{c}$ & $917.0 \pm 6.3^{c}$ & $-97 \pm 6^{c}$ \\
\hline & extended kinetic & $846.5^{\mathrm{j}}$ & $884.3^{\mathrm{j}}$ & $-18^{\mathrm{j}}$ \\
\hline & & $848.5^{\mathrm{e}}$ & $883.0^{\mathrm{e}}$ & $-7^{e}$ \\
\hline & theoretical & $839.5^{\mathrm{g}}$ & $881.5^{\mathrm{g}}$ & $-32^{g}$ \\
\hline \multirow[t]{6}{*}{ glycerol } & equilibrium & $820.0^{\mathrm{k}}$ & $874.8^{\mathrm{k}}$ & $-75^{\mathrm{k}}$ \\
\hline & extended kinetic & $811.7^{\mathrm{j}}$ & $848.6^{j}$ & $-15^{\mathrm{j}}$ \\
\hline & & $812.4^{\mathrm{e}}$ & $844.2^{\mathrm{e}}$ & $2^{\mathrm{e}}$ \\
\hline & theoretical & & $847.0^{1}$ & \\
\hline & & & (818) $824^{\mathrm{m}}$ & \\
\hline & & $813.7^{\mathrm{n}}$ & $842.4^{\mathrm{n}}$ & \\
\hline 1,2,4-butanetriol & equilibrium & $841.0^{\mathrm{k}}$ & $903.7^{\mathrm{k}}$ & $-109^{k}$ \\
\hline \multicolumn{5}{|c|}{$\begin{array}{l}\text { a) kJ.mol }{ }^{-1} \text {; b) J.K } \mathrm{K}^{-1} . \mathrm{mol}^{-1} \text {; c) (Chen \& Stone, 1995); d) (Bouchoux et al., 1993); e) (Bouchoux et al., 2003b); f) (Bouchoux, 2006); g) G2MP2 } \\
\text { calculations, (Bouchoux \& Berruyer-Penaud, 2003); h) MP2/Aug-cc-pVTZ//B3LYP/6-311++G(d,p) calculations, (da Silva, 2005); i) } \\
\text { (Bouchoux \& Buisson, 2006); j) (Bouchoux et al., 2003a); k) (Sunner et al., 1986); 1) B3LYP/6-311+G(2d,2p) calculations, (Bourcier \& } \\
\text { Hoppilliard, 2002); m) CBS-QB3 calculations, (Nimlos et al., 2006); n) G3B3, this work. }\end{array}$} \\
\hline
\end{tabular}

The gas-phase basicity of 1,3-propanediol has been recently re-examined by Fourier transform ion cyclotron resonance mass spectrometry (Bouchoux \& Buisson, 2006). Both the equilibrium and the thermokinetic methods were used and the results were compared with previous experimental and theoretical determinations. Note that it was not possible during this study to achieve a correct equilibrium due to an important water loss from protonated diols. Instead, the equilibrium constant has been estimated by measurement of experimental forward and reverse rate constants for reaction (i) and leads to a gas-phase basicity of $819.0 \pm 3.5$ $\mathrm{kJ} / \mathrm{mol}$ and is close to the data obtained by the extended kinetic method. However, this value is slightly different from the previous equilibrium measurement. This could be partly imparted to encountered difficulties with the handling of the diols under protonation conditions (low vapour pressure and dissociation of the protonated forms by dehydration). Chen and Stone also reported that dehydration could sometime prevent the equilibrium from being achieved. The dehydration process of ethylene glycol has been studied theoretically for both neutral and protonated ethylene glycol (Nimlos et al., 2003). For neat alcohol, the barrier to 1,2-dehydration is about 291 $\mathrm{kJ} / \mathrm{mol}$ at the CBS-QB3 level of theory. Protonation lowers the activation barrier by $176 \mathrm{~kJ} / \mathrm{mol}$, thus facilitating dehydration of protonated diols. This therefore explains the experimental difficulties encountered for determination of the GB of diols by equilibrium measurements. Interestingly, the thermokinetic method leads to a gas-phase basicity for 1,3-propanediol of $826.6 \pm 2.5 \mathrm{~kJ} / \mathrm{mol}$, in excellent agreement with the data of Chen and Stone. On the other hand, the proton affinity is particularly sensitive to the value of the protonation entropy $\Delta_{\mathrm{p}} \mathrm{S}^{\circ}{ }_{298}$. Using either a computed value of $-22 \mathrm{~J}^{-\mathrm{K}^{-1}} \cdot \mathrm{mol}^{-1}$ ) (Bouchoux \& Buisson, 2006) or the experimental value obtained by Chen and Stone $\left(-62 \mathrm{~J}^{-1} \mathrm{~K}^{-1} \cdot \mathrm{mol}^{-1}\right.$ (Chen \& Stone, 1995)), results in a proton affinity of $857.9 \pm 3.5 \mathrm{~kJ} / \mathrm{mol}$ and $877.5 \pm 3.6 \mathrm{~kJ} / \mathrm{mol}$, respectively. The proton affinities of 1,2-ethanediol (1), 1,3-propanediol (2), and 1,4-butanediol (3) were also calculated by ab initio molecular orbital calculations at the G2(MP2) level (Bouchoux \& Berruyer-Penaud, 2003). It first appears that G2(MP2) calculation correctly reproduces the increase in proton affinity experimentally observed from 1,2- to 1,4 diols (Table 11). Second, the entropy loss expected to be associated with protonation is confirmed by the calculation. Moreover, the increasing absolute value of $\Delta_{\mathrm{p}} \mathrm{S}^{\circ}(\mathrm{M})$, expected when the size of the diol increases, is reproduced. However, the computed absolute PAs are systematically lower than those deduced from equilibrium constant determinations. Finally, the relative 
gas-phase basicity of 1,2-ethanediol with respect to ammonia has been recently determined at various levels of calculations (da Silva, 2005). Combined with the tabulated values by Hunter \& Lias for ammonia, this gives a GB of $773.6 \mathrm{~kJ} / \mathrm{mol}$ and a proton affinity of $815.9 \mathrm{~kJ} / \mathrm{mol}$ at the MP2/Aug-cc-pVTZ//B3LYP/6-311++G(d,p) level. Although using the same geometry, the relative values tend to vary significantly with the level of calculations.

\section{c. Acyclic triols.}

To the best of our knowledge, the protonation thermochemistry of triols has been determined only for two compounds, namely glycerol and 1,2,4-butanetriol (Table 11). According to a recent theoretical study (Callam et al., 2001), among the 126 different possible conformations for neutral glycerol, the lowest energy form has a $\gamma \gamma$ orientation which enjoy three cooperative hydrogen bonds, as presented below (Figure 11). This theoretical result is in agreement with a microwave study, which showed that the structures bearing the $\gamma \gamma$ backbone is present in a mixture with the $\alpha \gamma$ forms. Note that these two conformations are practically degenerated at the $\operatorname{CCSD}(\mathrm{T}) / 6-31+\mathrm{G}(\mathrm{d}, \mathrm{p}) / / \mathrm{HF} / 6-31 \mathrm{G}(\mathrm{d})$ level of calculation.

Figure 11.

Protonation of glycerol can occur at either of the hydroxyl groups. Nimlos and co-workers found during a study carried out at the CBS-QB3 level (Nimlos et al., 2006), that primary and secondary hydroxyl groups exhibit a similar basicity, and estimated their proton affinity to be $\sim 824 \mathrm{~kJ} / \mathrm{mol}$ (in fact, the authors give $0 \mathrm{~K}$ proton affinities values of $\sim 818 \mathrm{~kJ} / \mathrm{mol}$ which may be roughly corrected to $824 \mathrm{~kJ} / \mathrm{mol}$ by assuming that the $298 \mathrm{~K}$ vibrational contribution to vibrational energies of neutral and protonated forms cancels). Another estimate of the proton affinity of glycerol has been done by Bourcier and Hoppilliard (Bourcier \& Hoppilliard, 2002) at the $\mathrm{B} 3 \mathrm{LYP} / 6-311+\mathrm{G}(2 \mathrm{~d}, 2 \mathrm{p}) / / \mathrm{B} 3 \mathrm{LYP} / 6-31+\mathrm{G}(\mathrm{d}, \mathrm{p})$ level including $298 \mathrm{~K}$ correction. The authors obtained a significantly higher proton affinity value of $847 \mathrm{~kJ} / \mathrm{mol}$. Such a large difference in theoretical proton affinity estimates is not usual, thus we re-examine here this question at the G3B3 level of theory. It turns out that the most stable neutral form of glycerol is indeed that presented in Figure 11 (and not the linear structure given by Bourcier and Hoppilliard) but that the most stable protonated form is that located by Bourcier and Hoppilliard (Bourcier \& Hoppilliard, 2002), not that retained by Nimlos and co-workers (Nimlos et al., 2006). The G3B3 proton affinity and gas-phase basicity of glycerol calculated in the present work are equal to 842.4 and 813.7 $\mathrm{kJ} / \mathrm{mol}$, respectively.

Surprisingly, the experimental PA value obtained by equilibrium measurements using pulsed high ion source pressure mass spectrometry at variable temperature (Sunner et al., 1986) is as high as $875 \mathrm{~kJ} / \mathrm{mol}$ i.e. 33 $\mathrm{kJ} / \mathrm{mol}$ above the theoretical estimates. More recently the extended kinetic method has also been applied to measure the gas-phase basicity of glycerol (Bouchoux et al., 2003b; Bouchoux et al., 2003a). The resulting proton affinity, $\sim 846 \mathrm{~kJ} / \mathrm{mol}$, is in excellent agreement with the G3B3 theoretical expectations. It may be underlined that the two types of experiment show very different entropy changes upon protonation (Table 11). As noted earlier (Bouchoux, 2006), on such circumstances, it is preferable to compare the gas-phase basicities 
values. Accordingly, the $\mathrm{GB}$ (glycerol) values are equal to 820 and $812 \mathrm{~kJ} / \mathrm{mol}$ when obtained from the equilibrium method or from the extended kinetic method, respectively. Since the latter GB value is closer to the theoretical estimate, the large discrepancies observed are probably due to difficulties during equilibrium experiments.

\section{d. Cyclic diols and polyols}

The thermochemistry of cycloalkanediols has been much less described. Several studies were devoted to their behaviour under methane, isobutane or ammonia chemical ionization. The main result is that stereochemical effects may lead to differentiation of cis and trans diastereoisomers. These observations were interpreted by assuming a higher proton affinity of the cis diols because of stabilization of $\mathrm{MH}^{+}$by proton chelation between the cis-oriented hydroxyl groups. By contrast, the trans-isomers are incapable of intramolecular hydrogen bonding and hence easily fragment by water elimination.

Following this idea, collisionally activated decompositions and ion-molecule reactions were used to distinguish between cis- and trans-1,2-cyclopentane diol isomers (Meyerhoffer \& Bursey, 1989). Moreover, proton affinity of both isomers could be roughly estimated from observation of ion/molecule reactions between protonated diols and ammonia. An exothermic proton transfer occurred for the trans isomer, suggesting that its PA is less than that of ammonia $(854 \mathrm{~kJ} / \mathrm{mol})$. On the other hand, the proton transfer reaction is endothermic for the cis isomer, indicating that $c i s-1,2$-cyclopentanediol is more basic than ammonia. Bouchoux et al investigated by calculation the structure of cis- and trans-1,2cyclopentanediol and their respective protonated form (Bouchoux et al., 1993). In the four structures, the cyclopentane ring is found to invariably adopt a distorted envelope conformation. The calculations predicted a difference in proton affinities between the cis- and the trans- isomers is of $30 \mathrm{~kJ} / \mathrm{mol}$ in favor of the former. Through the use of isodesmic reactions, the authors estimated the proton affinity of the cis and trans-cylopentanediol to be $845 \mathrm{~kJ} / \mathrm{mol}$ and $815 \mathrm{~kJ} / \mathrm{mol}$, respectively.

In the late seventies, the protonation of cyclohexanediols has also been investigated by chemical ionization (Winkler \& Stahl, 1979), thus providing a qualitative estimate of the gas-phase basicity of 1,2,1,3 and 1,4-cyclohexanediols. Isobutane chemical ionization experiments have shown that cyclohexane diols were more basic than isobutene, and again suggests a larger PA for the cis diols with respect to the trans- isomers. A stabilization process through the formation of an intramolecular hydrogen bond, as already postulated for deprotonated cyclohexanediols (Chen et al., 2004), might account for the stabilisation of the protonated form of the cis- isomers, and consequently to their greater intrinsic basicity. Use of ammonia as reagent gas again indicated that the PA of ammonia would lie between that of the cis and trans isomers for 1,3- and 1,4cyclohexane diols. Finally, both isomers of 1,2-cyclohexanediol would be less basic than ammonia since the $\mathrm{MNH}_{4}{ }^{+}$adduct is dominant regardless of the isomer considered.

Accurate determinations of the gas phase basicities of saccharides are particularly scarce. However, several reports tried to address this question. Tondeur recorded the positive FAB mass spectra of galactose, mannose, talose and glucose, by using two different matrices, namely glycerol and diethanolamine (DEA) (Tondeur, 1985). Whatever the matrix, the protonated forms of the hexoses were not detected. Instead, strong and stable adducts $[\text { sugar }+ \text { glycerol }+\mathrm{H}]^{+}$and $[\text {sugar }+\mathrm{DEA}+\mathrm{H}]^{+}$were detected. The $\mathrm{CAD} / \mathrm{MIKE}$ mass spectra of these adducts have been recorded. When DEA is used, the CAD/MIKE spectra show no sugar fragment ions. 
Instead, the entire neutral monosaccharide is lost, resulting in protonated DEA. In the context of the kinetic method, this finding clearly indicates that the proton affinity of DEA is greater than that of the monosaccharides. On the other hand, the CAD/MIKE spectra of the [sugar+glycerol $+\mathrm{H}]^{+}$exhibit both $[\text {glycerol }+\mathrm{H}]^{+}$and $[\text { monosaccharide }+\mathrm{H}]^{+}$ions. These two fragment ions have a similar abundance, indicating that the PA of hexoses should be similar (in fact slightly greater according to a note of the authors) to that of glycerol $(874.8 \mathrm{~kJ} / \mathrm{mol})$. However accurate determination of the proton affinities was rigorously not possible, because of numerous competitive fragmentation processes.

Given the fact that the formation of intramolecular hydrogen bonds greatly enhances the basicity of polyols, $D$-glucose, in its cyclic form, should be the least basic hexoses because all adjacent hydroxyl groups are in trans configuration. GB of both anomers of $D$-glucose have been evaluated by means of the bracketing technique (Jebber et al., 1996). The gas-phase basicities were measured separately for each glucose anomer. However, mutarotation could have occurred to some extent when each pure anomer was dissolved in glycerol. No significant difference was seen in the rates of deprotonation of these two species. For both anomers, very little reaction was observed with 2-methylpropene but a very effective proton transfer occurred with acetone. Using the tabulated values (Hunter \& Lias, 1998) for these two references leads to a GB of $778.8 \mathrm{~kJ} / \mathrm{mol}$ for the two anomers. An uncertainty of $12 \mathrm{~kJ} / \mathrm{mol}$ was considered in order to take into account the experimental problems encountered during the measurements. This GB value is similar to that of ethylene glycol. This suggests that the additional hydroxyl groups do not have a positive effect onto the intrinsic basicity of $D$-glucose. This seems not so surprising given the trans orientation of the adjacent hydroxyl groups. The experimental values were also compared to $a b$ initio estimate. To this purpose, authors first determined the most stable neutral form for $D$-glucose, by assuming a ${ }^{4} \mathrm{C}_{1}$ ring conformation. GBs were then estimated by assuming that the protonated form retained the reactant conformation, and notably the hydrogen bond network established between the hydroxyl groups.

Figure 12.

Starting from the most populated neutral form at $298 \mathrm{~K}$ as established by calculations, and considering that protonation occurred onto the pyranosic oxygen (Figure 12), a gas phase basicity of $786.6 \mathrm{~kJ} / \mathrm{mol}$ was obtained at the MP4/6-31+G(2d,2p)//MP2(full)/6-31+G(d,p) level of theory, slightly above the experimental values. Finally, another report mentioned the $\mathrm{CI} / \mathrm{NH}_{3}$ spectrum of $D$-ribose (Hunt \& Sethi Satinder, 1978) and concluded based upon a prominent $\left[\mathrm{M}+\mathrm{NH}_{4}\right]^{+}$adduct that that $D$-ribose is less basic than ammonia.

\section{Ethers and hydroxy-ethers}

\section{a. Peroxydes and methoxy oxides}

The gas-phase chemistry of organic peroxides has been the focus of active interest owing to the growing recognition of their role in atmospheric chemistry. Several reports were devoted to the study of the gas-phase reactivity of protonated peroxides. Schalley and co-workers (Schalley et al., 1997) described in detail the unimolecular fragmentations of protonated methyl hydroperoxide and dimethyl peroxide in a combined 
experimental and theoretical study. Protonation of the analytes was achieved by $\mathrm{H}_{2}$ chemical ionization. The MIKE spectra of the $\left[\mathrm{C}, \mathrm{H}_{5}, \mathrm{O}_{2}\right]^{+}$cation generated by protonation of methyl hydroperoxide is dominated by the formation of protonated formaldehyde and protonated water, which strongly suggest that a proton bound dimer between formaldehyde and water is generated as an intermediate. High energy CAD spectra were also recorded. Among the fragment ions observed, a loss of $\mathrm{OH}$. yielding the radical cation $\mathrm{CH}_{3} \mathrm{OH}^{+}$. is observed. This fragment ion indicated that the preferred protonation site is the oxygen near the methyl group. The two protonated forms have been studied theoretically and B3LYP/6-311++G(d,p) calculations show that the hydroxyl oxygen is slightly less basic than the other by $8 \mathrm{~kJ} / \mathrm{mol}$, leading to computed proton affinities of 719.2 $\mathrm{kJ} / \mathrm{mol}$ and $711.3 \mathrm{~kJ} / \mathrm{mol}$. Thus, $\mathrm{CH}_{3} \mathrm{OOH}$ appears more basic than hydrogen peroxide and water, but is somewhat less basic than methanol. Similar experiments were carried out by Aschi et al (Aschi et al., 1998). Both MIKE and CAD experiments experiment failed in determining the best protonation site of methyl hydroperoxide, but interestingly, the fragment ions observed, when the protonated methyl hydroperoxide is generated by water chemical ionization, did not point to an extensive formation of the formaldehyde/water proton bond dimer. Authors also determined experimentally the proton affinity of methyl hydroperoxide. However, use of the equilibrium method was prevented by the decomposition of protonated methyl hydroperoxide. Instead, Aschi et al. opted for the bracketing technique. These experiments led to an estimated proton affinity of $728 \pm 8 \mathrm{~kJ} / \mathrm{mol}$. They also used the kinetic method and methyl hydroperoxide was found more basic than formaldehyde and less basic than trifluoroacetic acid. Authors deduced a proton affinity of 722.2 \pm 8.4 $\mathrm{kJ} / \mathrm{mol}$. Their values are in reasonable agreement with the B3LYP calculation of Schalley et al. G2 calculations were also performed during that study. The theoretically estimated $\mathrm{PA}(\mathrm{CH} 3 \mathrm{OOH})$ relative to the formation of the most stable protomer is $722.2 \mathrm{~kJ} / \mathrm{mol}$ in good agreement with the experimental value. The PA of the terminal oxygen is $703.3 \mathrm{~kJ} / \mathrm{mol}$ (Figure 13). The energy difference slightly increases at the $\mathrm{G} 2$ level $(+19 \mathrm{~kJ} / \mathrm{mol})$ and a large barrier $(155 \mathrm{~kJ} / \mathrm{mol})$ was estimated for the interconversion of the two protonated forms.

Figure 13.

The proton affinity of ethyl hydroperoxide has not been experimentally determined, but its protonation sites have been studied theoretically. HF/3-21G calculations have shown that protonation of the internal oxygen is favored by $15 \mathrm{~kJ} / \mathrm{mol}$. (Van Driel et al., 1985) Our G3 calculations lead to a value of $27 \mathrm{~kJ} / \mathrm{mol}$ and a proton affinity of $749 \mathrm{~kJ} / \mathrm{mol}$, and underline the greater stabilization effect of the ethyl group compared to the methyl group. According to calculations (Van Driel et al., 1985), the two protonated forms are separated by a high energy barrier. Consequently, if both ions were generated they should not interconvert. Experimentally, Van Driel et al. demonstrated that protonation of ethylhydroperoxide lead mostly the internally protonated form. The second form is also detected but in weak amounts.

In the case of dimethylperoxide, the two oxygen atoms are equivalent. It has been shown (Van Driel et al., 1985; Schalley et al., 1997) that protonation of $\mathrm{CH}_{3} \mathrm{OOCH}_{3}$ under $\mathrm{CH}_{4}$ or $\mathrm{H}_{2}$ chemical ionization induces, to some extent, the formation of $\mathrm{CH}_{3}(\mathrm{OH}) \mathrm{OCH}_{3}{ }^{+}$ion even if dissociation mostly proceeds via a methanol/formaldehyde proton bound complex. Schwarz and co-workers also estimated its proton affinity by DFT calculations and obtained a value of $748.5 \mathrm{~kJ} / \mathrm{mol}$ (Schalley et al., 1997), while a value of $754 \mathrm{~kJ} / \mathrm{mol}$ is 
obtained at the G3 level. An experimental measurement was performed by using the equilibrium method with an FT-ICR instrument (Aschi et al., 1998). A single reference (trifluoroacetic acid) base was used. A free energy change of $11.3 \mathrm{~kJ} / \mathrm{mol}$ was measured which, when combined to the tabulated gas-phase basicity of the reference $(692 \mathrm{~kJ} / \mathrm{mol}$ (Hunter \& Lias, 1998)) gives a gas-phase basicity of $703.3 \mathrm{~kJ} / \mathrm{mol}$. Finally, using the rotational symmetry numbers to estimate the protonation entropy of dimethylperoxide results in a proton affinity of 734.0 $\mathrm{kJ} / \mathrm{mol}$. Dimethyl peroxide is found more basic than methyl hydroperoxide but is less basic than methanol (754.3 $\mathrm{kJ} / \mathrm{mol}$ ) or dimethyl ether $792 \mathrm{~kJ} / \mathrm{mol}$. This experimental value is in good agreement with our G2 estimates (754 $\mathrm{kJ} / \mathrm{mol})$.

\section{b. Methoxy alcohols}

Unlike aminoalcohols, methoxy alcohols have been rather scarcely studied. The values tabulated for methoxy ethanol (Hunter \& Lias, 1998) appears severely underestimated as one should expect this compound to be more basic than ethylene glycol. Audier and co-workers have explored in detail the gas-phase basicity of a series of methoxy alcohols by combining ICR and HPMS studies with theoretical calculations (Szulejko et al., 1998). Their data are summarized in Table 12. Values in parentheses correspond to a correction of the HPMS data, which takes into account the occurrence of an equilibrium taking place between open and cyclic conformers of neutral methoxy alcohols. 
Table 12 Protonation thermochemistry of $\omega$-methoxy alcohols

\begin{tabular}{|c|c|c|c|c|}
\hline $\mathrm{M}$ & Method & $\mathrm{GB}(\mathrm{M})^{\mathrm{a}}$ & $\mathrm{PA}(\mathrm{M})^{\mathrm{a}}$ & $\Delta_{\mathrm{p}} \mathrm{S}^{\circ}(\mathrm{M})^{\mathrm{b}}$ \\
\hline \multirow[t]{3}{*}{ 1,2-methoxy ethanol } & equilibrium & $797.9^{c}$ & $831.8(829.3)^{\mathrm{c}}$ & $-10^{c}$ \\
\hline & extended kinetic & $800.4^{\mathrm{d}}$ & $832.8^{\mathrm{d}}$ & $0^{\mathrm{d}}$ \\
\hline & theoretical & & $823.6^{\mathrm{e}}$ & \\
\hline \multirow[t]{2}{*}{ 1,3- methoxy propanol } & equilibrium & $839.7^{c}$ & $893.3(871.9)^{\mathrm{c}}$ & $-59^{c}$ \\
\hline & theoretical & & $872.2^{\mathrm{e}}$ & \\
\hline \multirow[t]{2}{*}{ 1,4-methoxy butanol } & equilibrium & $862.7^{\mathrm{c}}$ & $917.9(896.6)^{\mathrm{c}}$ & $-63^{c}$ \\
\hline & theoretical & & $896.0^{\mathrm{e}}$ & \\
\hline \multirow[t]{2}{*}{ 1,5-methoxy pentanol } & equilibrium & $859.0^{\mathrm{c}}$ & $918.4(899.1)^{\mathrm{d}}$ & $-75^{\mathrm{c}}$ \\
\hline & theoretical & & $905.3^{e}$ & \\
\hline \multirow[t]{2}{*}{ 2-methoxy propanol } & equilibrium & $860.9^{c}$ & $911.7^{c}$ & $-50^{c}$ \\
\hline & theoretical & & & \\
\hline $\begin{array}{c}\text { 2-méthyl-2-methoxy } \\
\text { propanol }\end{array}$ & equilibrium & $880.1^{\mathrm{c}}$ & $930.9^{c}$ & $-50^{c}$ \\
\hline
\end{tabular}

a) $\mathrm{kJ} . \mathrm{mol}^{-1}$; b) J.K $\mathrm{K}^{-1} \cdot \mathrm{mol}^{-1}$; c) (Szulejko et al., 1998), into parentheses, after analysis including neutral conformers equilibrium data ; d)

Bouchoux et al 2003a.; e) G3MP2B3 calculation, this work.

The gas-phase basicity measured for methoxy ethanol is logically greater than that of ethylene glycol. This finding is in agreement with a previous chemical ionization study (Pakarinen \& Vainiotalo, 1996) and was since confirmed by the use of the extended kinetic method (Bouchoux et al., 2003b). Globally, all the methoxy alcohols studied are more basic by than their corresponding $\alpha, \omega$-diol (Table 11). The large entropy changes measured during HPMS experiments clearly indicate that intramolecular cyclization takes places via hydrogen bonding in protonated methoxy alcohols. Intramolecular bonding stabilizes the protonated form $\mathrm{MH}^{+}$of methoxy alcohols, thus increasing their proton affinity over that of similarly sized monofunctional molecules (Table 9). Theoretical studies showed that an intramolecular hydrogen bond is already established in the neutral forms, promoting the folding up of the molecules into compact ring. Ethers are generally considered to be more basic than alcohols of similar size, and calculations indeed confirmed that protonation of $\omega$-methoxy alcohols occurs preferentially on the methoxy group oxygen site. Protonation reinforces the hydrogen bond strength as attested by $\mathrm{H}$ bond lengths which are much shorter than those of the corresponding neutrals. The strengthening of the hydrogen bond is also reflected in the shortening of the $\mathrm{O} \cdots \mathrm{H}$ and $\mathrm{O} \cdots \mathrm{O}$ distances as well as in the opening of the $\mathrm{O}-\mathrm{H} \cdots \mathrm{O}$ angle. The proton shifts toward midway between the two oxygen atoms as the length of the alkyl chain increases (Szulejko et al., 1998). Like for other bifunctional compounds, the strength of the hydrogen bond in methoxy alcohols can be qualitatively appreciated by estimating the proton affinity difference $\Delta \mathrm{H}_{\mathrm{M}-\mathrm{B}}$ between methoxy alcohol and the homologue methoxy ether (see paragraph I.C), which as expected increase with increasing ring size of the protonated species. A comparison of $\Delta \mathrm{H}_{\mathrm{M}-\mathrm{B}}$ and the ionic hydrogen bond energy $\mathrm{D}\left(\mathrm{Me}_{2} \mathrm{O} \ldots \mathrm{H}^{+} \ldots \mathrm{O}(\mathrm{H}) \mathrm{Me}\right)$ of $110.0 \mathrm{~kJ} / \mathrm{mol}$ for the protonated dimethyl ether/methanol proton-bound dimer (Sharma et al., 1984) provides an estimate on the strain energies associated with the cyclisation by internal hydrogen bonding. The difference $\Delta \mathrm{H}_{\text {strain }}=110.0-\Delta \mathrm{H}_{\mathrm{M}-\mathrm{B}}$ decreases with increasing the ring size, as expected. The value obtained for 1,4 and 1,5- methoxy alcohols (13-16 kJ/mol) is weak suggesting that the rings are weakly constrained. Calculations support these qualitative estimates. It was indeed shown (Szulejko et al., 1998) that the hydrogen bond angle rapidly increases as the number of methylene groups increases, since the hydrogen 
bond appears almost linear to finally attain $170.9^{\circ}$ very close from the angle typically found in proton bound dimers.

To conclude this section, one may also mention that the proton affinity of methoxymethanol, $\mathrm{CH}_{3} \mathrm{OCH}_{2} \mathrm{OH}$, has been evaluated by ab initio calculations (Ganguly \& Fuchs, 1997). In this paper, the authors performed a detailed analysis of the anomeric effect on the geometry and conformational behavior of neutral and protonated 1,3-dioxa systems, namely, methoxymethanol, dimethoxymethane, and 1,3-dioxane. Authors estimated their proton affinities but did not include the translational energy of the proton. Adding a 5/2RT term to their estimates leads to a proton affinity of $801 \mathrm{~kJ} / \mathrm{mol}$ for the most stable neutral conformer of methoxymethanol. Protonation onto the methoxy group is favored, whereas protonation of the hydroxyl group leads to an ion/neutral complex between water and the methylmethoxonium cation $\mathrm{CH}_{3}=\mathrm{OCH}_{2}{ }^{+}$. The free lone pair of the methoxy oxygen is much easier to protonate than the lone pair involved in the $\mathrm{n}_{\mathrm{O}}-\sigma^{*}{ }_{\mathrm{C}-\mathrm{O}}$ interaction typical of the anomeric effect.

\section{c. Aliphatic polyethers}

Two kinds of acyclic aliphatic polyethers have been studied in the gas phase. The first series of compounds corresponds to $\alpha, \omega$-dimethoxy alkanes, in which two methoxy functions are separated by an increasing number of methylene groups. The second series corresponds to glymes, which are of general formula $\mathrm{CH}_{3}-\left(\mathrm{OCH}_{2} \mathrm{CH}_{2}\right)_{\mathrm{n}}-\mathrm{OCH}_{3}$. Note that 1,2-dimethoxy ethane is in fact the smallest glyme, called glyme1. Gasphase basicities and proton affinities of these molecules are summarized in Table 13.

Table 13 Protonation thermochemistry of $\alpha, \omega$-dimethoxyalkanes and glymes

\begin{tabular}{|c|c|c|c|c|}
\hline $\mathrm{M}$ & Method & $\mathrm{GB}(\mathrm{M})^{\mathrm{a}}$ & $\overline{\mathrm{PA}(\mathrm{M})^{\mathrm{a}}}$ & $\Delta_{\mathrm{p}} \mathrm{S}^{\circ}(\mathrm{M})^{\mathrm{b}}$ \\
\hline \multirow{5}{*}{$\begin{array}{c}\text { 1,2-dimethoxy ethane } \\
\text { (glyme-1) }\end{array}$} & equilibrium & $819.1 \pm 1.3^{c}$ & $857.6 \pm 1.3^{\mathrm{c}}$ & $-8 \pm 4^{c}$ \\
\hline & & $822.8^{\mathrm{d}}$ & $861.2^{\mathrm{d}}$ & $-19^{d}$ \\
\hline & extended kinetic & $813.1^{\mathrm{f}}$ & $845.5^{\mathrm{e}} / 845.7^{\mathrm{f}}$ & $0^{\mathrm{f}}$ \\
\hline & theoretical & & $865.5^{\mathrm{g}}$ & \\
\hline & theoretical & & $856.5^{\mathrm{h}}$ & \\
\hline \multirow[t]{2}{*}{ 1,3-dimethoxy propane } & equilibrium & $858.6 \pm 2.4^{\mathrm{c}}$ & $897.3 \pm 3.2^{c}$ & $-21 \pm 7^{c}$ \\
\hline & theoretical & & $919.8^{g}$ & \\
\hline \multirow[t]{2}{*}{ 1,4- dimethoxy butane } & equilibrium & $880.6^{\mathrm{d}}$ & $931.5^{\mathrm{d}}$ & $-68^{2 \mathrm{~d}}$ \\
\hline & theoretical & & $945.8^{\mathrm{g}}$ & \\
\hline \multirow[t]{2}{*}{ 1,5-dimethoxy pentane } & equilibrium & $879.5^{\mathrm{d}}$ & $931.3^{\mathrm{d}}$ & $-70^{d}$ \\
\hline & theoretical & & $947.1^{\mathrm{g}}$ & \\
\hline \multirow{2}{*}{$\begin{array}{l}\text { diethylene glycol } \\
\text { dimethyl ether } \\
\text { (glyme-2) }\end{array}$} & equilibrium & $871.2 \pm 0.4^{\mathrm{c}}$ & $919.7 \pm 6.4^{\mathrm{c}}$ & $-53 \pm 11^{c}$ \\
\hline & & $869.8^{\mathrm{d}}$ & $917.6^{\mathrm{d}}$ & $-52^{\mathrm{d}}$ \\
\hline \multirow{2}{*}{$\begin{array}{l}\text { triethylene glycol } \\
\text { dimethyl ether } \\
\text { (glyme-3) }\end{array}$} & equilibrium & $894.0 \pm 1.1^{\mathrm{c}}$ & $949.2 \pm 1.2^{\mathrm{c}}$ & $-75 \pm 8^{c}$ \\
\hline & & $888.6^{\mathrm{d}}$ & $940.6^{\mathrm{d}}$ & $-69^{d}$ \\
\hline $\begin{array}{c}\text { tetraethylene glycol } \\
\text { dimethyl ether } \\
\text { (glyme-4) }\end{array}$ & equilibrium & $897.8^{\mathrm{d}}$ & $953.6^{\mathrm{d}}$ & $-79^{d}$ \\
\hline $\begin{array}{c}\text { Pentaethylene glycol } \\
\text { dimethyl ether } \\
\text { (glyme-5) }\end{array}$ & theoretical & & $967^{\mathrm{i}}$ & \\
\hline
\end{tabular}


Experimental data mostly arise from two equilibrium studies carried out in the early 80's (Meot-Ner, 1983; Sharma et al., 1984). Expectedly, the experimental data show that the PAs of the $\alpha, \omega$-dimethoxy ethers are substantially higher than that aliphatic monoethers, and also slightly more basic than the corresponding $\alpha, \omega-$ methoxy alcohols (Table 12). These equilibrium studies carried out at different temperatures lead to the determination of negative entropy changes. This again points out to the formation of an intramolecular hydrogen bond in the protonated forms, which stabilize the ions and increase the proton affinity of the molecules. Protoninduced cyclization results in a loss of freedom, hence the negative entropy changes observed upon protonation. The entropy change measured for 1,2-dimethoxy ethane is rather small compared to higher homologues, suggesting that only a partial hydrogen bond would be formed in its protonated form. Several theoretical studies were devoted to this particular system. Neutral 1,2-dimethoxy ethane does not exhibit any hydrogen bond (Esseffar et al., 1990; Yamabe et al., 1992; Adötoledo et al., 1998). The most stable form has an opened trans configuration in which the oxygen atoms are as far as possible from each other. On the other hand, protonation of one of the methoxy group is associated with an important conformational change allowing a hydrogen bond to be established. However, as suggested by the experiments, these calculations show that this interaction is rather weak due to ring strain. The $\mathrm{O}-\mathrm{H}^{+\ldots} \mathrm{O}$ bond angle is indeed strongly distorted and far from the optimal value of $180^{\circ}$. As the number of methylene groups becomes larger, this angle approaches $180^{\circ}$ and the proton is progressively shifted midway from the two methoxy groups (Yamabe et al., 1992). The hydrogen bond is therefore strengthened and the computed proton affinity increased consistently, to finally reach a plateau for 1,4dimethoxy butane, in agreement with the experimental results. The gas-phase basicity of 1,2-dimethoxyethane has also been studied by the kinetic method. The values are slightly below those deduced from equilibrium experiments, and the difference is more pronounced for the proton affinity. Such differences have been often observed in the case of molecules presenting two remote basic sites. On the other hand, a good agreement is globally observed between the two sets of equilibrium measurements. Both studies concluded that large glymes$\mathrm{n}(\mathrm{n}>1)$ are more basic than dimethoxy alkanes. Again large negative entropy changes are measured for these species. In glymes, protonation of the first $\mathrm{OCH}_{3}$ group is then followed by a cyclization process promoted by the formation of an intramolecular hydrogen bond in which the proton is located between two basic sites. Sharma and co-workers interpreted the greater proton affinities of the large glymes by the combination of this intramolecular hydrogen bond and an additional stabilization of the incoming proton by well-oriented dipoles of the $\mathrm{CH}_{2} \mathrm{OCH}_{2}$ groups. Brodbelt and co-workers used both the kinetic method and ligand exchange experiments to study the order of relative gas-phase basicities of a series of crown ethers, glycols and glymes (Liou \& Brodbelt, 1992; Wu \& Brodbelt, 1993).The relative order of gas-phase basicities thus obtained for glymes agrees with the order established previously by HPMS equilibrium measurements. Finally, note that only a computed proton affinity is available for glyme-5 (Esseffar et al., 1991). This value was deduced from AM1 calculations performed on a series of glymes and crown ethers. Although calculated absolute proton affinities were systematically lower than the experimental values, the relative order was respected, and importantly, a linear correlation was found between computed and experimental data, allowing the proton affinity of glyme-5 to be estimated. 


\section{d. Cyclic mono-ethers}

Before examining the protonation chemistry of cyclic polyethers, the gas-phase basicity of cyclic saturated and unsaturated monoethers will be briefly discussed. Gas-phase basicities and proton affinities of representative cyclic monoethers are given in Table 14. When possible, a comparison is made between the tabulated values and the measurements that have not been taken into account in the Hunter and Lias database (Hunter \& Lias, 1998).

Table 14. Protonation thermochemistry of cyclic monoethers

\begin{tabular}{|c|c|c|c|c|c|}
\hline $\mathrm{M}$ & Structure & Method & $\mathrm{GB}(\mathrm{M})^{\mathrm{a}}$ & $\mathrm{PA}(\mathrm{M})^{\mathrm{a}}$ & $\Delta_{\mathrm{p}} \mathrm{S}^{\circ}(\mathrm{M})^{\mathrm{b}}$ \\
\hline \multirow[t]{2}{*}{ Oxirane } & & Equilibrium & $745.3^{\mathrm{c}}$ & $774.2^{\mathrm{c}}$ & $12^{\mathrm{c}}$ \\
\hline & & Theoretical & & $776.2^{\mathrm{d}}$ & \\
\hline \multirow[t]{2}{*}{ Methyl oxirane } & & Equilibrium & $772.7^{\mathrm{c}}$ & $803.3^{c}$ & $6^{\mathrm{c}}$ \\
\hline & & Theoretical & & $794.5^{\mathrm{d}}$ & \\
\hline \multirow[t]{5}{*}{ oxetane } & & Equilibrium & $773.9^{\mathrm{c}}$ & $801.3^{c}$ & $17 \mathrm{c}$ \\
\hline & & Equilibrium & $769^{\mathrm{e}}$ & $796(801)^{\mathrm{e}}$ & $17(0)^{\mathrm{e}}$ \\
\hline & & Equilibrium & $787.2^{\mathrm{f}}$ & $822.0^{\mathrm{f}}$ & $-8^{\mathrm{f}}$ \\
\hline & & Theoretical & & $819^{g}$ & \\
\hline & & Theoretical & & $802.9^{\mathrm{h}}$ & \\
\hline Tetrahydrofuran & & Equilibrium & $794.7^{\mathrm{c}}$ & $822.1^{\mathrm{c}}$ & $17^{\mathrm{c}}$ \\
\hline \multirow[t]{5}{*}{ (THF) } & & Equilibrium & $797^{\mathrm{e}}$ & $824(829)^{e}$ & $? ?(0)^{\mathrm{e}}$ \\
\hline & & Equilibrium & $794.7^{\mathrm{f}}$ & $829.3^{\mathrm{f}}$ & $-7^{f}$ \\
\hline & & Equilibrium & $799.3^{\mathrm{i}}$ & $828.9^{\mathrm{i}}$ & $9^{\mathrm{i}}$ \\
\hline & & Theoretical & & $829^{g}$ & \\
\hline & & Theoretical & & $818.0^{\mathrm{h}}$ & \\
\hline Tetrahydropyran & & Equilibrium & $795.4^{\mathrm{c}}$ & $822.8^{\mathrm{c}}$ & $17^{\mathrm{c}}$ \\
\hline \multirow[t]{2}{*}{ (THP) } & & Equilibrium & $798^{\mathrm{e}}$ & $825(830)^{\mathrm{e}}$ & $17(0)^{\mathrm{e}}$ \\
\hline & & Theoretical & & $829 \mathrm{~g}$ & \\
\hline \multirow[t]{3}{*}{ Oxepane } & & Equilibrium & $806.8^{\mathrm{c}}$ & $834.2^{\mathrm{c}}$ & $17^{\mathrm{c}}$ \\
\hline & & Equilibrium & 802 & $829(834)^{\mathrm{e}}$ & $17(0)^{\mathrm{e}}$ \\
\hline & & Theoretical & & $840 \mathrm{~g}$ & \\
\hline \multirow[t]{3}{*}{ 2,3-dihydrofuran } & & Equilibrium & $834.3^{\mathrm{c}}$ & $866.9^{\mathrm{c}}$ & $0^{c}$ \\
\hline & & Theoretical & & $867^{g}$ & \\
\hline & & & & $866^{\mathrm{j}}$ & \\
\hline 2-methyl-2,3- & & Equilibrium & $877.9^{c}$ & $910.3^{\mathrm{c}}$ & $0^{\mathrm{c}}$ \\
\hline dihydrofuran & & Theoretical & & $911^{\mathrm{j}}$ & \\
\hline 3-methyl-2,3- & & Equilibrium & $836.2^{\mathrm{c}}$ & $866.8^{\mathrm{c}}$ & $0^{\mathrm{c}}$ \\
\hline dihydrofuran & & Theoretical & & $869^{j}$ & \\
\hline
\end{tabular}




\begin{tabular}{|c|c|c|c|c|}
\hline \multirow[t]{2}{*}{ 2,5-dihydrofuran } & Equilibrium & $796^{\mathrm{c}}$ & $823.4^{\mathrm{c}}$ & \multirow[t]{2}{*}{$17^{\mathrm{c}}$} \\
\hline & Theoretical & & $809^{j}$ & \\
\hline \multirow[t]{6}{*}{ Furan } & Equilibrium & $770.9^{\mathrm{c}}$ & $803.4^{\mathrm{c}}$ & $0^{\mathrm{c}}$ \\
\hline & Equilibrium & $782^{\mathrm{k}}$ & $814^{\mathrm{k}}$ & $6^{\mathrm{k}}$ \\
\hline & Equilibrium & $780^{1}$ & $816^{1}$ & \\
\hline & Theoretical & & $814^{\mathrm{m}}$ & \\
\hline & Theoretical & $781^{\mathrm{n}}$ & $815^{\mathrm{n}}$ & $6^{\mathrm{n}}$ \\
\hline & Theoretical & & $816.7^{\circ}$ & \\
\hline
\end{tabular}

a) $\mathrm{kJ} . \mathrm{mol}^{-1}$; b) J.K $\mathrm{K}^{-1} \cdot \mathrm{mol}^{-1}$; c) (Hunter \& Lias, 1998) (entropy terms into parentheses are estimated values indicated as such in the original reference); d) B3LYP/6-311++G(d,p) calculations (Vila \& Mosquera, 2003); e) (Kabli et al., 2006); f) (Bordeje et al., 1993); g) G3 calculations (Kabli et al., 2006); h) MP2/6-31G(d) calculations (Bordeje et al., 1993); i) (Sharma et al., 1984); j) G3 calculations, this work; k) (van Beelen et al., 2004); 1) (Houriet et al., 1980); m) G2(MP2) calculation (Esseffar et al., 2002); n) G3(MP2) calculation (van Beelen et al., 2004); o) MP2/aug'-cc-pVTZ calculations (Chan et al., 2005)

Protonation of cyclic aliphatic ethers occurs onto the oxygen atom. The protonation chemistry of protonated oxirane and methyloxirane oxetane has been studied theoretically (Nobes et al., 1981; Coxon et al., 1997; Vila \& Mosquera, 2003). In addition, the study of the $\mathrm{C}_{2} \mathrm{H}_{5} \mathrm{O}^{+}$potential energy surface has shown that the interconversion of the protonated oxirane into the most stable form (1-hydroxyethyl cation), which implies ring opening and hydrogen migration between the $\alpha$ and $\beta$ methylene groups, is associated to a high energy barrier (115.9 $\mathrm{kJmol}^{-1}$ at the MP2/6-31G(d,p)//MP2/6-31G(d) (Coxon et al., 1997)). The size of this barrier indicates that the cyclic protonated oxirane, once generated should be a stable species in the gas phase and should not interconvert.

Examination of Table 14 indicates that the proton affinity of simple cyclic ethers, oxirane, oxetane, tetrahydrofuran, tetrahydropyran and oxepane is found to increase with the ring size. An important finding is that the first elements of this series are less basic than their opened chain analogues. This is explained by a lone pair hybridization effect, which increases the s-character in the lone pair orbitals, which makes protonation of the oxygen less favourable than for acyclic ethers, and therefore lowers the proton affinity. The effect is less pronounced as ring strain decreases and the difference in basicity is attenuated as the size of the ring increases. One can notice some discrepancies among the data reported for oxetane. The proton affinity in the NIST table is $801.3 \mathrm{~kJ} \mathrm{~mol}^{-1}$ as based upon a gas-phase basicity of $773.9 \mathrm{~kJ} \mathrm{~mol}^{-1}$, while Bordeje et al. (Bordeje et al., 1993) reported a higher experimental value $\left(819 \mathrm{~kJ} \mathrm{~mol}^{-1}\right)$. The results of recent FT-ICR experiments (Kabli et al., 2006) are in reasonable agreement with the value in the NIST tables. The discrepancy between these experimental determinations remains unclear.

The effect of the substitution by methyl groups onto the proton affinity of cyclic ethers has been evaluated for oxirane and THF. Bromilow et al. (Bromilow et al., 1981) determined the proton affinity of THF and its methyl derivatives by the equilibrium method, and the experimental PAs presently reported have been reevaluated by using the values of the Hunter and Lias database for the reference bases. Vila and Mosquera (Vila \& Mosquera, 2003) performed DFT calculations to estimate the proton affinities of methyl oxiranes. The different values are summarized in Figure 14.

Figure 14. 
As already observed for other systems, methylation significantly enhances the basicity of the molecules. The effect is particularly pronounced for the first methyl group, and gradually decreases for the subsequent methylations. In the case of oxiranes, calculations indicated that protonation preferentially occurs at the less hindered side.

The gas-phase basicities of THF and THP appear similar, whereas the difference should be more important given the greater polarizability of the latter. The equilibrium constant for the proton transfer between THF and THP has been determined a couple of time by FT-ICR (Bromilow et al., 1981; Kabli et al., 2006), and led to a difference of gas-phase basicity of 2.9 and $0.7 \mathrm{~kJ} / \mathrm{mol}$ in favour of THP, thus confirming that THP is slightly more basic than THF. The calculated proton affinities of these two molecules are within $1 \mathrm{~kJ} \mathrm{~mol}^{-1}$ of each other. Proton affinities of all the simple cyclic saturated monoethers have been estimated by theory considering that the cyclic oxonium cation was indeed generated during the protonation event, and Table 14 shows that the calculated proton affinities are globally in good agreement with the experimental values.

Like for alcohols, the basicity of ethers is enhanced when an unsaturation is conjugated with the oxygen atom. This effect was demonstrated by Bouchoux and co-workers during their study dealing with unsaturated ethers (Bouchoux et al., 1986). The protonation of 2,3- and 2,5-dihydrofuran has been examined by gas-phase equilibrium proton transfer reactions conducted in an ion cyclotron resonance spectrometer. 2,3-dihydrofuran appears roughly $40 \mathrm{~kJ} / \mathrm{mol}$ more basic than THF. Protonation of 2,3-dihydrofuran may lead to three different $\left[\mathrm{C}_{4} \mathrm{H}_{7} \mathrm{O}\right]^{+}$species (Figure 15) and a good agreement between computed and experimental proton affinities is observed is one considers that protonation occurs preferentially on the $\beta$-carbon during the equilibrium proton transfer experiments.

Figure 15.

Protonation on the $\beta$-carbon corresponds to the most stable structure, for which the positive charge, formally located on the carbon adjacent to the oxygen atom, is stabilized by the $\pi$-donating effect of the oxygen atom center. The increase in proton affinity observed for 2-methyl-2,3-dihydrofuran confirms the $\beta$-protonation process, which leads in that particular case to a tertiary carbocation. It is worth noting that in turn 2,5dihydrofuran is much less basic. Its thermodynamically favoured site of protonation is different. Ab initio calculations indeed indicate that the oxygen is now the most basic site (Figure 15). Consequently, in equilibrium proton transfer, protonation of $\beta, \gamma$-unsaturated ethers should occur on the $\mathrm{O}$ atom.

Finally, Table 14 also reports the data for furan. The thermochemistry of this molecule has been extensively studied. The gas-phase basicity and proton affinity of furan have been recently redetermined to be 782 and $812 \mathrm{~kJ} \mathrm{~mol}^{-1}$, respectively, on the basis of the experimental equilibrium constant for the proton transfer to acetone (van Beelen et al., 2004). This result disagrees with the average gas-phase basicity value reported in the Hunter and Lias compendium, which was deduced from previous high-pressure mass spectrometry and the ICR data. The high-pressure experiments yielded GB values of 775 and $767 \mathrm{~kJ} \mathrm{~mol}^{-1}$ (Meot-Ner, 1983), whereas use of the bracketing technique led to GB value between 756 and $765 \mathrm{~kJ} \mathrm{~mol}^{-1}$ (Houriet et al., 1981). On the other hand, in an ICR equilibrium study (Houriet et al., 1980), the proton transfer between furan and protonated acetone was reported to be reversible and led to a GB value of $780 \mathrm{~kJ} \mathrm{~mol}^{-1}$. The various theoretical studies 
strongly suggest that the tabulated value of $803 \mathrm{~kJ} \mathrm{~mol}^{-1}$ for the proton affinity of furan is too low, since high level ab initio methods lead to computed proton affinity of $814-817 \mathrm{~kJ} / \mathrm{mol}$ for a protonation occurring onto the $\mathrm{C}_{\alpha}$ carbon. Protonation at $\mathrm{C}_{\alpha}$ leads to a more delocalized charge than protonation at $\mathrm{C}_{\beta}$, and the oxygen is the less favourable protonation site. For example, G3(MP2) calculation predict proton affinities of 814, 771 and 699 $\mathrm{kJ} / \mathrm{mol}$ for the positions $\alpha, \beta$ and $\mathrm{O}$, respectively (van Beelen et al., 2004). It must be emphasized that the fact that $\mathrm{C}_{\alpha}$ is the most favorable protonation site of furan (as well as pyrrole) has been demonstrated experimentally by IRMPD spectroscopy (Lorenz et al., 2007).

\section{e. Cyclic polyethers: dioxanes and crown ethers}

To complete this survey about the gas-phase basicity of bifunctional molecules, the last section will be devoted to the intrinsic basicity of cyclic polyethers, and more especially to dioxanes and crown ethers. Like for acyclic polyethers, most of the data available so far come from two HPMS studies (Meot-Ner, 1983; Sharma et al., 1984).

Table 15. Protonation thermochemistry of cyclic polyethers

\begin{tabular}{|c|c|c|c|c|}
\hline $\mathrm{M}$ & Method & $\mathrm{GB}(\mathrm{M})^{\mathrm{a}}$ & $\mathrm{PA}(\mathrm{M})^{\mathrm{a}}$ & $\Delta_{\mathrm{p}} \mathrm{S}^{\circ}(\mathrm{M})^{\mathrm{b}}$ \\
\hline \multirow[t]{2}{*}{ 1,3-dioxane } & equilibrium & $796.4 \pm 0.7^{c}$ & $823.9 \pm 0.7^{\mathrm{c}}$ & $11^{\mathrm{d}}$ \\
\hline & theoretical & & $821.2^{\mathrm{e}}$ & \\
\hline \multirow[t]{4}{*}{ 1,4-dioxane } & equilibrium & $770.0^{\mathrm{d}}$ & $797.4^{\mathrm{d}}$ & $17^{\mathrm{d}}$ \\
\hline & equilibrium & $770.6^{\mathrm{f}}$ & 798.0 & $17^{\mathrm{d}}$ \\
\hline & equilibrium & $771.7^{\mathrm{g}}$ & 798.5 & $17^{\mathrm{d}}$ \\
\hline & theoretical & & $799^{\mathrm{h}}$ & \\
\hline 9-crown-3 & theoretical & & $857.7^{\mathrm{i}}$ & \\
\hline \multirow[t]{3}{*}{ 12-crown-4 } & equilibrium & $890.6 \pm 0.9^{c}$ & $923.0 \pm 2.0^{c}$ & $-7 \pm 2^{c}$ \\
\hline & equilibrium & $887.3^{\mathrm{i}}$ & $930.2^{\mathrm{i}}$ & $-27^{\mathrm{i}}$ \\
\hline & theoretical & & $911.7^{\mathrm{j}}$ & \\
\hline \multirow[t]{2}{*}{ 15-crown-5 } & equilibrium & $900.6 \pm 1.9^{c}$ & $928.4 \pm 2.1^{\mathrm{c}}$ & $(-15)^{c}$ \\
\hline & & $894.8^{\mathrm{i}}$ & $938.5^{\mathrm{i}}$ & $-39^{i}$ \\
\hline \multirow[t]{2}{*}{ 18-crown-6 } & equilibrium & $910.5 \pm 2.1^{\mathrm{c}}$ & $927.2 \pm 2.1^{\mathrm{c}}$ & $(-19)^{\mathrm{c}}$ \\
\hline & equilibrium & $907.2^{\mathrm{i}}$ & $967.0^{\mathrm{i}}$ & $-84^{\mathrm{i}}$ \\
\hline
\end{tabular}

a) $\mathrm{kJ} . \mathrm{mol}^{-1}$; b) J.K ${ }^{-1} \cdot \mathrm{mol}^{-1}$; c) (Meot-Ner, 1983); d) (Hunter \& Lias, 1998) (entropy terms into parentheses are estimated values indicated as such in the original reference); e) MP2/6-31+G(d) calculations (Ganguly \& Fuchs, 1997); f) (Lias et al., 1980) g) (Bromilow et al., 1981) h) (Kabli et al., 2006); i) (Sharma et al., 1984); j) (Adötoledo et al., 1998)

Only one experimental determination has been reported for 1,3 dioxane (Meot-Ner, 1983), and comparison with the gas-phase basicity of tetrahydropyran (THP) shows that the additional electron-withdrawing effect brought by the oxygen in position 3 does not decrease the gas-phase basicity. The protonation process of 1,3-dioxane has been studied theoretically by assuming that 1,3-dioxane retained its chair conformation upon protonation (Ganguly \& Fuchs, 1997). Adding the translational energy for the proton (5/2RT) to the original theoretical estimate leads to a $\mathrm{PA}_{298}$ of 1,3-dioxane of $821.2 \mathrm{~kJ} / \mathrm{mol}$ in very good agreement with the experimental value. Moreover, axial protonation is found $9 \mathrm{~kJ} / \mathrm{mol}$ more favourable than equatorial protonation, indicating that when 1,3-dioxane is in chair conformation, the axial lone pair of oxygen is more available for protonation than the equatorial one. On the other hand, the replacement of a $\mathrm{CH}_{2}$ group by an oxygen atom in 
position 4 of THP results in a lowering of the gas-phase basicity by c.a. $26 \mathrm{~kJ} / \mathrm{mol}$, as attested by the experimental value obtained for 1,4-dioxane, which was recently confirmed by G2 calculations (Kabli et al., 2006). 1,4-dioxane may be view as the smallest crown-ether ("6-crown-2"). The chair conformation in neat 1,4dioxane is sensibly more stable than the boat form. Unlike what was assumed in the previous HPMS study (Sharma et al., 1984), protonation of one of the oxygen atoms results preferentially in a chair form. In the boat form, the possible hydrogen bond is not strong enough to promote the conformational change. Consistently, our calculated proton affinity at the G2MP2 level of the chair form is $20 \mathrm{~kJ} / \mathrm{mol}$ more stable than that of the boat form, while AM1 calculations pointed to a reverse order (Esseffar et al., 1990). The important ring strain induces destabilizing interactions between the positive charge and the two remote $\mathrm{C}-\mathrm{O}$ bond dipoles, and consequently a lower proton affinity with respect to THP. Note also that according to our G2MP2 calculations, equatorial protonation is slightly more favoured $(2 \mathrm{~kJ} / \mathrm{mol})$ than axial protonation.

From Table 15 one can see that the intrinsic basicity of crown ethers regularly increases with the ring size. A proton affinity of $858 \mathrm{~kJ} / \mathrm{mol}$ has been deduced for 9-crown-3 from a linear correlation between AM1 and experimental proton affinities of crown ethers and glymes (Esseffar et al., 1991). The intrinsic basicity of 12-crown-4 has been studied both experimentally and theoretically. The protonated form is characterized by the formation of an intramolecular hydrogen bond. More optimal hydrogen bond geometry is achieved if the proton is located between to opposite oxygen atoms (Esseffar et al., 1991; Adötoledo et al., 1998). 15-crown-5 and 18crown- 6 are more and more flexible and therefore would allow a better orientation of the $\mathrm{CH}_{2} \mathrm{OCH}_{2}$ groups dipoles, and consequently an improved stabilization of the positive charge. One can also see that the entropy loss observed for 12-crown-4 and 15-crown-5 are significantly lower than those determined for the corresponding acyclic forms, glyme 3 and glyme4, respectively (Table 14). This was rather expected since crown ethers already exhibit a cyclic form prior to protonation. Interestingly these acyclic and cyclic polyethers have similar gasphase basicities, but glymes have a higher proton affinity due to their enhanced flexibility resulting in more negative protonation entropy change. Finally, it is worth noting that while the gas-phase basicities determined by the two HPMS studies are very close, some discrepancies, especially for 18-crown-6, are observed for proton affinities. This disagreement is due to the way the proton affinity of 15 -crown-5 and 18-crown- 6 were estimated by Meot-Ner (Meot-Ner, 1983). For these two species, Mautner could not perform experiments at different temperatures, and assumed that their protonation entropy was only slightly more negative than the one measured for 12-crown-4. Results obtained by Sharma et al. indicate that the entropy change is in fact rather large in spite of the cyclic nature of these compounds (Sharma et al., 1984). Finally, it is worth noting that the use of the kinetic method led to the same order of relative basicities for crown ethers (Liou \& Brodbelt, 1992). In addition, the acyclic glyme analogues typically demonstrated greater proton affinities than the corresponding cyclic compounds. 


\section{References}

2005. NIST Computational Chemistry Comparison and Benchmark Database. NIST Standard Reference Database Number 101.

Adötoledo D, Aviyente V, Martin J M L, Lifshitz C. 1998. Modeling proton-bound methanol, ammonia, and amine complexes of 12-crown-4-ether and dimethoxyethane ("glyme") using density functional theory. Journal of Physical Chemistry A. 102:6357-6365.

Alcami M, Mó O, Yanez M, Abboud J L M, Elguero J. 1990. Bond Activation by Protonation in the Gas-Phase. Chemical Physics Letters. 172:471-477.

Alder R W, Bowman P S, Steele W R S, Winterma.Dr. 1968. Remarkable Basicity Of 1,8Bis(Dimethylamino)Naphthalene. Chemical Communications. 723-+.

Alder R W, Arrowsmith R J, Casson A, Sessions R B, Heilbronner E, Kovac B, Huber H, Taagepera M. 1981. Proton Affinities And Ionization Energies Of Bicyclic Amines And Diamines - The Effects Of Ring Strain And Of 3-Electron Sigma-Bonding. Journal of The American Chemical Society. 103:6137-6142.

Angelelli F, Aschi M, Cacace F, Pepi F, Depetris G. 1995. Gas-Phase Reactivity Of Hydroxylamine Toward Charged Electrophiles - A Mass-Spectrometric And Computational Study Of The Protonation And Methylation Of H2noh. Journal of Physical Chemistry. 99:6551-6556.

Armentrout P B. 2000. Entropy measurements and the kinetic method: A statistically meaningful approach. Journal of the American Society for Mass Spectrometry. 11:371-379.

Armstrong D A, Yu D, Rauk A. 1997. Gas phase and aqueous thermochemistry of hydrazine and related radicals and the energy profiles of reactions with H-. and $\mathrm{OH} .:$ An ab initio study. Journal of Physical Chemistry A. 101:4761-4769.

Aschi M, Attina M, Cacace F, Cipollini R, Pepi F. 1998. Gas-phase positive and negative ion chemistry of methyl hydroperoxide. Inorganica Chimica Acta. 276:192-202.

Aschi M, Attina M, Cacace F, Cartoni A, Pepi F. 2000. A mass spectrometric and computational study of gaseous peroxynitric acid and $(\mathrm{HOONO} 2) \mathrm{H}+$ protomers. International Journal Of Mass Spectrometry. 195:1-10.

Aubry C, Holmes J L. 2000. Correlating thermochemical data for gas-phase ion chemistry. International Journal of Mass Spectrometry. 200:277-284. 
Aue D H, Bowers M T. 1979. Stabilities of positive ions from equilibrium gas-phase basicity measurements. Gas phase ion Chemistry. New-York: Academic Press.

Aue D H, Webb H M, Bowers M T. 1973. Quantitative Evaluation of Intramolecular Strong Hydrogen-Bonding in Gas-Phase. Journal of the American Chemical Society. 95:2699-2701.

Baboul A G, Curtiss L A, Redfern P C, Raghavachari K. 1999. Gaussian-3 theory using density functional geometries and zero-point energies. Journal of Chemical Physics. 110:7650-7657.

Bartmess J E, Basso T, Georgiadis R. 1983. Electron-Affinity Of A Nitroxide Radical. Journal of Physical Chemistry. 87:912-912.

Benson S W. 1976. Thermochemical Kinetics. 2nd Edition. New-York: John Wiley \& Sons.

Bordeje M C, Mo O, Yanez M, Herreros M, Abboud J L M. 1993. Cyclization effects on the gas-phase basicities of esters and ethers. An experimental and MO study. Journal of the American Chemical Society. 115:7389.

Bouchoux G. 2006. Evaluation of the protonation thermochemistry obtained by the extended kinetic method. Journal of Mass Spectrometry. 41:1006-1013.

Bouchoux G. 2007. Gas-phase basicities of polyfunctional molecules. part 1: Theory and methods. Mass Spectrometry Reviews. 26:775-835.

Bouchoux G, Berruyer-Penaud F. 2003. Protonation thermochemistry of alpha,omega-alkane diols in the gas phase: A theoretical study. Journal of Physical Chemistry A. 107:7931-7937.

Bouchoux G, Buisson D A. 2006. Gas phase basicity of X(CH2)(3)Y(X, Y=OH, NH2) by the thermokinetic method. International Journal of Mass Spectrometry. 249:412-419.

Bouchoux G, Jezequel S, Penaudberruyer F. 1993. Conformational Effect On Gas-Phase Protonation And Nh4+ Clustering Of 1,2-Diols. Organic Mass Spectrometry. 28:421-427.

Bouchoux G, Choret N, Flammang R. 1997. Unimolecular chemistry of protonated diols in the gas phase: Internal cyclization and hydride ion transfer. Journal of Physical Chemistry A. 101:4271-4282.

Bouchoux G, Choret N, Berruyer-Penaud F. 2001a. Protonation thermochemistry of alpha,omega-alkyldiamines in the gas phase: A theoretical study. Journal of Physical Chemistry A. 105:3989-3994. 
Bouchoux G, Choret N, Berruyer-Penaud F, Flammang R. 2001b. Unimolecular reactivity of protonated alpha,omega-alkanediamines in the gas phase. Journal of Physical Chemistry A. 105:9166-9177.

Bouchoux G, Choret N, Berruyer-Penaud F, Flammang R. 2002a. Thermochemistry and unimolecular reactivity of protonated alpha,omega-aminoalcohols in the gas phase. International Journal of Mass Spectrometry. 217:195-230.

Bouchoux G, Buisson D A, Bourcier S, Sablier M. 2003a. Application of the kinetic method to bifunctional bases ESI tandem quadrupole experiments. International Journal of Mass Spectrometry. 228:1035-1054.

Bouchoux G, Djazi F, Gaillard F, Vierezet D. 2003b. Application of the kinetic method to bifunctional bases MIKE and CID-MIKE test cases. International Journal of Mass Spectrometry. 227:479-496.

Bouchoux G, Bourcier S, Blanc V, Desaphy S. 2009. Gas Phase Protonation Thermochemistry of Phenylalanine and Tyrosine. Journal of Physical Chemistry B. 113:5549-5562.

Bouchoux G, Djazi F, Hoppilliard Y, Houriet R, Rolli E. 1986. Gas-Phase Protonation Of Unsaturated Ethers Experimental And Theoretical-Study Of 2,3-Dihydrofuran And 2,5-Dihydrofuran And RelatedCompounds. Organic Mass Spectrometry. 21:209-213.

Bouchoux G, Defaye D, McMahon T, Likholyot A, Mó O, Yanez M. 2002b. Structural and energetic aspects of the protonation of phenol, catechol, resorcinol, and hydroquinone. Chemistry-A European Journal. 8:2900-2909.

Boulanger A M, Rennie E E, Holland D M P, Shaw D A, Mayer P M. 2006. Threshold-photoelectron spectroscopic study of methyl-substituted hydrazine compounds. Journal of Physical Chemistry A. 110:8563-8571.

Boulanger A M, Rennie E E, Holland D M P, Shaw D A, Mayer P M. 2008. Thermochemistry of N-N containing ions: A threshold photoelectron photoion coincidence spectroscopy study of ionized methyland tetramethylhydrazine. Journal of Physical Chemistry A. 112:866-879.

Boulet P, Gilardoni F, Weber J, Chermette H, Ellinger Y. 1999. Theoretical study of interstellar hydroxylamine chemistry: protonation and proton transfer mediated by H-3(+). Chemical Physics. 244:163-174.

Bourcier S, Hoppilliard Y. 2002. B3LYP DFT molecular orbital approach, an efficient method to evaluate the thermochemical properties of MALDI matrices. International Journal of Mass Spectrometry. 217:231244. 
Bromilow J, Abboud J L M, Lebrilla C B, Taft R W, Scorrano G, Lucchini V. 1981. Oxonium ions. Solvation by single acetonitrile molecules in the gas phase and by bulk solvents. Journal of the American Chemical Society. 103:5448.

Burton R D, Watson C H, Eyler J R, Lang G L, Powell D H, Avery M Y. 1997. Proton affinities of eight matrices used for matrix-assisted laser desorption/ionization. Rapid Communications In Mass Spectrometry. 11:443-446.

Callam C S, Singer S J, Lowary T L, Hadad C M. 2001. Computational analysis of the potential energy surfaces of glycerol in the gas and aqueous phases: Effects of level of theory, basis set, and solvation on strongly intramolecularly hydrogen-bonded systems. Journal of The American Chemical Society. 123:1174311754.

Cao J, Aubry C, Holmes J L. 2000. Proton affinities of simple amines; entropies and enthalpies of activation and their effect on the kinetic method for evaluating proton affinities. Journal of Physical Chemistry A. 104:10045-10052.

Cardoso A M, Alexandre S M G, Barros C M F, Ferrer-Correia A J, Nibbering N M M. 1998. Proton affinities of phenylalkylamines by the kinetic method. International Journal of Mass Spectrometry. 172:123-127.

Chan B, Del Bene J E, Elguero J, Radom L. 2005. On the relationship between the preferred site of hydrogen bonding and protonation. Journal of Physical Chemistry A. 109:5509-5517.

Chen Q F, Stone J A. 1995. A High-Pressure Mass-Spectrometric Determination Of The Proton Affinities Of C2, C-3, And C-4 Alpha,Omega-Alkanediols. Journal of Physical Chemistry. 99:1442-1453.

Chen X, Walthall D A, Brauman J I. 2004. Acidities in Cyclohexanediols Enhanced by Intramolecular Hydrogen Bonds. Journal of the American Chemical Society. 126:12614.

Cheng X H, Wu Z C, Fenselau C. 1993. Collision Energy-Dependence Of Proton-Bound Dimer Dissociation Entropy Effects, Proton Affinities, And Intramolecular Hydrogen-Bonding In Protonated Peptides. Journal of The American Chemical Society. 115:4844-4848.

Coxon J M, Maclagan R G A R, Rauk A, Thorpe A J, Whalen D. 1997. Rearrangement of Protonated Propene Oxide to Protonated Propanal. Journal of the American Chemical Society. 119:4712.

Crittenden D L, Thompson K C, Jordan M J T. 2005. On the extent of intramolecular hydrogen bonding in gasphase and hydrated 1,2-ethanediol. Journal of Physical Chemistry A. 109:2971-2977. 
Curtiss L A, Raghavachari K. 2002. Gaussian-3 and related methods for accurate thermochemistry. Theoretical Chemistry Accounts. 108:61-70.

Curtiss L A, Redfern P C, Raghavachari K. 2005. Assessment of Gaussian-3 and density-functional theories on the G3/05 test set of experimental energies. Journal of Chemical Physics. 123:

Curtiss L A, Raghavachari K, Trucks G W, Pople J A. 1991. Gaussian-2 Theory For Molecular-Energies Of 1stRow And 2nd-Row Compounds. Journal of Chemical Physics. 94:7221-7230.

Curtiss L A, Raghavachari K, Redfern P C, Pople J A. 2000. Assessment of Gaussian-3 and density functional theories for a larger experimental test set. Journal of Chemical Physics. 112:7374-7383.

da Silva E F. 2005. Comparison of quantum mechanical and experimental gas-phase basicities of amines and alcohols. Journal of Physical Chemistry A. 109:1603-1607.

Deakyne C A. 2003. Proton affinities and gas-phase basicities: theoretical methods and structural effects. International Journal of Mass Spectrometry. 227:601-616.

Deakyne C A, Meotner M. 1985. Unconventional Ionic Hydrogen-Bonds.2. Nh+.Pi - Complexes Of Onium Ions With Olefins And Benzene-Derivatives. Journal of The American Chemical Society. 107:474-479.

Debons F E, Loudon G M. 1980. Protected Diaminomethane. Journal of Organic Chemistry. 45:1703-1704.

Dookeran N N, Harrison A G. 1995. Reactive Collisions In Quadrupole Cells.3. H/D Exchange-Reactions Of Protonated Aromatic-Amines With Nd(3). Journal of The American Society For Mass Spectrometry. 6:19-26

Drahos L, Peltz C, Vekey K. 2004. Accuracy of enthalpy and entropy determination using the kinetic method: are we approaching a consensus? Journal of Mass Spectrometry. 39:1016-1024.

Ervin K M. 2001. Experimental techniques in gas-phase ion thermochemistry. Chemical Reviews. 101:391-444.

Ervin K M. 2002. Microcanonical analysis of the kinetic method. The meaning of the "apparent entropy". Journal of The American Society For Mass Spectrometry. 13:435-452.

Ervin K M, Armentrout P B. 2004. Systematic and random errors in ion affinities and activation entropies from the extended kinetic method. Journal of Mass Spectrometry. 39:1004-1015.

Esseffar M, Elmouhtadi M, Smeyers Y G. 1990. Protonation And Dicoordination Deformation In Polyethers Dioxane And Dimethoxyethane. Theochem-Journal of Molecular Structure. 208:179-188. 
Esseffar M, Elmouhtadi M, Abboud J L M, Elguero J, Liotard D. 1991. Theoretical-Study (Am1) On Proton Affinity Of Cyclic Polyethers (Crown Ethers) And Noncyclic Polyethers (Glymes). Canadian Journal of Chemistry-Revue Canadienne De Chimie. 69:1970-1975.

Esseffar M, Quintanilla E, Davalos J Z, Abboud J L M, Mo O, Yanez M. 2002. Nitro derivatives of pyrrole, furan and 1H-tetrazole: ring or nitro bases? New Journal Of Chemistry. 26:1567-1574.

Feldmann M T, Widicus S L, Blake G A, Kent D R, Goddard W A. 2005. Aminomethanol water elimination: Theoretical examination. Journal of Chemical Physics. 123:

Flammang R, Deschamps N, Pascal L, Van Haverbeke Y, Gerbaux P, Nam P C, Nguyen M T. 2004. Ring Versus Nitrogen Protonation of Anilines. Letters in Organic Chemistry. 1:23-30.

Gal J F, Maria P C, Raczynska E D. 2001. Thermochemical aspects of proton transfer in the gas phase. Journal of Mass Spectrometry. 36:699-716.

Galasso V. 1997. Ab initio study of the molecular structure and photoelectron spectra of caged monoamines and diamines. Theochem-Journal of Molecular Structure. 391:101-110.

Ganguly B, Fuchs B. 1997. Stereoelectronic Effects in Negatively and Positively (Protonated) Charged Species. $\mathrm{Ab}$ Initio Studies of the Anomeric Effect in 1,3-Dioxa Systems. The Journal of Organic Chemistry. 62:8892.

Ganguly B, Koley D, Thiel W. 2007. Intra-annular cyclophane diamines as proton sponges: a computational study. Tetrahedron. 63:7970-7976.

Green M K, Lebrilla C B. 1998. The role of proton-bridged intermediates in promoting hydrogen-deuterium exchange in gas-phase protonated diamines, peptides and proteins. International Journal of Mass Spectrometry. 175:15-26.

Guo H, Salahub D R. 2001. Origin of the high basicity of 2,7-dimethoxy-1,8-bis-(dimethylamino)naphthalene: Implications for enzyme catalysis. Journal of Molecular Structure-Theochem. 547:113-118.

Hache J J, Futrell J H, Laskin J. 2004. Relative proton affinities from kinetic energy release distributions for dissociation of proton-bound dimers 2. Diamines as a test case. International Journal of Mass Spectrometry. 233:223-231.

Hahn I S, Wesdemiotis C. 2003. Protonation thermochemistry of beta-alanine - An evaluation of proton affinities and entropies determined by the extended kinetic method. International Journal of Mass Spectrometry. 222:465-479. 
Harrison A G, Tu Y P. 2000. Site of protonation of N-alkylanilines. International Journal of Mass Spectrometry. 195:33-43.

Hillebrand C, Klessinger M, EckertMaksic M, Maksic Z B. 1996. Theoretical model calculations of the proton affinities of aminoalkanes, aniline, and pyridine. Journal of Physical Chemistry. 100:9698-9702.

Houriet R, Schwarz H, Zummack W. 1980. Proton And Hydrogen Affinity Of Furan And The Site Of Protonation In The Gas-Phase. Angewandte Chemie-International Edition In English. 19:905-906.

Houriet R, Schwarz H, Zummack W, Andrade J G, Schleyer P V. 1981. Alpha-Protonation Vs Beta-Protonation Of Pyrrole, Furan, Thiophene And Cyclopentadiene - Gas-Phase Proton And Hydrogen Affinities - The Bishomocyclopropenyl Cation. Nouveau Journal De Chimie-New Journal of Chemistry. 5:505-509.

Houriet R, Rufenacht H, Carrupt P A, Vogel P, Tichy M. 1983. Site Of Protonation And Conformational Effects On Gas-Phase Basicity In Beta-Amino Alcohols - The Nature Of Internal H-Bonding In Beta-Hydroxy Ammonium-Ions. Journal of The American Chemical Society. 105:3417-3422.

Houriet R, Feng W G, Vogel E, Wolfrum P, Schwarz H. 1989. Chain-Length-Dependent Inside/OutsideProtonation Of N,N'-Polymethylene-Syn-1,6-8,13-Diimino[14]Annulenes In The Gas-Phase. International Journal of Mass Spectrometry And Ion Processes. 91:R1-R4.

Howard S T. 2000. Relationship between basicity, strain, and intramolecular hydrogen-bond energy in proton sponges. Journal of The American Chemical Society. 122:8238-8244.

Howard S T, Platts J A, Alder R W. 1995. Ab-Initio Studies Of Proton Sponges.2. 1,6Diazabicyclo[4.4.4]Tetradecane. Journal of Organic Chemistry. 60:6085-6090.

Hunt D F, Sethi Satinder K. 1978. Analytical Applications of Postive and Negative Ion Chemical Ionization Mass Spectrometry. In: Edit. High Performance Mass Spectrometry: Chemical Applications AMERICAN CHEMICAL SOCIETY.p. 150-178.

Hunter E P L, Lias S G. 1998. Evaluated gas phase basicities and proton affinities of molecules: An update. Journal of Physical And Chemical Reference Data. 27:413-656.

Ikuta S, Nomura O. 1987. Intramolecular Hydrogen-Bonding Of Protonated Ethylene Diamine. Journal of Molecular Structure-Theochem. 37:315-318.

Ikuta S, Nomura O. 1989. An Abinitio Study On The Intramolecular Hydrogen-Bond Of Protonated EthyleneGlycol And Ethylenediamine. Chemical Physics Letters. 154:71-76. 
Jebber K A, Zhang K, Cassady C J, Chung-Phillips A. 1996. Ab Initio and Experimental Studies on the Protonation of Glucose in the Gas Phase. Journal of the American Chemical Society. 118:10515.

Jorgensen T J D, Bojesen G, Rahbek-Nielsen H. 1998. The proton affinities of seven matrix-assisted laser desorption/ionization matrices correlated with the formation of multiply charged ions. European Mass Spectrometry. 4:39-45.

Kabli S, van Beelen E S E, Ingemann S, Henriksen L, Hammerum S. 2006. The proton affinities of saturated and unsaturated heterocyclic molecules. International Journal of Mass Spectrometry. 249:370-378.

Karpas Z. 1989. Evidence Of Proton-Induced Cyclization Of Alpha,Omega-Diamines From Ion Mobility Measurements. International Journal of Mass Spectrometry And Ion Processes. 93:237-242.

Khrustalev D P, Khamzina G T, Fazylov S D, Gazaliev A M. 2008. Preparation of diaminomethanes under microwave irradiation. Russian Journal of General Chemistry. 78:331-331.

Klein R A. 2002. Ab initio conformational studies on diols and binary diol-water systems using DFT methods. Intramolecular hydrogen bonding and 1:1 complex formation with water. Journal of Computational Chemistry. 23:585.

Klein R A. 2003. Hydrogen bonding in diols and binary diol-water systems investigated using DFT methods. II. Calculated infrared $\mathrm{OH}$-stretch frequencies, force constants, and NMR chemical shifts correlate with hydrogen bond geometry and electron density topology. A reevaluation of geometrical criteria for hydrogen bonding. Journal of Computational Chemistry. 24:1120-1131.

Kovacevic B, Maksic Z B. 2002. The proton affinity of the superbase 1,8-bis (tetramethylguanidino) naphthalene (TMGN) and some related compounds: A theoretical study. Chemistry-A European Journal. 8:16941702.

Kumar M K, Rao J S, Prabhakar S, Vairamani M, Sastry G N. 2005. The effect of spacer chain length on ion binding to bidentate alpha,omega-diamines: Contrasting ordering for $\mathrm{H}+$ and $\mathrm{Li}+$ ion affinities. Chemical Communications. 1420-1422.

Larson J W, McMahon T B. 1982. Formation, thermochemistry, and relative stabilities of proton-bound dimers of oxygen n-donor bases from ion cyclotron resonance solvent-exchange equilibrium measurements. Journal of the American Chemical Society. 104:6255.

Lascola R, Withnall R, Andrews L. 1988. Infrared-Spectra Of Hydrazine And Products Of Its Reactions With Hf, F2, And O-3 In Solid Argon. Inorganic Chemistry. 27:642-648. 
Lau Y K, Kebarle P. 1976. Substituent Effects On Intrinsic Basicity Of Benzene - Proton Affinities Of Substituted Benzenes. Journal of The American Chemical Society. 98:7452-7453.

Lau Y K, Saluja P P S, Kebarle P, Alder R W. 1978. Gas-Phase Basicities Of N-Methyl Substituted 1,8Diaminonaphthalenes And Related Compounds. Journal of The American Chemical Society. 100:73287333.

Lau Y K, Nishizawa K, Tse A, Brown R S, Kebarle P. 1981. Protonation And Site Of Protonation Of Anilines Hydration And Site Of Protonation After Hydration. Journal of The American Chemical Society. 103:6291-6295.

Lias S G, Shold D M, Ausloos P. 1980. Proton-Transfer Reactions Involving Alkyl Ions And Alkenes - Rate Constants, Isomerization Processes, And The Derivation Of Thermochemical Data. Journal Of The American Chemical Society. 102:2540-2548.

Lias S G, Liebman J F, Levin R D. 1984. Evaluated Gas Phase Basicities and Proton Affinities of Molecules; Heats of Formation of Protonated Molecules. Journal of Physical and Chemical Reference Data. $13: 695$.

Lias S G, Bartmess J E, Liebman J F, Holmes J L, Levin R D, Mallard W G. 1988. Gas-phase Ion and Neutral Thermochemistry. Journal of Physical And Chemical Reference Data. 17, Supplement No. 1:

Lindinger W, Albritton D L, Howard C J, Fehsenfeld F C, Ferguson E E. 1975. Flow-Drift Tube Measurements Of H2o2+ Reactions With H2o, Nh3, No, And Co And Charge-Transfer Of O2+ With H2o2. Journal Of Chemical Physics. 63:5220-5222.

Liou C C, Brodbelt J S. 1992. Comparison Of Gas-Phase Proton And Ammonium Ion Affinities Of Crown Ethers And Related Acyclic Analogs. Journal of The American Chemical Society. 114:6761-6764.

Longevialle P, Milne G W A, Fales H M. 1973. Chemical Ionization Mass-Spectrometry Of Complex Molecules.11. Stereochemical And Conformational Effects In Isobutane Chemical Ionization MassSpectra Of Some Steroidal Amino Alcohols. Journal of The American Chemical Society. 95:66666669.

Lorenz U J, Lemaire J, Maitre P, Crestoni M-E, Fornarini S, Dopfer O. 2007. Protonation of heterocyclic aromatic molecules: IR signature of the protonation site of furan and pyrrole. International Journal of Mass Spectrometry. 267:43. 
Maquestiau A, Vanhaverbeke Y, Mispreuve H, Flammang R, Harris J A, Howe I, Beynon J H. 1980. The GasPhase Structure Of Some Protonated And Ethylated Aromatic-Amines. Organic Mass Spectrometry. $15: 144-148$.

Martin J M L, de Oliveira G. 1999. Towards standard methods for benchmark quality ab initio thermochemistry - W1 and W2 theory. Journal of Chemical Physics. 111:1843-1856.

Maziarz K, Ball D W. 2002. Basic thermochemical properties of NH2NHOH and NH2ONH2: new potential fuels? Journal of Molecular Structure-Theochem. 577:213-218.

Meot-Ner M. 1983. The ionic hydrogen bond. 2. Intramolecular and partial bonds. Protonation of polyethers, crown ethers, and diketones. J. Am. Chem. Soc. 105:4906-4911.

Meot-Ner M. 2003. The proton affinity scale, and effects of ion structure and solvation. International Journal of Mass Spectrometry. 227:525-554.

Meot-Ner M. 2005. The Ionic Hydrogen Bond. Chem. Rev. 105:213-284.

Meot-Ner M, Hamlet P, Hunter E P, Field F H. 1980. Internal and external solvation of polyfunctional ions. J. Am. Chem. Soc. 102:6393-6399.

Meot-Ner M, Nelsen S F, Willi M F, Frigo T B. 1984. Special effects of an unusually large neutral to radical cation geometry change. Adiabatic ionization energies and proton affinities of alkylhydrazines. J. Am. Chem. Soc. 106:7384-7389.

Meyerhoffer W J, Bursey M M. 1989. Differentiation Of The Isomeric 1,2-Cyclopentanediols By Ion-Molecule Reactions In A Triple-Quadrupole Mass-Spectrometer. Organic Mass Spectrometry. 24:169-175.

Miller K J. 1990. Additivity Methods In Molecular Polarizability. Journal Of The American Chemical Society. 112:8533-8542.

Mirza S P, Raju N P, Vairamani M. 2004. Estimation of the proton affinity values of fifteen matrix-assisted laser desorption/ionization matrices under electrospray ionization conditions using the kinetic method. Journal of The American Society For Mass Spectrometry. 15:431-435.

Mó O, Yanez M, Decouzon M, Gal J F, Maria P C, Guillemin J L. 1999. Gas-phase basicity and acidity trends in alpha,beta-unsaturated amines, phosphines, and arsines. Journal of The American Chemical Society. 121:4653-4663. 
Morlender-Vais N, Holmes J L. 2001. Proton affinities of two weakly bidentate molecules: 1,2-dimethoxyethane and methoxyacetone. International Journal of Mass Spectrometry. 210:147-152.

Mormann M, Bashir S, Derrick P J, Kuck D. 2000. Gas-phase basicities of the isomeric dihydroxybenzoic acids and gas-phase acidities of their radical cations. Journal Of The American Society For Mass Spectrometry. 11:544-552.

Nam P C, Nguyen M T, Chandra A K. 2006. Methyl and phenyl substitution effects on the proton affinities of hydrides of first and second row elements and substituent effects on the proton affinities of ring carbons in benzene: A DFT study. Journal of Physical Chemistry A. 110:4509-4515.

Nelsen S F, Rumack D T, Sieck L W, Meotner M. 1988. Proton Affinities And Pka Values Of Tetraalkylhydrazines. Journal of The American Chemical Society. 110:6303-6308.

Nimlos M R, Blanksby S J, Ellison G B, Evans R J. 2003. Enhancement of 1,2-dehydration of alcohols by alkali cations and protons: a model for dehydration of carbohydrates. Journal of Analytical And Applied Pyrolysis. 66:3-27.

Nimlos M R, Blanksby S J, Qian X H, Himmel M E, Johnson D K. 2006. Mechanisms of glycerol dehydration. Journal of Physical Chemistry A. 110:6145-6156.

Nobes R H, Radom L. 1983. The Vinyloxonium Cation (Ch2choh+2). Chemical Physics Letters. 99:107-111.

Nobes R H, Rodwell W R, Bouma W J, Radom L. 1981. The Oxygen Analog Of The Protonated Cyclopropane Problem - A Theoretical-Study Of The C2h5o+ Potential-Energy Surface. Journal Of The American Chemical Society. 103:1913-1922.

Nold M J, Wesdemiotis C. 1996. Differentiation of N- from C-protonated aniline by neutralization-reionization. Journal of Mass Spectrometry. 31:1169-1172.

Ochterski J W, Petersson G A, Montgomery J A. 1996. A complete basis set model chemistry.5. Extensions to six or more heavy atoms. Journal of Chemical Physics. 104:2598-2619.

Oiestad E L, Uggerud E. 1997. Unimolecular reactions of protonated hydrazine. Reaction mechanisms and dynamics from observation of metastable ion fragmentations and ab initio calculations. International Journal of Mass Spectrometry. 165:39-47.

Pakarinen J M H, Vainiotalo P. 1996. The protonation site of 2-methoxyethanol under chemical ionization. An experimental and theoretical study. Rapid Communications In Mass Spectrometry. 10:1901-1904. 
Pasker F M, Solca N, Dopfer O. 2006. Spectroscopic identification of carbenium and ammonium isomers of protonated aniline $(\mathrm{AnH}(+))$ : IR spectra of weakly bound $\mathrm{AnH}(+)-\mathrm{L}-\mathrm{n}$ clusters $(\mathrm{L}=\mathrm{Ar}, \mathrm{N}-2)$. Journal of Physical Chemistry A. 110:12793-12804.

Perakyla M. 1996. Ab initio quantum mechanical study on the origin of the $\mathrm{pK}(\mathrm{a})$ differences of the proton sponges 1,8-bis(dimethylamino)naphthalene, 1,8-bis(dimethylamino)-2,7-dimethoxynaphthalene, 1,6dimethyl-1,6-diazacyclodecane, and 1,6-diazabicyclo[4.4.4]tetradecane. Journal of Organic Chemistry. 61:7420-7425.

Pitzer K S, Gwinn W D. 1942. Energy levels and thermodynamic functions for molecules with internal rotation I rigid frame with attached tops. Journal of Chemical Physics. 10:428-440.

Platts J A, Howard S T, Wozniak K. 1994. Ab-Initio Studies Of Proton Sponges - 1,8Bis(Dimethylamino)Naphthalene. Journal of Organic Chemistry. 59:4647-4651.

Pollack S K, Devlin J L, Summerhays K D, Taft R W, Hehre W J. 1977. Site Of Protonation In Aniline. Journal of The American Chemical Society. 99:4583-4584.

Poutsma J C, Andriole E J, Sissung T, Morton T H. 2003. cis-1,5-diaminocyclooctane: the most basic gaseous primary amine? Chemical Communications. 2040-2041.

Raab V, Gauchenova E, Merkoulov A, Harms K, Sundermeyer J, Kovacevic B, Maksic Z B. 2005. 1,8bis(hexamethyltriaminophosphazenyl)naphthalene, HMPN: A superbasic bisphosphazene "proton sponge". Journal of The American Chemical Society. 127:15738-15743.

Raczynska E D, Rudka T, Darowska M, Dabkowska L, Gal J F, Maria P C. 2005. Experimental (FT-ICR) and theoretical (DFT) estimation of the basic site preference for the bidentate molecule 2-(beta-aminoethyl)pyridine: similarity with histamine. Journal of Physical Organic Chemistry. 18:856-863.

Rebber B L, Halfacre J A, Beran K A, Beller N R, Gomez M, Bashir S, Giannakopulos A E, Derrick P J. 2006. Theoretical investigation of the proton affinity and gas-phase basicity of neutral x,y-dihydroxybenzoic acid and its derivatives. European Journal of Mass Spectrometry. 12:385-396.

Reyzer M L, Brodbelt J S. 1998. Gas-phase basicities of polyamines. Journal of The American Society For Mass Spectrometry. 9:1043-1048.

Rõõm E-I, Kütt A, Kaljurand I, Koppel I, Leito I, Koppel I A, Mishima M, Goto K, Miyahara Y. 2007. Brønsted Basicities of Diamines in the Gas Phase, Acetonitrile, and Tetrahydrofuran. Chemistry - A European Journal. 13:7631. 
Russo N, Toscano M, Grand A, Mineva T. 2000. Proton Affinity and Protonation Sites of Aniline. Energetic Behavior and Density Functional Reactivity Indices. The Journal of Physical Chemistry A. 104:4017.

Salehzadeh S, Bayat M. 2006. Three new defined proton affinities for polybasic molecules in the gas-phase: Proton microaffinity, proton macroaffinity and proton overallaffinity. Chemical Physics Letters. 427:455-460.

Salehzadeh S, Bayat M, Hashemi M. 2007. Complete gas-phase proton microaffinity analysis of two bulky polyamine molecules. Journal of Physical Chemistry A. 111:8188-8192.

Schalley C A, Fiedler A, Hornung G, Wesendrup R, Schröder D, Schwarz H. 1997. Dimethyl Peroxide Radical Cation: A New Theoretical and Experimental Approach to the $\mathrm{C} 2 \mathrm{H} 6 \mathrm{O} \bullet+2$ Potential Energy Surface. Chemistry - A European Journal. 3:626.

Schwabe T, Grimme S. 2008. Theoretical thermodynamics for large molecules: Walking the thin line between accuracy and computational cost. Accounts Of Chemical Research. 41:569-579.

Sharma R B, Blades A T, Kebarle P. 1984. Protonation of Polyethers, Glymes and Crown Ethers, in the GasPhase. Journal of the American Chemical Society. 106:510-516.

Singh A, Ganguly B. 2007. DFT studies toward the design and discovery of a versatile cage-functionalized proton sponge. European Journal of Organic Chemistry. 420-422.

Singh A, Ganguly B. 2008. Strategic design of small and versatile bicyclic organic superbases: a density functional study. New Journal of Chemistry. 32:210-213.

Smith R L, Chyall L J, Beasley B J, Kenttamaa H I. 1995. The Site Of Protonation Of Aniline. Journal of The American Chemical Society. 117:7971-7973.

Steenvoorden R, Breuker K, Zenobi R. 1997. The gas-phase basicities of matrix-assisted laser desorption/ionization matrices. European Mass Spectrometry. 3:339-346.

Summerhays K D, Pollack S K, Taft R W, Hehre W J. 1977. Gas-Phase Basicities Of Substituted Anilines Inferences About Role Of Solvent In Dictating Site Of Protonation. Journal of The American Chemical Society. 99:4585-4587.

Sunner J A, Kulatunga R, Kebarle P. 1986. Fast-Atom-Bombardment Mass-Spectrometry and Gas-Phase Basicities. Analytical Chemistry. 58:1312-1316. 
Szulejko J E, McMahon T B, Troude V, Bouchoux G, Audier H E. 1998. Structure and energetics of protonated omega-methoxy alcohols. Journal of Physical Chemistry A. 102:1879-1887.

Tian Z, Fattahi A, Lis L, Kass S R. 2009. Neutral intramolecular hydrogen bond bases. Croatia Chemica Acta. $82: 41-45$.

Tondeur Y. 1985. Role of the matrix in the FAB MS analysis of monosaccharides. Organic Mass Spectrometry. 20:157-160.

Tsuzuki S, Honda K, Uchimaru T, Mikami M, Tanabe K. 2000. Origin of the attraction and directionality of the $\mathrm{NH} / \mathrm{pi}$ interaction: Comparison with $\mathrm{OH} / \mathrm{pi}$ and $\mathrm{CH} / \mathrm{pi}$ interactions. Journal of The American Chemical Society. 122:11450-11458.

van Beelen E S E, Koblenz T A, Ingemann S, Hammerum S. 2004. Experimental and theoretical evaluation of proton affinities of furan, the methylphenols, and the related anisoles. Journal of Physical Chemistry A. 108:2787-2793.

Van Driel J H, Heerma W, Terlouw J K, Halim H, Schwarz H. 1985. Stable [C2h7o2]+ Isomers - Experimental And Theoretical Evidence For The Existence Of Protonated Peroxides And Proton-Bound Dimers In The Gas-Phase. Organic Mass Spectrometry. 20:665-673.

Vázquez S A, Ríos M A, Carballeira L. 1992. Molecular mechanics study of conformational trends in simple alcohols and ethers. II. Intramolecular hydrogen bonding. Journal of Computational Chemistry. 13:851.

Vila A, Mosquera R A. 2003. AIM study on the protonation of methyl oxiranes. Chemical Physics Letters. 371:540.

Wang Z, Chu I K, Rodriquez C F, Hopkinson A C, Siu K W M. 1999. alpha,omega-diaminoalkanes as models for bases that dicoordinate the proton: An evaluation of the kinetic method for estimating their proton affinities. Journal of Physical Chemistry A. 103:8700-8705.

Wind J J, Papp L, Happel M, Hahn K, Andriole E J, Poutsma J C. 2005. Proton affinity of betaoxalylaminoalanine (BOAA): Incorporation of direct entropy correction into the single-reference kinetic method. Journal of The American Society For Mass Spectrometry. 16:1151-1161.

Winkler F J, Stahl D. 1979. Intramolecular ion solvation effects on gas-phase acidities and basicities. A new stereochemical probe in mass spectrometry. Journal of the American Chemical Society. 101:3685.

Wolf J F, Staley R H, Koppel I, Taagepera M, McIver R T, Beauchamp J L, Taft R W. 1977. Gas-Phase Basicities And Relative Proton Affinities Of Compounds Between Water And Ammonia From Pulsed 
Ion-Cyclotron Resonance Thermal Equilibria Measurements. Journal Of The American Chemical Society. 99:5417-5429.

Wood K V, Burinsky D J, Cameron D, Cooks R G. 1983. Site of gas-phase cation attachment. Protonation, methylation, and ethylation of aniline, phenol, and thiophenol. The Journal of Organic Chemistry. 48:5236.

Wu H F, Brodbelt J S. 1993. Comparison Of The Orders Of Gas-Phase Basicities And Ammonium Ion Affinities Of Polyethers By The Kinetic Method And Ligand-Exchange Technique. Journal of The American Society For Mass Spectrometry. 4:718-722.

Yamabe S, Hirao K, Wasada H. 1992. A Correlation Between Proton Affinities And Intramolecular HydrogenBonds In Bifunctional Organic-Compounds. Journal of Physical Chemistry. 96:10261-10264.

Yamdagni R, Kebarle P. 1973. Gas-Phase Basicities of Amines - Hydrogen-Bonding in Proton-Bound Amine Dimers and Proton-Induced Cyclization of Alpha,Omega-Diamines. Journal of the American Chemical Society. 95:3504-3510.

Zhao Y, Truhlar D G. 2008. Density functionals with broad applicability in chemistry. Accounts Of Chemical Research. 41:157-167. 


\section{FIGURES CAPTION}

Figure 1. Linear correlation between proton affinities (PA), or gas-phase basicities (GB), and the size of the molecules: n-alkylamines.

Figure 2. Plot of proton affinities versus (a) the decrease of vertical ionization energies, (b) the reverse of the number of atoms for the two series of hydrazines listed in Table 3.

Figure 3. Evolution of the proton affinities ( $\triangle \mathrm{PA})$, or gas-phase basicities $(\triangle \mathrm{GB})$, with the number of $\mathrm{CH}_{2}$ groups in $\alpha, \omega$-diamino alkanes, $\mathrm{NH}_{2}\left(\mathrm{CH}_{2}\right)_{\mathrm{n}} \mathrm{NH}_{2}$ (see text for the meaning of the strain enthalpy term $\Delta \mathrm{H}_{\text {strain }}$ ).

Figure 4. Normalized reaction efficiency as a function of $\mathrm{PA}\left(\mathrm{B}_{\mathrm{i}}\right)$ for deprotonation of Hydroxylamine $\mathrm{H}^{+}$by reference bases $\mathrm{B}_{\mathrm{i}}$.

Figure 5. Experimental and theoretical proton affinity change with the NCCO dihedral angle of 1,2aminoethanol.

Figure 6. Linear correlation between proton affinities (PA) and the size of the molecules: n-alkanols and methoxy-ethers.

Figure 7. Potential energy surface associated with the protonation of vinyl alcohol. Relative energies are given in $\mathrm{kJ} / \mathrm{mol}$.

Figure 8. Relative basicities of the various protonation sites of phenol and derivatives (in $\mathrm{kJ} / \mathrm{mol}$ ). Values taken from (van Beelen et al., 2004) and (Bouchoux et al., 2002a).

Figure 9. Peroxynitric acid and its three protonated forms (B3LYP/6-311++G(3df,2p) relative enthalpies in $\mathrm{kJ} / \mathrm{mol})$.

Figure 10. MP2/6-31G(d) optimized geometries of neutral and protonated $\alpha, \omega$-diols

Figure 11. The most stable forms of neutral and protonated glycerol in the gas-phase (G3B3 calculations).

Figure 12. Neutral and protonated forms of $\alpha-D$-glucose used in the computation of gas-phase basicity.

Figure 13. Protonated forms of alkyl hydroperoxides and dimethoxy oxide (G3 relative 298K enthalpies are given in $\mathrm{kJ} / \mathrm{mol}$.

Figure 14. Effect of methyl group(s) onto the proton affinity of cyclic saturated monoethers (values given in $\mathrm{kJ} / \mathrm{mol}$; see text for details)

Figure 15. G3 proton affinities of dihydrofuran derivatives (values given in $\mathrm{kJ} / \mathrm{mol}$ ). 


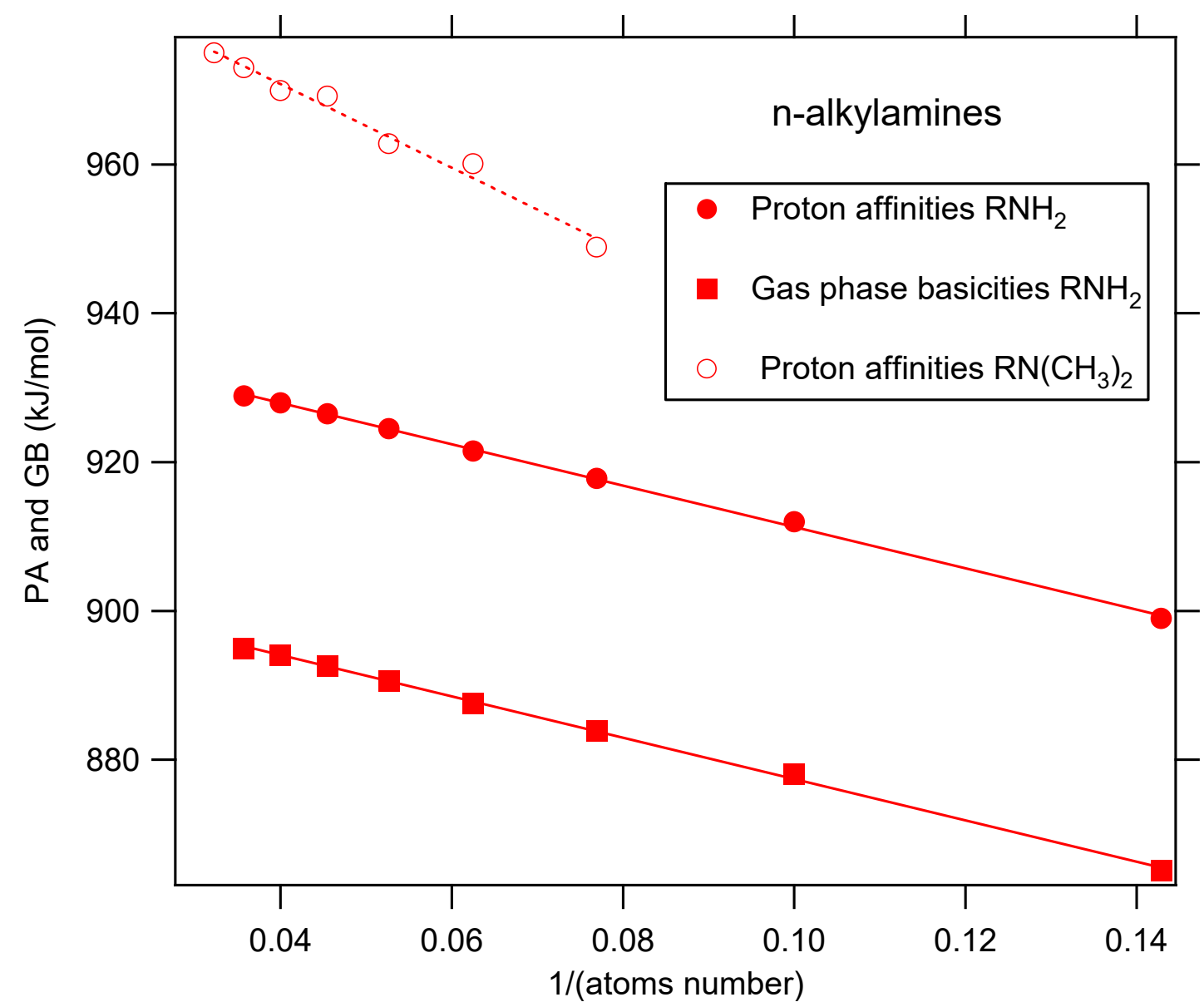

Figure 1. Linear correlation between proton affinities (PA), or gas-phase basicities (GB), and the size of the molecules: n-alkylamines. 


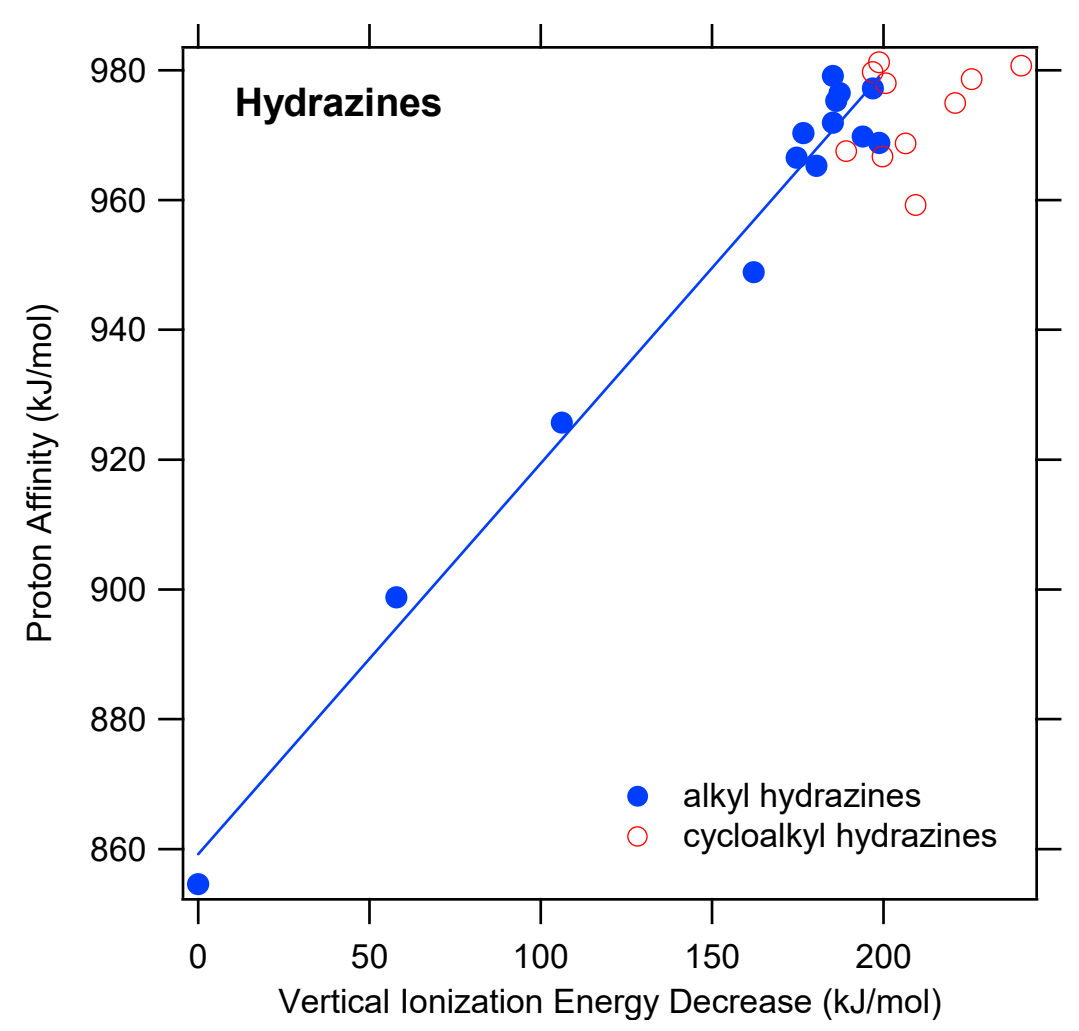

(a)

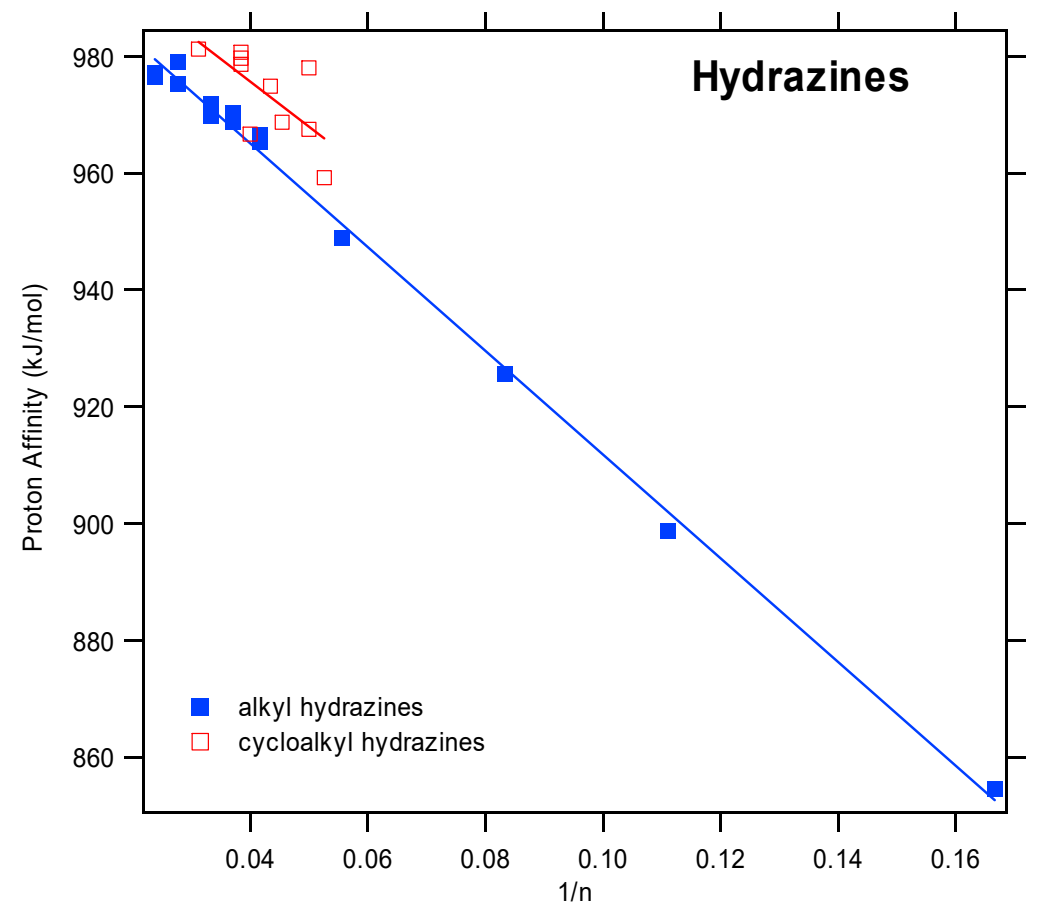

(b)

Figure 2. Plot of proton affinities versus (a) the decrease of vertical ionization energies, (b) the reverse of the number of atoms for the two series of hydrazines listed in Table 3. 


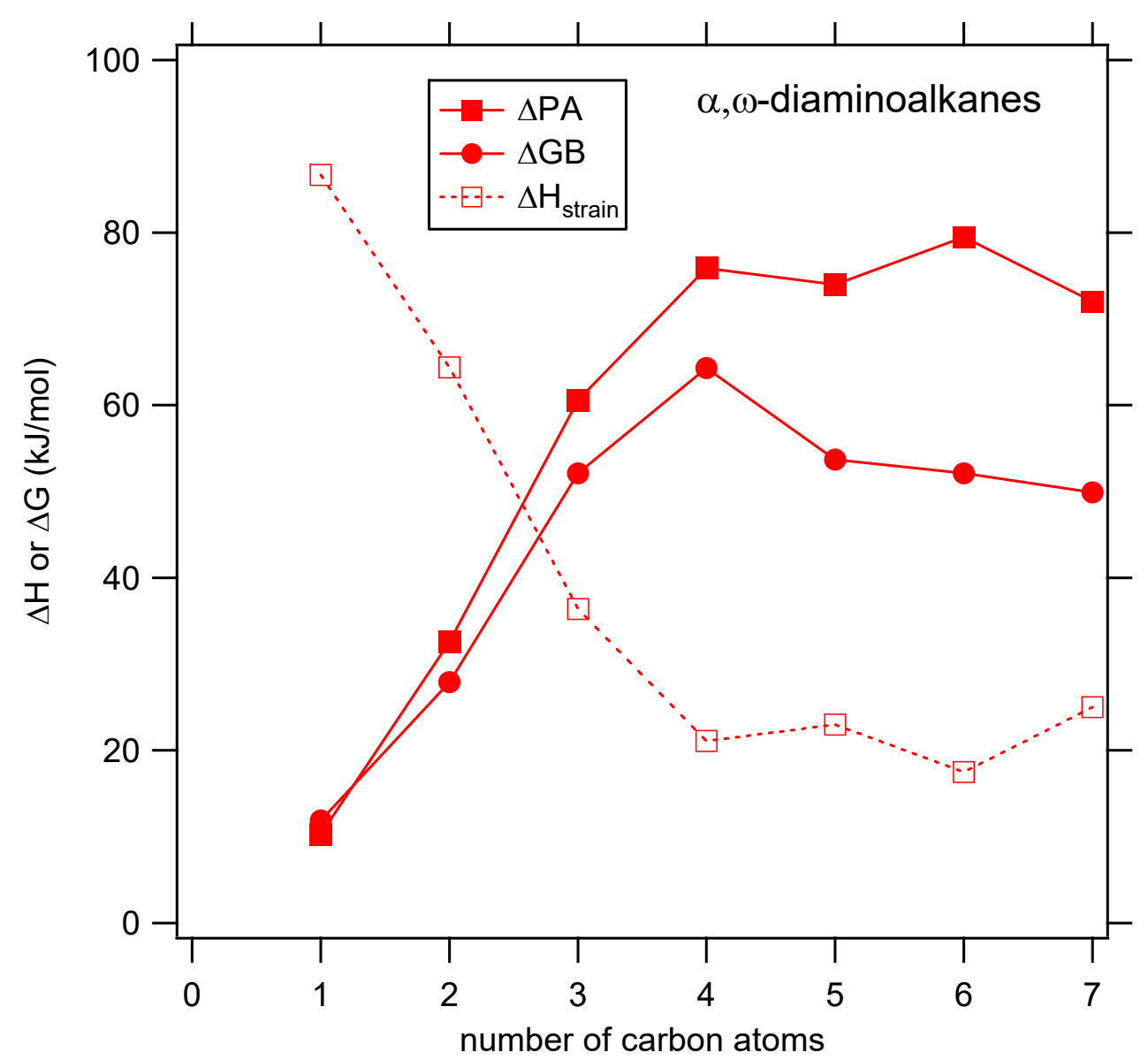

Figure 3. Evolution of the proton affinities $(\Delta \mathrm{PA})$, or gas-phase basicities $(\Delta \mathrm{GB})$, with the number of $\mathrm{CH}_{2}$ groups in $\alpha, \omega$-diamino alkanes, $\mathrm{NH}_{2}\left(\mathrm{CH}_{2}\right)_{\mathrm{n}} \mathrm{NH}_{2}$ (see text for the meaning of the strain enthalpy term $\Delta \mathrm{H}_{\text {strain }}$ ). 


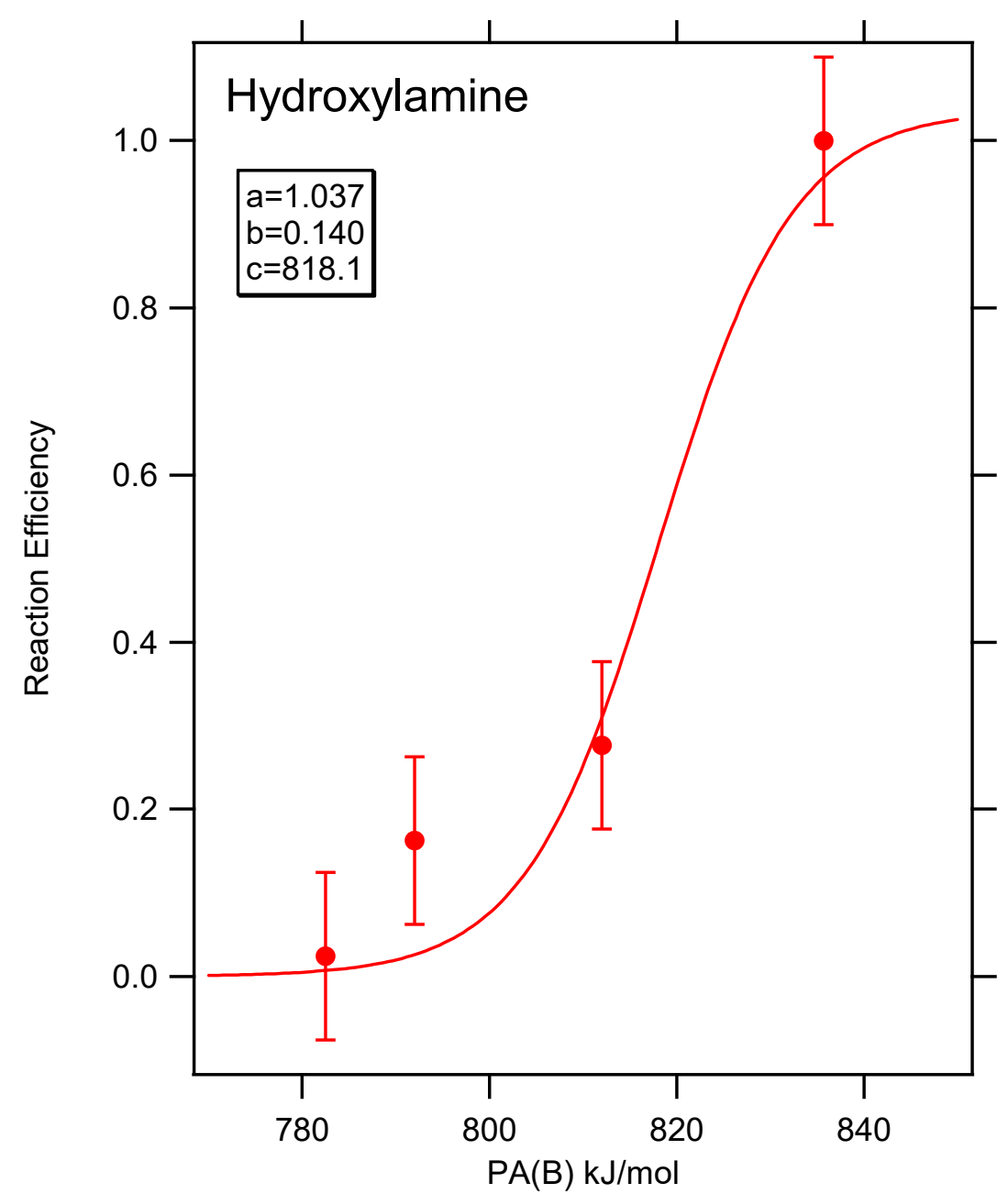

Figure 4. Normalized reaction efficiency as a function of $\mathrm{PA}\left(\mathrm{B}_{\mathrm{i}}\right)$ for deprotonation of Hydroxylamine $\mathrm{H}^{+}$by reference bases $\mathrm{B}_{\mathrm{i}}$. 


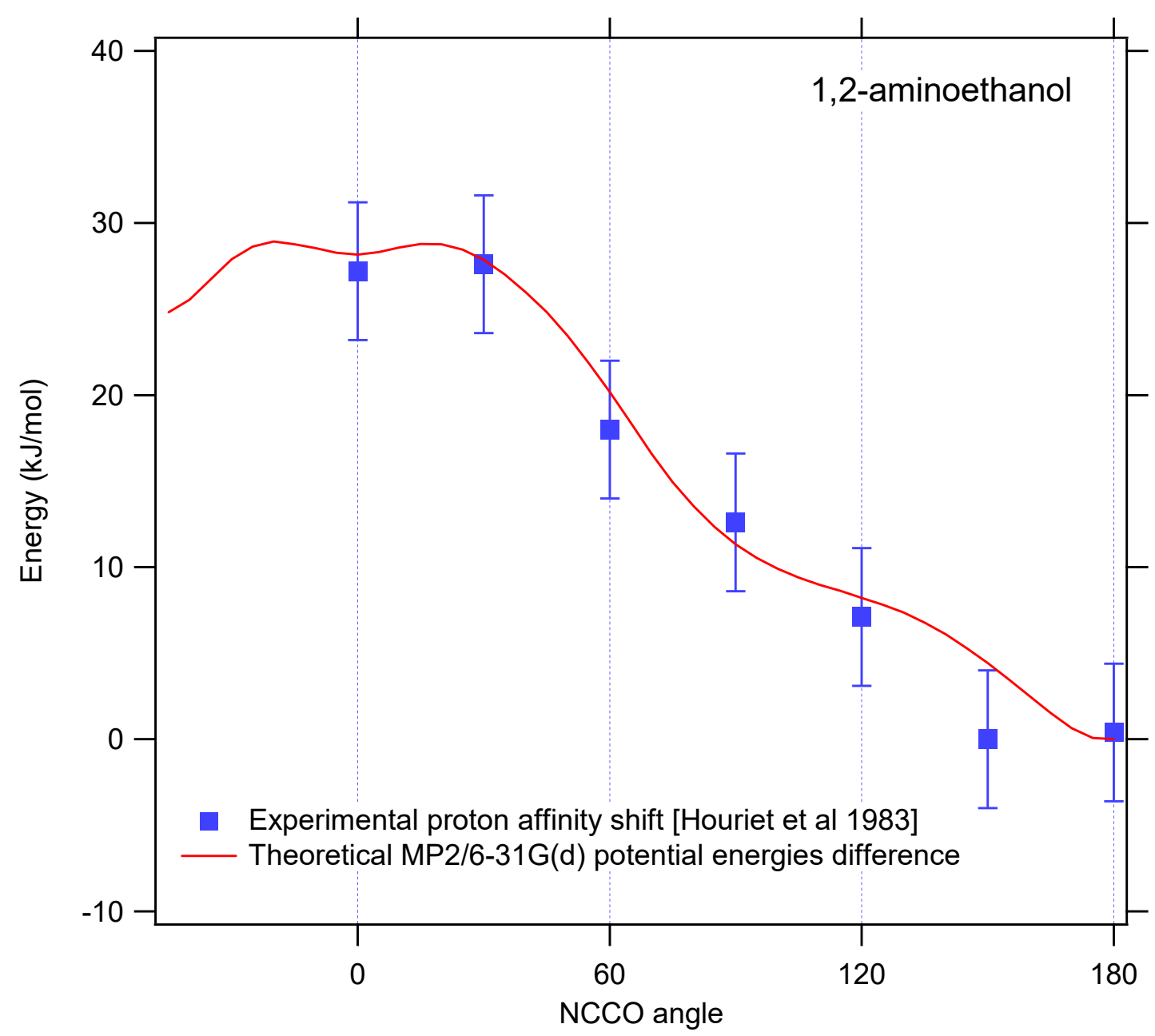

Figure 5. Experimental and theoretical proton affinity change with the NCCO dihedral angle of 1,2-aminoethanol. 


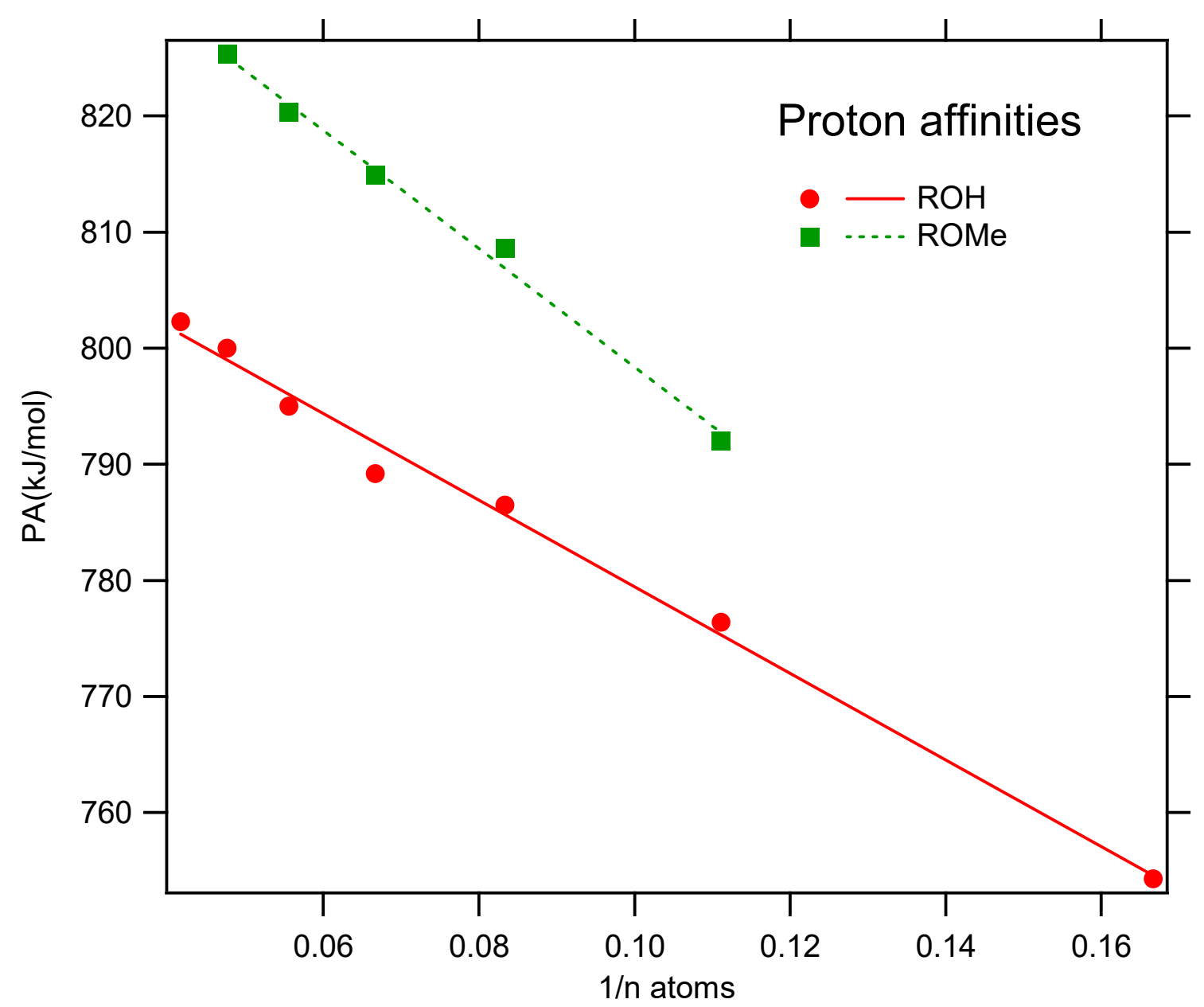

Figure 6. Linear correlation between proton affinities (PA) and the size of the molecules: nalkanols and methoxy-ethers. 


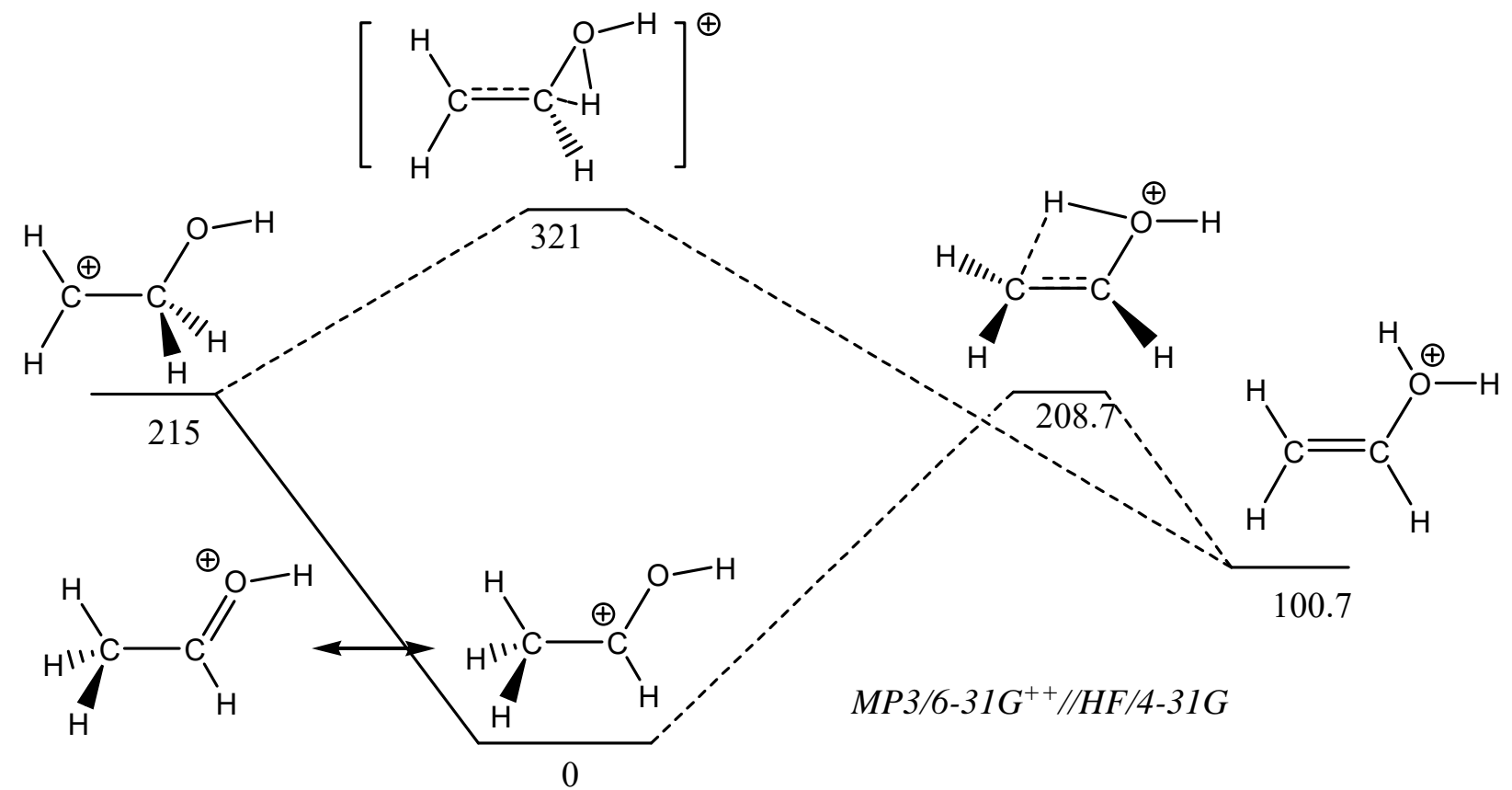

Figure 7. Potential energy surface associated with the protonation of vinyl alcohol. Relative energies are given in $\mathrm{kJ} / \mathrm{mol}$. 

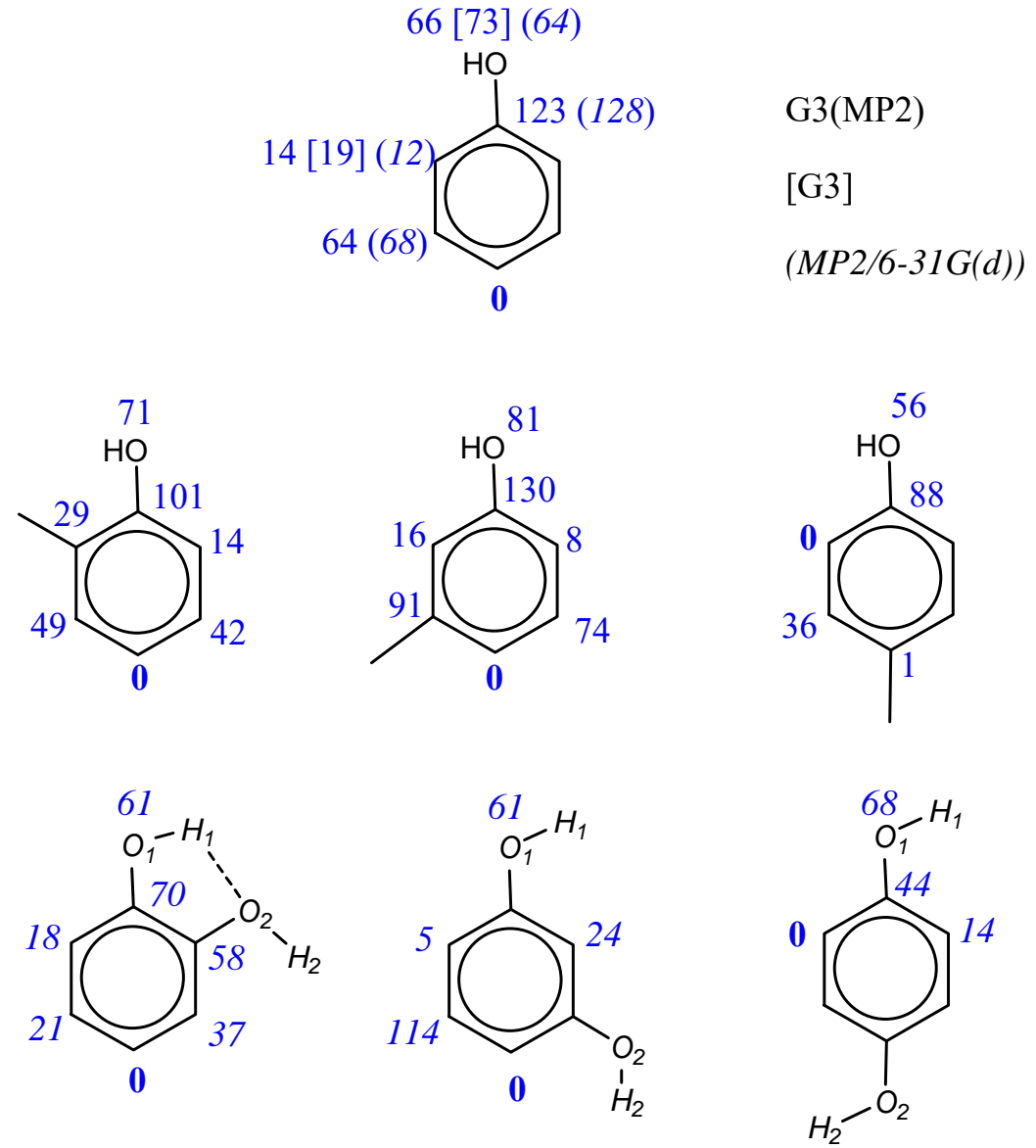

Figure 8. Relative basicities of the various protonation sites of phenol and derivatives (in $\mathrm{kJ} / \mathrm{mol}$ ). Values taken from (van Beelen et al., 2004) and (Bouchoux et al., 2002a). 


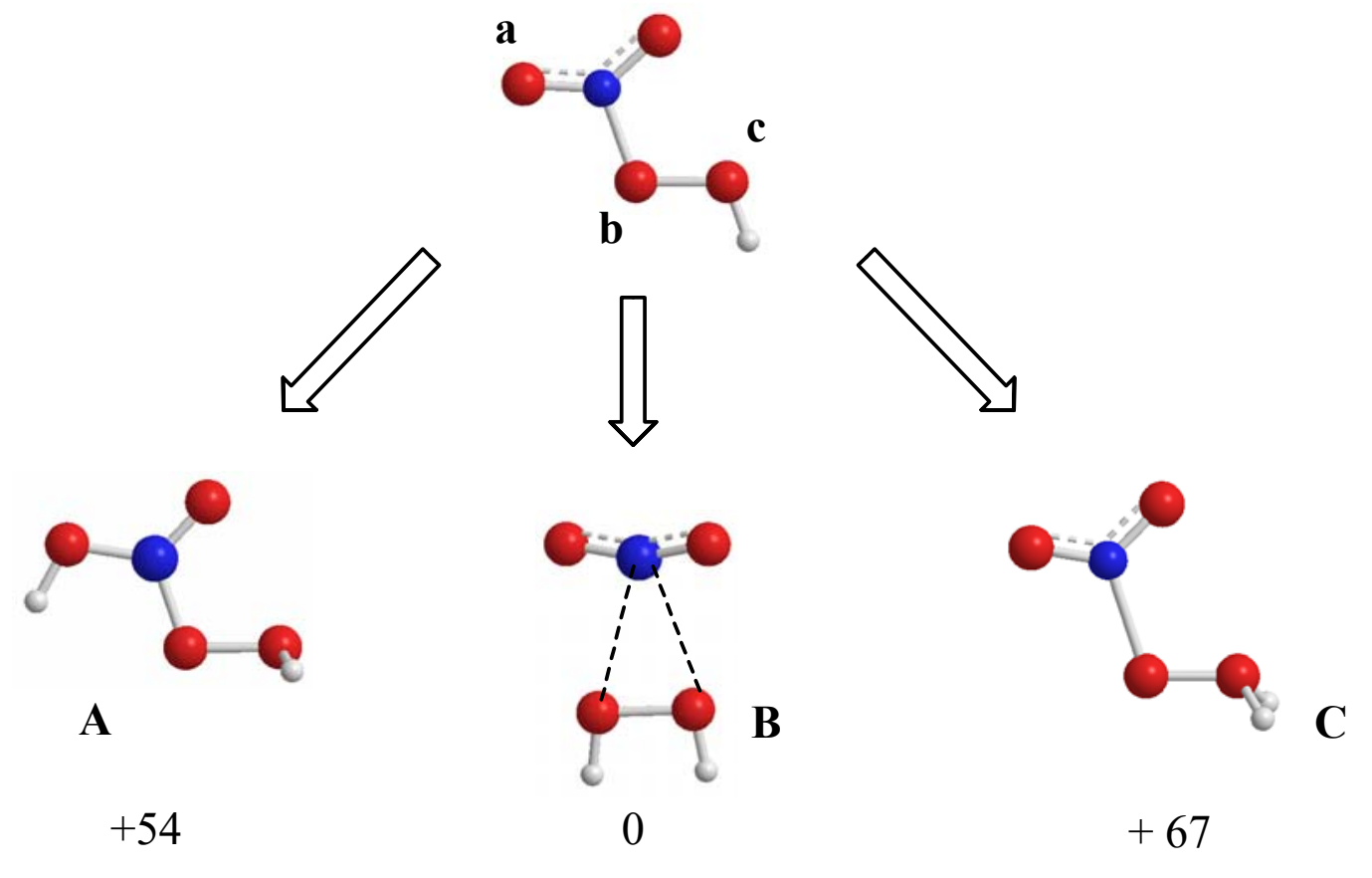

Figure 9. Peroxynitric acid and its three protonated forms (B3LYP/6-311++G(3df,2p) relative enthalpies in $\mathrm{kJ} / \mathrm{mol})$. 

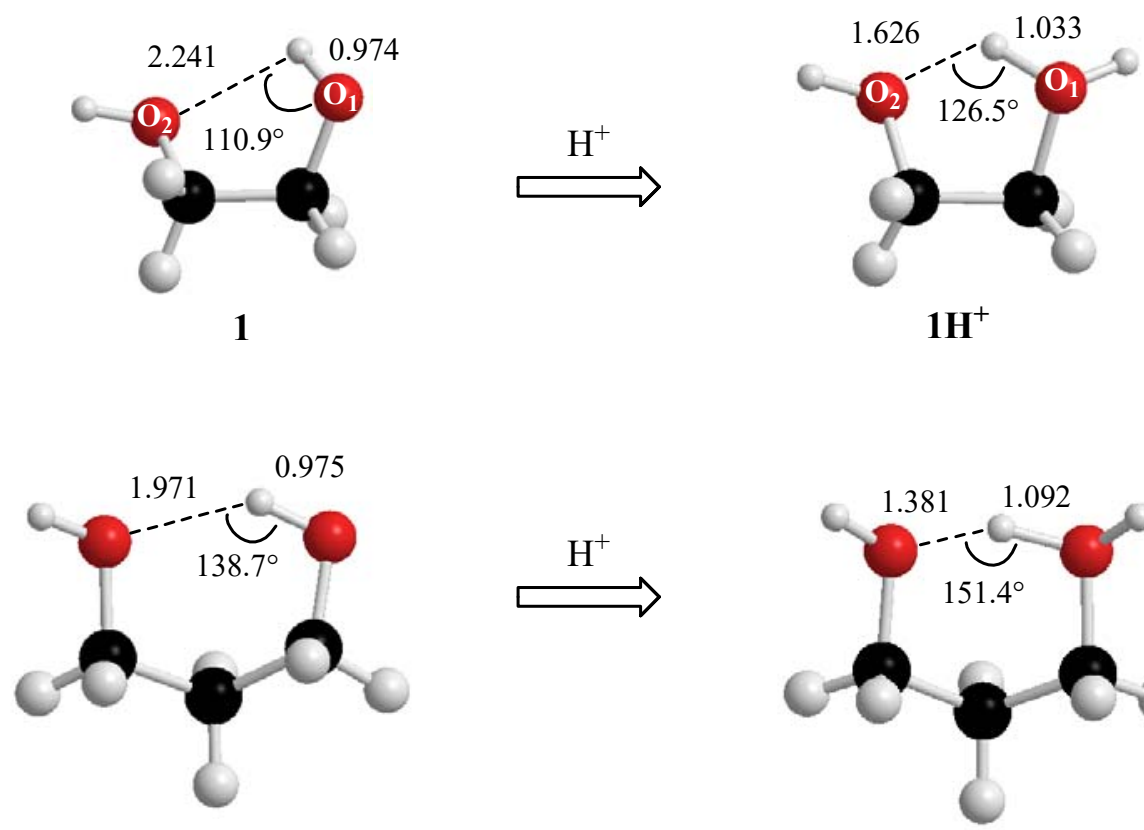

2

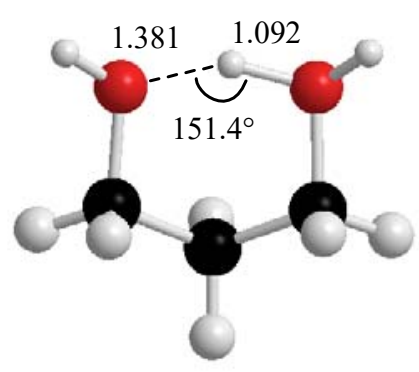

$\mathbf{2} \mathbf{H}^{+}$

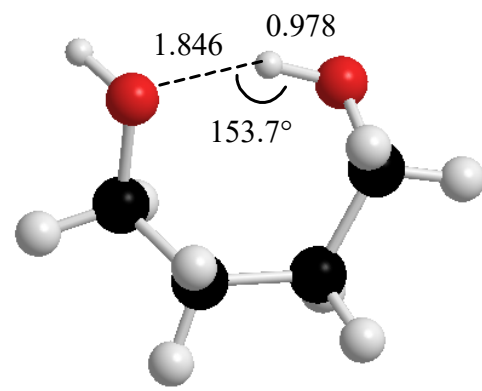

3

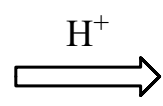

Figure 10. MP2/6-31G(d) optimized geometries of neutral and protonated $\alpha, \omega$-diols 

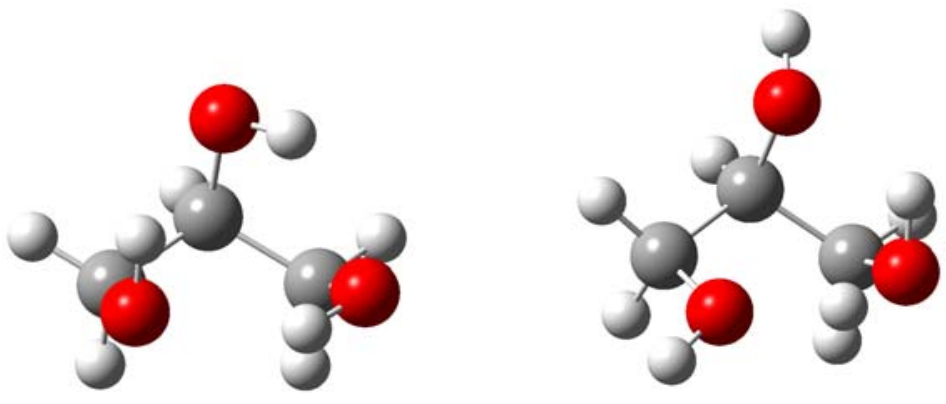

Figure 11. The most stable forms of neutral and protonated glycerol in the gas-phase (G3B3 calculations).
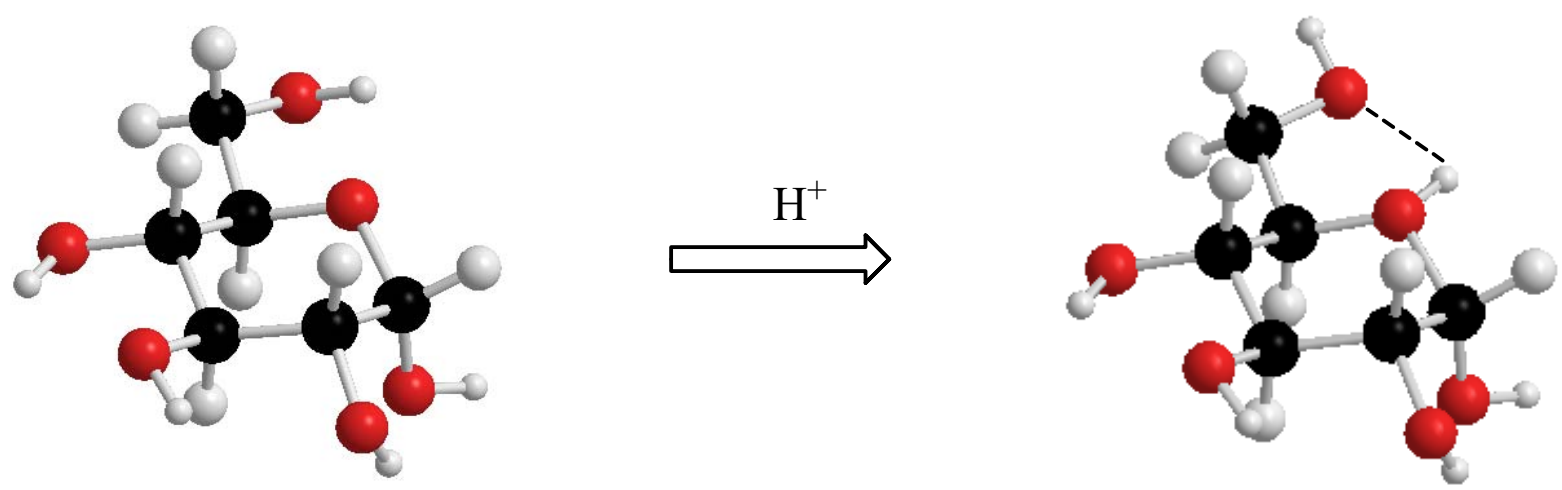

Figure 12. Neutral and protonated forms of $\alpha-D$-glucose used in the computation of gas-phase basicity. 


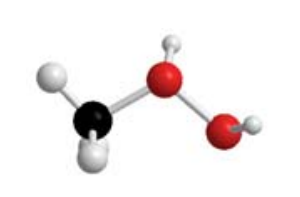

$\mathbf{0}$

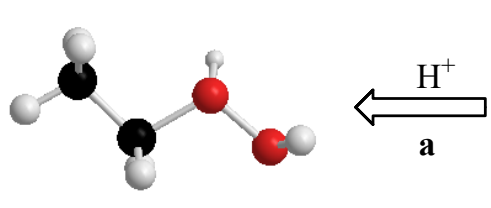

$\mathbf{0}$

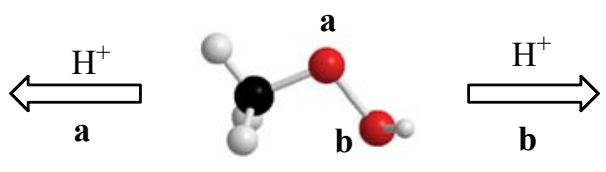

b
$+19$
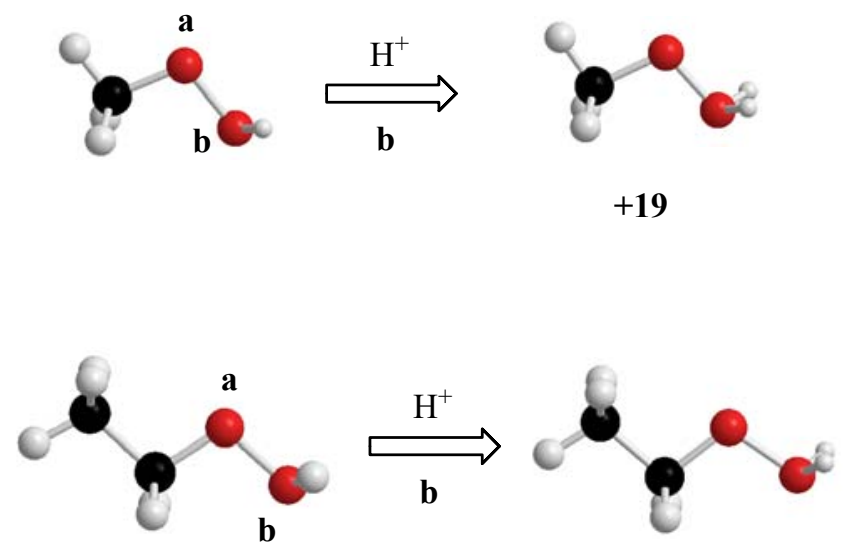

$+27$

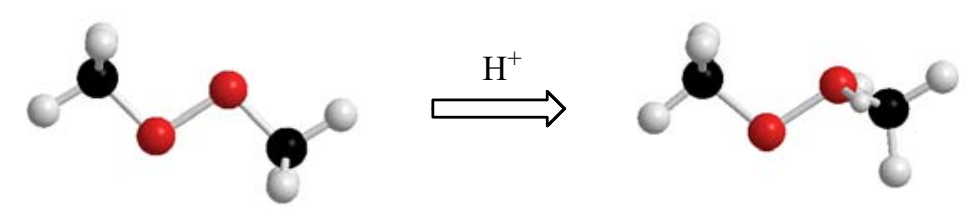

Figure 13. Protonated forms of alkyl hydroperoxides and dimethoxy oxide (G3 relative 298K enthalpies are given in $\mathrm{kJ} / \mathrm{mol}$ )

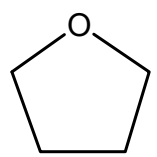

822.1

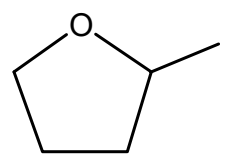

844

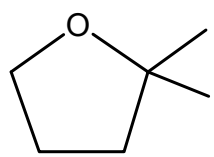

856

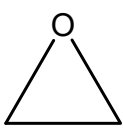

776.2

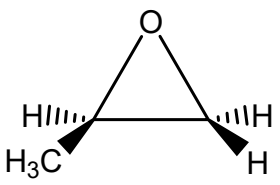

794.5

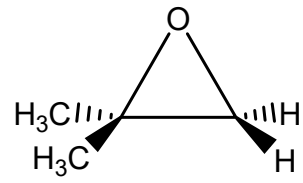

823.9

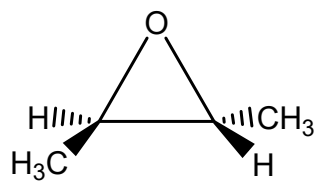

819.8

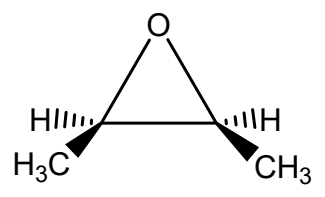

821.0

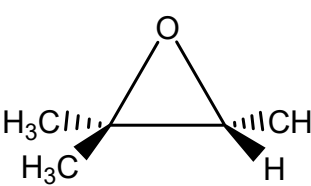

842.2

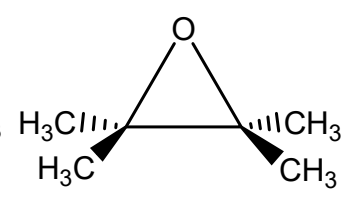

857.6

Figure 14. Effect of methyl group(s) onto the proton affinity of cyclic saturated monoethers (values given in $\mathrm{kJ} / \mathrm{mol}$; see text for details) 

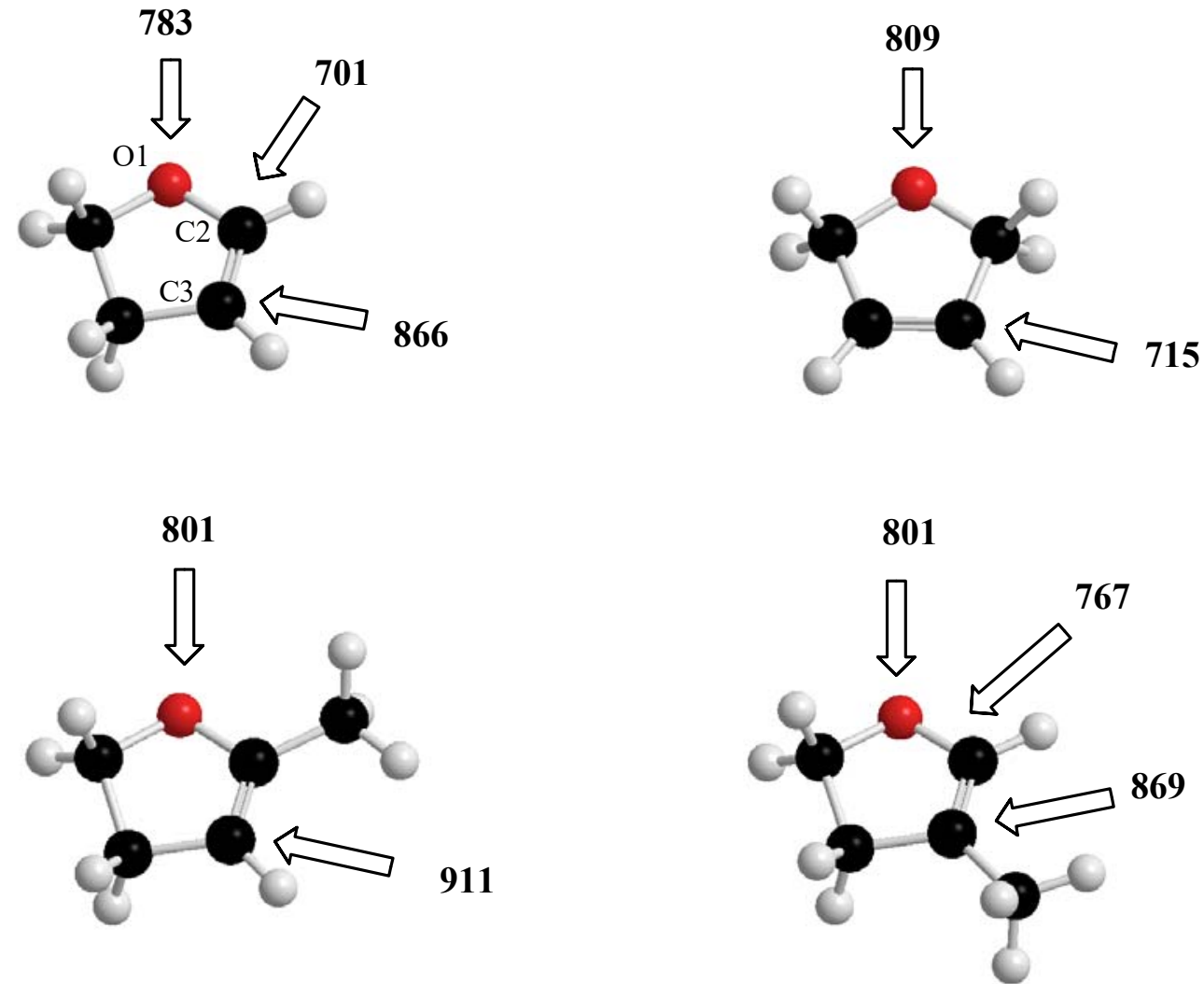

Figure 15. G3 proton affinities of dihydrofuran derivatives (values given in $\mathrm{kJ} / \mathrm{mol}$ ). 